(Aus der Syphilidologischen Klinik des Karolinischen Instituts [Vorstand: Prof. Dr. Johan Almkvist].)

\title{
Über merkurielle Dermatosen; klinische, histologische und experimentelle Studien*).
}

\author{
Von \\ Prof. Dr. Johan Almkvist. \\ Mit 13 Abbildungen auf Tafel I-VIII. \\ (Eingegangen am 23. März 1922.)
}

Die Zeit, in der man begonnen hat, sich eingehender mit dem Studium jener Hautaffektionen zu befassen, welche mit der Anwendung des Quecksilbers zusammenhängen, liegt nur einige Dezennien zurück. Unsere ersten Kenntnisse über dieses Leiden sind aber viel älter.

Schon in der Abhandlung von Bonet (Genf, 1684-1686) findet man ${ }^{39}$ ) Andeutungen über derartige Hautveränderungen und $J u s s i e u^{129}$ ) spricht (1719) ,de pustules observées à la peau, sur les ouvriers employés dans les mines d'Espagne à l'extraction du mercure". Die ersten deutlichen Beschreibungen aber stammen von britischen Ärzten am Ende des 18. und Anfang des 19. Jahrhunderts.

Benjamin Bell ${ }^{22}$ ), der berühmte Edinburger Wundarzt, der würdevollste der Gegner John Hunters, beschrieb 1793 Hautausschläge bei innerlicher wie bei äußerlicher Anwendung der verschiedenartigsten Quecksilberpräparate, entweder auf einzelne Stellen der Haut beschränkt oder über den ganzen Körper verbreitet und unter verschiedener Form wie Masernflecken, Urticaria, Erythem und Bläschen. Außer von Bell sollen diese Ausschläge noch von J. Gregory in Edinburg, der sie in seinen Vorlesungen als Erythema mercuriale bezeichnete, und in Dublin von Burrows, W. Dease und Whitley Stokes beobachtet worden sein. Letzterer hielt in seinem Kollegium 1798 ausführliche Vorträge über diesen Ausschlag. Von Dublin gingen ferner 1804 die ersten beiden Monographien über dieses Hautleiden aus, von Georg Alley ${ }^{3}$ ) und Moriarty ${ }^{165}$ ). Ersterer wählte den (dann lange sehr gebräuchlichen) neuen Namen „Hydrargyria“ und der letztere gab ihr auf den Rat Professor Stokes, dessen Beobachtungen er neben seinen eigenen mitteilte, die ungeeignete Bezeichnung "Lepra mercurialis".

Im folgenden Jahre erschienen in Edinburg die erste Dissertation über dieses Thema ,De erythemate mercuriali" von Joannes Mc Mullin ${ }^{167}$ ) und eine Beschreibung dreier neuer Fälle des Erythema mercuriale von Tom Spens ${ }^{212}$ ), Physician on the Royal Infirmary in derselben Stadt.

*) Als vorläufige Mitteilung zu dieser Arbeit hat Verf. in der Unnaschen Festschrift (Arch. f. Dermatol. u. Syphilis 129. 1921) einen Artikel „Histologische Studien über merkurielle Hautveränderungen " veröffentlicht. 
Trotz dieser vorher erschienenen Arbeiten sucht John Pearson ${ }^{176}$ ), Senior Surgeon of the Lock-Hospital in London, berühmt durch das von ihm aufgestellte Krankheitsbild Erethismus mercurialis, in der 1807 erschienenen zweiten Auflage seines Werkes „Observations on the Effects of Various Articles of the Materia Medica", die Priorität zu beanspruchen, indem er behauptet, diese Krankheit schon seit 1781 gekannt und bereits 1783 in seinen Vorlesungen unter dem Namen ,Eczema mercuriale" mehrmals vorgestellt zu haben. Im Jahre 1810 bringt Alley eine größere neue Ausgabe seiner Abhandlung zur Veröffentlichung ${ }^{4}$ ), die in London erschien, und in welcher er, Seite 44, eine Tabelle von 43 Fällen der Hydrargyria mitteilt, darunter 14 von Hydrargyria maligna, von welchen 8 tödlich endeten.

Die ziemlich zahlreichen Arbeiten, welche in der folgenden Zeit, nicht nur von englischen, sondern nunmehr auch von französischen, deutschen und dänischen Autoren erschienen, zeigen von dem großen Interesse für diese Quecksilbererkrankungen. Von diesen Autoren möchte ich erwähnen: A. Ramsay ${ }^{184}$ ) 1811, J. Frank $\left.{ }^{93}\right)^{94}$ ) und J. Nikolsson ${ }^{172}$ ) 1812," T. Bateman ${ }^{27}$ ) 1814, Hermannus Becker ${ }^{30}$ ). 1817, A. Crawford ${ }^{58}$ ) und R. Grattan $\left.{ }^{104}\right)$ 1820, Benjamin Kahleis ${ }^{131}$ ) und J.C.Wendt ${ }^{231}$ ) 1823, G. Schmal ${ }^{197}$ ) 1825, M.N. Devergie $\left.{ }^{*}\right)$ 1826, J. Johnstone ${ }^{125}$ ) 1827, John Bacot ${ }^{24}$ ) und Lagneau ${ }^{139}$ ) 1828. Einige dieser Autoren haben außer den bereits erwähnten vier Bezeichnungen noch andere Namen für dieses Hautleiden eingeführt. So hat Joseph Frank die Benennung Exanthema mercuriale gebraucht, wodurch er die Krankheit mit Scharlach, Masern, Blattern und anderen ähnlichen in eine Kategorie stellte. Schmalz schlägt den Namen Spilosis mercuriales vor, und Devergie und L.V. Lagneau sprechen in ihren Büchern von ,érysipèle produit par le mercure" (Erysipelas mercuriale); wobei Devergie jedoch die so benannte Erkrankung eigentich nur als eine besondere Art der merkuriellen Hautveränderungen auffaßt. Johnstone hat die eigentümliche Benennung von Stokes und Moriatry Lepra mercurialis wieder aufgenommen. Ferner hat Crawford die beiden Benennungen "Erythema ${ }^{4}$ or ,"Lepra ${ }^{46}$ verworfen, weil ,this eruption puts on a vesicular form" und ebenso die Namen „Hydrargyria" or "Eczema mercuriale", ,as mercury is not the only exciting cause" und hat die von Bateman (1814) herrührende Bezeichnung Eczema rubrum, wenn nicht als befriedigend, so doch unter den vorgeschlagenen als allein möglich erklärt.

Man hatte also ziemllich früh nicht weniger als acht verschiedene Namen für dieses Hautleiden eingeführt, was vielleicht auf seinem variierenden Aussehen beruhen mag. Keiner dieser Autoren scheint daran gezweifelt zu haben, daß diese Hautaffektionen durch die Wirkung des Quecksilbers hervorgerufen waren, wenngleich einige, besonders Crawford, außerdem auch andere Ursachen für ihr Auftreten als möglich annahmen.

Nach dieser Periode sichtlich großen Interesses für diese Hautaffektionen hat man ihnen eine Zeitlang nach den Angaben mehrerer Autoren ziemlich wenig Beachtung geschenkt: So sagt Fournier ${ }^{85}$ ) nach Besprechung der Arbeiten Alleys bezüglich der merkuriellen Hautveränderungen „Puis elles tombèrent immédiatement dans un oubli profond“". Bossard $d^{41}$ ) betont, ,daß zu dieser Zeit die Hydrargyria so ziemlich in Vergessenheit geraten war", und in ähnlicher Weise äußern sich Rosenthal ${ }^{19 i}$ ) und mehrere andere Autoren.

Meine Literaturstudien haben mich aber zu einer anderen Ansicht geführt. Fürs erste wäre es, scheint mir, sehr eigentümlich, wenn man an die in Frage stehende Quecksilberveränderung vergessen hätte, zu einer Zeit, in der man nach dem Erscheinen der Arbeit Andrew Mathias" "The mercurial disease " (1810) so viel über diese Merkurialkrankheit schrieb und in der man die aktuelle Streitfrage der Zeit, welche Veränderungen merkurieller und welche syphilitischer Natur wären,

*) Clinique de la Maladie syphilitique, Paris 1826. 
so fleißig diskutierte. Manche Ärzte, die Anhänger Mathias', waren geneigt, viele ja sogar die meisten syphilitischen Veränderungen als Quecksilberwirkung anzusehen. Zweitens stammen aus diesen Dezennien mehrere große Werke, die niemals vergessen waren, und die sich eingehend mit den merkuriellen Hautveränderungen beschäftigen. In Dieterichs 1837 erschienener großer Monographie, ,, die Merkurialkrankheit in allen ihren Formen "62), sind unter den 40 verschiedenen Formen des Merkurialismus die merkuriellen Hautausschläge (S. 219-243) ausführlich besprochen, and 1855 beschreibt $C$. Ph. Falck in Virchows Handbuch eingehend die Hydrargyria oder das Eczema mercuriale. Von anderen Arbeiten kann ich außerdem erwähnen:Alexandre ${ }^{2}$ ) und Rayer ${ }^{186}$ ) 1835, Aschersson ${ }^{19}$ ) 1837, Briquet ${ }^{43}$ ) 1838, Azum ${ }^{22}$ ) 1844, Simon ${ }^{205}$ ) 1847, Baron ${ }^{26}$ ) und J. A. Rapp $\left.{ }^{185}\right) 1850$ und Grabscheid ${ }^{103}$ ) 1857. Wahrscheinlicher scheint es mir, daß die Hitze und Leidenschaftlichkeit, mit welcher dieser traurige und lange Streit geführt wurde, eine gewisse Verwirrung bezüglich der Stellung der Diagnose verursachte. So ist die merkurielle Natur dieses Leidens von mehreren Autoren wie von Cullerier et Ratier ${ }^{60}$ ) und Cazenave bestritten worden. Die beiden ersten erklären in ihrem Werk (T. XI, S. 461), dieses Hautleiden niemals gesehen zu haben, und nebmen an: "Qu'on a souvent attribué au mercure des syphilides développées pendant le traitement." Der Letzterwähnte behauptet 1839 direkt: "L'hydrargyrie est donc une maladie imaginaire." Simon ${ }^{205}$ ) spricht sogar deutlich von einer "confusion perpétuelle“ zwischen merkuriellen und syphilitischen Symptomen, und andere drücken sich mehr oder weniger in ähnlicher Wesie aus.

Nach 1860 entwickeln sich aber die Anschanungen in anderer Richtung. Die Streitfrage fängt an sich zu klären. Overbeck $k^{174}$ ) gibt 1861 in seinem Buch eine kurze, aber deutliche Beschreibung merkurieller Hautausschläge, und $K$ ussmaul $^{138}$ ) widmet in seinem, im selben Jahr ersehienenen Werke über Merkurialismus diesem Leiden, für welches er noch eine neue Benennung Dermatitis mercurialis einführt viele Seiten (S. 303-325). Auer ${ }^{21}$ ) hatte schon ein Jahr vorher einen rubeolaähnlichen Fall mitgeteilt und 1862 trat $B a z i n^{28}$ ) in seiner Arbeit über die merkuriellen Hautveränderungen für die Annahme einer derartigen Einwirkung des Quecksilbers auf die Haut ein. Er scheint aber hauptsächlich einen äußeren Ursprung anzunehmen: „Autant est fréquente l'hydrargyrie provoquée par des frictions mercurielles, autant est rare l'hydrargyrie pathogénétique. Je n'en ai pas observé plus de 2 ou 3 cas dans le cours de ma longue pratique. Il parait qu'elle est plus fréquente en Angleterre." Sowohl Overbeck wie Kussmaul und Bazin erwähnen die Beschreibungen von Alley. Bald danach (1868) beschreibt Ferrand ${ }^{79}$ ) ein morbillenähnliches merkurielles Exanthem. Insgesamt habe ich während dieses Dezenniums acht hierhergehörige Arbeiten gefunden.

Während des Dezenniums 1870-1879 erschienen 11 Mitteilungen über dieses Thema. Erwähnenswert ist außerdem die 1877 erschienene Arbeit Köbners, Über Arzneiexantheme insbesondere über Chininexanthem", welche das Interesse für diese Frage besonders gefördert zu haben scheint. Köbner hatte hier die Anschauung vertreten, ,daß als Arzneiexantheme nur diejenigen durch Arzneistoffe entstandenen Eruptionen bezeichnet werden sollten, die durch innerliche oder subcutane Anwendung oder durch Inhalation zustandekommen, daß dagegen die durch äußere Anwendung entstandenen von dieser Gruppe auszuschließen seien".

Diese Anschauung Köbners hat aber ihre Gegner gefunden, Am 16. I. 1895 trat $O$. Rosentha $7^{191}$ ) in einem Vortrag in der Berliner med. Gesellschaft mit der Ansicht auf, daß das Quecksilber bei innerlicher und bei subcutaner resp. intramuskulärer Anwendung in gleicher Weise wirke wie bei äuBerlicher Applikation (S. 524), und am 23. XI. desselben Jahres berichtete Jadassohn ${ }^{122}$ ) in einem Vortrag beim 5. Kongreß der Deutschen Dermatologischen Gesellschaft in Graz über 
interessante Beobachtungen und Experimente zur Klärung der Frage über die Identität der Dermatosen nach innerer und äußerer Arzneianwendung. Diese, wenn auch nicht mit Rosenthal ganz übereinstimmend, schienen doch zu zeigen, daß der Begriff der Arzneiexantheme von der Applikationsweise ziemlich unabhängig sei. Das wird jetzt wohl auch allgemein anerkannt, doch mit der Beschränkung, daß die Toxidermien inneren und äußeren Ursprungs nicht immer ganz gleichartig sind. Mir scheint, daß die derzeit verbreitetste Ansicht in dieser Frage durch folgendes Zitat aus Dariers Précis de Dermatologie ausgedrückt werden kann: "L'origine externe ou interne d'une toxidermie est parfois évidente à première vue; la modalité éruptive, la distribution topographique de l'éruption, sa localisation ou sa généralisation, peuvent fournir à cet égard de précieux indices. Mais d'autres fois cette question ne saurait être résolue de plano. Il peut arriver, en effet, qu'une substance appliquée sur la peau agisse à la fois localement et par absorption. La délimination entre les toxidermies externes et internes n'est donc pas absolue."

Wieviel aber die Arbeit Köbners, wenn sie auch teilweise unrichtig war, zu der Entwicklung dieser Frage beigetragen hat, geht aus der steigenden Anzahl von Arbeiten in der nächstkommenden Zeit hervor. So sind in dem Dezennium. 1880-1889 nicht weniger als 27 und zwischen 1890-1899 sogar 66 kleinere oder größere Arbeiten über merkurielle Hautveränderungen erschienen. (Siehe das chronologische Register!) Nachher wurden allerdings die Veröffentlichungen etwas spärlicher: 1900-190934 und 1910-1921 15.

Infolge dieser großen Anzahl von Arbeiten über diese Frage sind die verschiedenen klinischen Formen der merkuriellen Hautveränderungen sehr gut bekannt und man kann durch bloße klinische, Studien kaum etwas Neues zur Kenntnis dieses Leidens hinzufügen. Referierend näher auf die verschiedenen Arbeiten einzugehen, ist aber überflüssig, da viele Autoren die frühere Literatur mehr oder weniger ausführlich besprechen. In dieser Hinsicht möchte ich besonders auf die Arbeiten von Rosenthal ${ }^{191}$ ), Bossard ${ }^{41}$ ) and Tomasczewski ${ }^{225}$ ) verweisen. Auch habe ich in meinem Literaturverzeichnis so viele Arbeiten über merkurielle Hautleiden wie möglich zu sammeln versucht. Ich will deshalb hier nur eine Zusammenfassung über den Stand unseres Wissens bringen, welcher sich aus allen diesen Arbeiten ergibt.

Ubbereinstimmend heben alle Autoren hervor, daß das Bild der merkuriellen Hautveränderungen außerordentlich polymorph ist, und daß den durch das Quecksilber hervorgerufenen Veränderungen keine spezifischen Merkmale zukommen. Diese Variationen betreffen: 1. die Art der Quecksilbereinwirkung, 2. die Art der Hautveränderungen, 3. die Lokalisation, 4. die Art und die Schnelligkeit der Ausbreitung der Hautveränderungen und 5. das gleichzeitige Vorkommen anderer Veränderungen merkurieller Natur.

1. Hautveränderungen vermag das Quecksilber zu erzeugen, auf welchem von den bekannten Resorptionswegen es auch aufgenommen werden mag.

Es ist also gleichgïltig, ob das Quecksilber per os eingenommen oder als Quecksilberdampf eingeatmet wird, ob es durch die lädierte Haut oder Schleimhaut 
oder aus eingespritzten Quecksilberdepots resorbiert wird. Fälle von merkuriellen Hautveränderungen infolge von Vaginalspülungen mit Sublimat sind mehrmals beschrieben (z. B. Audry und Laurent ${ }^{20}$ ), Petrini ${ }^{178}$ ), Fleischmann $\left.{ }^{82}\right)$ ), durch Sublimatwaschung der Conjunctiven von Fournier ${ }^{87}$ ), durch Sublimatumschläge auf der Haut von Holmes ${ }^{118}$ ) (Fall 2), Fanelli da Loiano $\left.{ }^{76}\right)$, Eudlitz ${ }^{74}$ ) u. a. Eigentümlich ist der Fall von Max Joseph ${ }^{127}$, wo die Hautveränderungen nach dem Einsetzen von Amalgamplomben in mehrere Zähne auftraten und nicht verschwanden, bevor diese Plomben entfernt wurden. Das Quecksilber kann von jeder Resorptionsstelle aus dieselbe Hautveränderung hervorrufen. Für das einzelne Individuum aber scheinen die verschiedenen Wege in dieser Hinsicht doch nicht ganz gleichwertig zu sein. Es sind mehrere Fälle bekannt, in denen Personen nur durch einen oder einige dieser Resorptionswege, nicht aber durch einen anderen oder mehrere andere, Haut. veränderungen bekommen haben.

Als Beispiel kann ich den Fall von Courtade ${ }^{57}$ ) erwähnen, in dem ein 16 jähriges Mädchen 22 Quecksilberinunktionen gut vertrug, nach Protojodurpillen aber eine Hautveränderung bekam, die während eines Monates andauerte. Ferner den Fall Lesser $\mathrm{s}^{145}$ ), einen Cand. med. betreffend, der durch leichten Kontakt mit einer schwachen Sublimatlösung und durch eine Injektion von $0,06 \mathrm{~g}$ Kalomel Quecksilberexanthem bekam, dagegen bis 4 Pillen täglich à $0,05 \mathrm{~g}$ Hydrargyrum tannicum gut vertrug, und den Fall von Ramally ${ }^{182}$ ), in welchem ein 22 jähriger Mann nach Aufstreichen von $4 \mathrm{~g}$ graver Salbe während zweier Tage, am folgenden Tag ein universelles Erythem mit $40^{\circ} \mathrm{C}$ bekam, das nach 3 Tagen in der Hauptsache vorüber war. 8 Tage später begann er mit Sublimatinjektionen, die gut vertragen wurden. Ferner berichtet $S u c h y^{219}$ ) über einen Pat. mit absoluter Idiosynkrasie gegen $\mathrm{Hg}$-Einreibungen, der aber $\mathrm{Hg}$-Pillen und Hydrarg. oxydul. tannic. innerlich so gut vertrug, daß die syphilitischen Erscheinungen bald verschwanden. Sehr instruktiv ist der Flal von Ledermann ${ }^{141}$ ), wo die Pat. Kalomel innerlich gut vertrug, nicht aber externe Applikation an den Labien und ebensowenig Inunktionen oder Injektionen. Auch die Fälle von Ehrmann ${ }^{68}$ ) und Alexander ${ }^{1}$ ) können als Beispiele dienen. Man muß also sagen, daß es eine individuelle Vesrchiedenheit gibt betreffs der Bedeutung der Resorptionswege für das Entstehen der merkuriellen Hautveränderungen.

Ungefähr ebenso ist aber auch eine individuell verschiedene Empfindlichkeit gegen die verschiedenen Quecksilberpräparate zu konstatieren. Nun sind aber in den meisten der obenerwähnten Beispiele nicht nur die Resorptionswege, sondern auch die Quecksilberpräparate verschieden, so daß man nicht ganz sicher wissen kann, ob der Resorptionsweg oder das Präparat die Ursache der verschiedenen Wirkung war. Soviel ich weiß, sind von all den unzähligen verschiedenen Quecksilberpräparaten Fälle bekannt, in denen sie Hautveränderungen hervorrufen. Wohl gibt es einige, z. B. das Hydxargyrum amidato-bichloratum (weißes Präcipitat), welche sehr selten Hautveränderungen hervorzurufen scheinen. Aber auch durch dieses Quecksilberpräparat sind Fälle von Quecksilberexanthem entstanden und beschrieben, von Rosenblat ${ }^{190}$ ), Hoffmann ${ }^{117}$ ) (Fall 5)*) und Alexander ${ }^{1}$ ). (Siebe auch meinen Fall 34.) Es besteht aber, wie gesagt, ein Unterschied in der Hinsicht, daß manche Personen von einem gewissen Quecksilberpräparat leichter Hautveränderungen bekommen als von einem anderen, auf demselben Resorptionsweg eingeführten Präparat. Das obenerwähnte Mädchen Courtades, welches von Protojodurpillen einen Ausschlag bekommen hatte, vertrug Sublimatpillen von derselben

*) Ein Pat. mit Psoriasis vulgaris behandelte sich — nach überstandener Dermatitis ehrysarobinica - durch 8 Tage mit einer Salbe, die nur 4\% Hydrargyrum praecipitatum album enthielt, bekam aber ein scharlachähnliches Quecksilbererythem. 
Stärke ganz gut. Ein Pat. Starks ${ }^{214}$ ) bekam nach Injektion von $0,05 \mathrm{~g}$ Hydrarg. salicyl. einen Hautausschlag von roten Flecken und Blasen nebst Erbrechen. Nach einer zweiten, dieselben Symptome. Von 0,1 g injiziertem Kalomel aber nur lokale Schmerzen. Eine Pat. Tomasczewskis ${ }^{225}$ ), die nach Injektionen von Hydrargyrum thymolo-aceticum immer Hautveränderungen bekam, vertrug dagegen ohne Nebenwirkung Einreibung von $6 \mathrm{~g}$ Unguentum cinereum. In dem Fall von Allgeyer $\left.{ }^{5}\right) 1901$ traten mehrmals Hautveränderungen nach Injektionen von Hydrargyrum salicylicum auf, nicht aber nach solchen von Sublimat.

Ferner können verschiedene Behandlungsmethoden (ob der Weg oder das Mittel Schuld tragen, ist schwer zu bestimmen) bei einer und derselben Person verschiedene Arten von Hautveränderungen hervorrufen, wie der Fall von Ascherson ${ }^{\mathbf{1 1}}$ ) zeigt.

Bei einem jungen Mann erschien nach dem Einnehmen eines Pulvers aus Jalappe mit 4 Gran Kalomel, noch ehe die Darmentleerungen erfolgt waren, in der Schamgegend ein Erythem, das sich binnen 24 Stunden wie Scharlach über den ganzen Körper verbreitete, aber weder Schmerz noch Fieber verursachte. Nach 2 Tagen war der Ausschlag verschwunden. - Derselbe Mann ließ sich ein anderes Mal gegen Pediculi pubis einen mit Quecksilber gefüllten Federkiel in die Unterhose einnähen. Schon nach 24 Stunden bildete sich an den Genitalien und Oberschenkeln eine Urticaria aus, die sich, wenngleich nur stellenweise, auch an Brust und Unterleib zeigte. Nach 2 Tagen war alles verschwunden.

Die Menge von Quecksilber, die nötig ist, um Hautveränderungen hervorzurufen, ist außerordentlich verschieden. Es gibt Leute, die schon durch minimale Quecksilbermengen ausgebreitete Hautveränderungen bekommen können. In solchen Fällen spricht man von einer Idiosynkrasie; sonst, wenn etwas größere Mengen nötig sind, von einer Überempfindlichkeit. Beispiele einer wahren Idiosymkrasie sind nicht selten. Schnell ${ }^{198}$ ) erzählt von einem Gärtner, der sich durch eine einmalige Einreibung eines erbsengroßen Stückes von Unguient. cinereum ein fast universelles Exanthem zuzog. Andere Beispiele sind der Fall von Dubreuilh ${ }^{63}$ ), wo ein 12 jähriges Mädchen nach einem Pulver von $0,1 \mathrm{~g}$ Kalomel und der Fall Bossards $s^{41}$ ), wo eine 40 jährige Frau nach zwei Pulvern à $0,05 \mathrm{~g}$ Kalomel ausgebreitete scharlachartige Erytheme aufwiesen. Ferner Gaucherands Fall ${ }^{102}$ ), der nach einer Dupuytrenschen Sublimatpastille ein universelles, diffuses dunkelrotes Erythem bekam, der Lessersche Fall ${ }^{145}$ ), der zweimal nach kurzdauernder Berührung der Hände mit einer 1/2-1promill. Sublimatlösung schwere Hautveränderungen mit taubeneigroßen Blasen an den Händen und Schwellung der Augenlider zeigte; der Fall von Alexander ${ }^{1}$ ), der seinem Pat. ein einziges Mal die beiden Augenlider mit weißer Präcipitatsalbe hatte einreiben lassen, wonach sich eine äußerst heftige, zum Teil erysipelatöse, zum Teil ekzematöse Dermatitis, zuerst lokal, dann über den ganzen Körper entwickelte. Der Fall von Siredey ${ }^{207}$ ), wo ein junger Mann nach Einreiben von grauer Salbe in die Schamgegend ein universelles, scarlatinöses und desquamatives Erythem bekam; endlich Meeres' Fall $\left.{ }^{158}\right)$, der letal verlief:

Ein 9 jähriges Kind bekam nach Einpinselung einer alkoholischen Sublimatlösung auf einen früher mit Carbolsäure behandelten Herpes tonsurans, ohne vorhergehende Schmerzen, eine Hautanschwellung am Capillitium mit Rötung und Blasenbildung, außerdem Diarrhöe, Übelkeit, Speichelfluß, Anschwellung von Parotis und Submaxillaris, Schlaflosigkeit und psychische Unruhe. Nach 5 Tagen plötzlicher Tod durch Syncope.

Auch ich selbst habe einen Fall beobachtet, den ich wegen der Geringfügigkeit der Veränderungen nicht in meine Kasuistik aufgenommen habe. 
Eine 36 jährige Frau sagte mir unmittelbar vor der Untersuchung wegen Gonorrhöe, daß sie keine Berührung mit Sublimatlösung vertragen könne, sondern durch dieselbe immer Hautausschläge bekomme. Am folgenden Tage, als Pat. zurückkam, zeigte sie mir aber eine erythematöse Hautrötung in der Schamgegend, zerstreute rote Flecken am Körper und eine ödematöse Hautanschwellung unter den Augen. Sie behauptete, daB ich unbedingt ein Quecksilbermittel angewandt haben müßte, denn sie erkenne den Ausschlag sehr gut wieder. Daraufhin erinnerte ich mich, daß das Gleitmittel für das Speculum $0,2 \%$ Hydrargyrum oxycyanatum enthielt. Am folgenden Tag war der Ausschlag verschwunden, und als ich später nur Glycerin als Gleitmittel für das Speculum verwendete, trat kein Ausschlag auf.

Ziemlich ähnlich ist der Fall von Tissier und Corpechot ${ }^{224}$ ), wo eine Frau Quecksilberexanthem an allen Stellen bekam, die der Arzt mit seinen von Sublimatlösung noch feuchten Händen berührt hatte.

Wenn demnach die eigentliche Ursache der merkuriellen Hautveränderungen in einer individuellen Idiosynkrasie oder Überempfindlichkeit und nicht in der Größe der Quecksilberdosis liegt, so spielt doch - wenn man von den hochgradigeren Idiosynkrasien absieht, die keine Spur von $\mathrm{Hg}$ vertragen - die eingeführte Quecksilbermenge für den einzelnen Fall eine Rolle, indem die Pat. gewöhnlich eine kleine Dosis tolerata haben und um so schwerere Hautveränderungen bekommen, je mehr die Quecksilberdosis diese Grenze überschreitet.

In diesem Zusammenhang möchte ich ferner die Dauer des Bestehens und die Möglichkeit von Änderungen in dem Grade der Idiosynkrasie bzw. der Überempfindlichkeit berühren. Die fragliche Disposition scheint gewöhnlich sehr beständig zu sein und sich oft während des ganzen Lebens zu erhalten. Man findet deshalb sehr oft Fälle, die mehrmals Quecksilberexantheme gehabt haben.

Die obenerwähnten sind solche Beispiele. Außerdem verweise ich auf die Arbeiten von Alley $^{4}$ ), Ascherson ${ }^{19}$ ), Rosenblatt ${ }^{190}$ ) and Watson ${ }^{229}$ ). Schwankungen kommen jedoch vor, besonders in den Fällen, bei welchen nur Überempfindlichkeit vorliegt. Daß zufällige Umstände eine vorübergehende Überempfindlichkeit hervorrufen können, scheint der Fall Alleys zu zeigen, in dem ein 22 jähriger Soldat, der gewöhnlich Kalomel gut vertrug, ein Quecksilberexanthem bekam, als er während einer Kalomelkur in einer kalten, feuchten Zelle eingesperrt war. Man nimmt an, daß Änderungen in der Konstitution und besonders Veränderungen in der Ausscheidung des Quecksilbers auch die Empfindlichkeit gegen Quecksilber ändern können. Besonders Sillard hat (1876) die veränderte Ausscheidung des Quecksilbers als Ursache betont. Sackur ${ }^{194}$ ) hebt dagegen 1894 die Anämie als ein sehr begünstigendes und gewöhnliches ursächliches Moment hervor. Farquharson ${ }^{77}$ ) hat schon 1873 großes Gewicht auf die Bedeutung eines Klimawechsels für diese Hautveränderungen gelegt und hierbei auf seine Beobachtungen hingewiesen, daß bei Europäern in den Tropen viel leichter eine Quecksilberintoxikation stattfindet und daß sich diese Empfindlichkeit gegenüber dem Quecksilber noch lange Zeit nach der Wiederkehr nach Europa erhalte.

Sehr oft findet man die Ansicht, daß durch Gewöhnung an das Quecksilber die Empfindlichkeit gegenüber diesem Mittel vermindert wird. Ein Beispiel hierfür ist der Fall von Gaucherand102).

Dieser Pat. hatte von einer Dupuytrenschen Pille ein universelles Exanthem bekommen. 6 Wochen nach der Genesung nahm er 2 ähnliche Pillen, worauf trotz 
der doppelten Dosis wohl ein gleichartiges, aber viel schwächeres Exanthem auiftrat.

Ferner der Fall von Fournier (erwähnt von Hallopeau ${ }^{110}$ ), S. 110):

Nach einer Pille von $0,05 \mathrm{~g}$ Protojoduretquecksilber ein universelles scarlatiniformes Exanthem. Die Hautveränderungen dauerten 24 Tage. Nach Beendigung der Desquamation kauterisierte Fournier den Skleroserest mit saurem Quecksilbernitrat, und schon am folgenden Tage zeigten sich Hautveränderungen in ähnlicher Weise wie früher, mit Rötung und Schwellung der Hände und Füße. Dann Abschuppung durch 14 Tage. Ungefähr einen Monat später begann Pat. mit Dupuytrenschen Sublimatpillen und vertrug jetzt 2 solche täglich durch 10 Tage.

Ebenso der Fall von Schulze $\left.{ }^{200}\right)$ :

Ein Pat. hat nach Einstauben des Primäraffektes mit Kalomel ein Queoksilberexanthem bekommen, ebenso nach Aufstreichen von $1 \mathrm{~g}$ grauer Salbe und später - sogar mehrmals - nach Injektion von 0,01 g Sublimat. Er vertrug: dagegen Pillen von $0,01 \mathrm{~g}$ Hydrargyrum tannicum, zuerst eine Pille, dann 3 Pillen täglich und endlich eine tägliche Dosis von $0,30 \mathrm{~g}$ Hydrarg. tannic.

Ein sprechendes Beispiel ist ferner Casparys Fall ${ }^{54}$ ):

Eine 28 jährige Russin habe nach der ersten Injektion von $\mathrm{Hg}$. salicyl. ein geradezu „tolles" universelles Erythem bekommen, nach der zweiten ein schwächeres, nach den weiteren Injektionen aber keine Hautveränderungen. Zwei Jahre später nach 0,1 g Hydrarg. tannic. oxydul. innerlich ein kollosales, scharlachähnliches Erythem mit Exanthem im Pharynx und Fieber bis $40^{\circ} \mathrm{C}$. Konnte später dasselbe Präparat bis $0,2 \mathrm{~g}$ vertragen.

Ebenso der Fall von Galewsky ${ }^{98}$ ):

Junge, kräftige Pat. bekam nach Einreibung mit Unguentum neapolitanum eine bullöse Dermatitis. Später wegen Chancre mixte mit Kalomeleinstaubung behandelt, darauf Erythem und Fieber; nach Beginn der Sekundärerscheinungen Protojoduretpillen; darnach ebenfalls Erythem und Fieber. Allmähliche Gewöhnung an Quecksilber durch interne Darreichung minimaler Mengen von Hydrargyrum oxydulatum nitrico-ammoniacatum anfänglich dreimal täglich 0,0025 metallisches Quecksilber, später dreimal täglich $=0,025$. metallisches Quecksilber; dann je eine Protojoduretpille täglich à 0,05 , später 6 à 0,05 , und schlieBlich wurde Kalomeleinstaubung anstandslos vertragen.

Mit diesen Fragen der Idiosynkrasie hat sich besonders Rebecka Slepjan ${ }^{206}$ ) beschäftigt.

Als eine Ausnahme von obgenannter Regel, die man gewöhnlich als für alle Quecksilberpräparate gültig annimmt, und deren Richtigkeit auch mir selbst wahrscheinlich ist, möchte ich auf meine Fälle $\mathbf{3 2}$ und $\mathbf{3 r}$ und auf eine Arbeit von M. Zigler, New York ${ }^{234}$ ), über Anaphylaxie gegen Quecksilber hinweisen.

SchlieBlich finden sich mehrere Tatsachen, welche auch auf eine Vererbung der Idiosynkrasie gegen Quecksilber deuten, so z. B. Alleys Fall 3 seiner zweiten Auflage 1810, S. 79.

Es handelt sich hier um einen 10 jährigen Knaben, dem am Abend des 29. April 18054 Gran Kalomel als Purgans verabreicht wurden. Die Arznei hatte nicht den gewünschten Erfolg. Am nächsten Morgen kam der Vater voll Bestïrzung zu Alley, um ihn zu seinem Knaben zu holen, der in der Nacht ein Hautexanthem mit Hitze, Rötung und Jucken bekommen hatte; auch winzige Bläschen waren zu sehen, aber schon am nächsten Tage verschwunden. - Am 10. VII. hatte eine gleiche Dosis die gleichen Wirkungen. - Der Vater des Knaben aber erzählte, ihm sei vor 20 Jahren in Edinburg, nachdem er Quecksilber eingenommen, die ganze Haut ,abgegangen", und man habe ihn für verloren gehalten. 
Ebenso teilt Rosenblatt ${ }^{190}$ ) einen Fall von ausgeprägter ererbter Idiosynkrasie mit.

Eine Frau erhielt ungefähr 6 Kalomelpulver à $0,1 \mathrm{~g}$ als Purgans. Unter Fieber bis $40^{\circ} \mathrm{C}$ trat eine universelle scarlatiniforme Rötung auf, welche nach dem Aussetzen des Kalomels verschwand. Dieselbe Frau hatte vor mehreren Jahren einen Ausschlag an den Händen bekommen, nachdem sie mit dem Quecksilber eines zerbrochenen Thermometers gespielt hatte. Eine Tochter dieser Frau erhielt nach Applikation von weißer Präcipitatsalbe ein intensives Exanthem, dagegen vertrug ein anderes, drei Jahre altes Kind derselben Frau Kalomelpulver à 0,06 g sehr gut.

2. Als verschiedene Arten merkurieller Hautveränderungen sind beschrieben: erythematöse Flecken, teilweise follikulär angeordnet, oder follikuläre Papeln, oft — nach Neisser - mit einer eigentümlichen, violettroten Farbe; diffuses Erythem; Urticariaquadeln oder verschiedene urticarielle Erscheinungen; circumscripte Ödembildungen; Blasen, und zwar teils kleine, miliariaähnliche, teils größere pemphigusartige; Blutungen, teils punktförmige, teils größere purpuraähnliche; ferner Pusteln von verschiedener Größe und nach Eintrocknen derselben Borken und Krusten; nässende und krustöse Hautpartien, das Bild eines echten nässenden Ekzems zeigend; entzündliche Hautinfiltration; Pigmentierung, gewöhnlich in schmutzigen braunen Farbentönen; und endlich nach langem Bestehen derartiger Veränderungen Schuppung, welche mitunter die größten Dimensionen annehmen kann.

Eine besondere Stellung unter allen Hauterscheinungen nach Quecksilbergebrauch nimmt die sog. Folliculitis s. Acne mercurialis ein. Sie wird bekanntlich durch die Wirkung der in die Haarbälge eingedrungenen grauen Salbe besonders bei stark behaarten Personen hervorgerufen und breitet sich nie außerhalb des eingeriebenen Hautbezirks aus.

Eine ähnliche Stellung nehmen ferner jene flüchtigen Dermatitiden ein, die an den Gelenkbeugen (namentlich den Achselhöhlen und. Inguinalbeugen) nicht gar zu selten auftreten. Meist von ephemärem Dasein, kommen sie - isoliert - wohl gleichfalls ausschließlich nach äußerer Applikation vor. In Anbetracht ihrer besonderen Stellung unter den mercurialen Affektionen und ihrer ohne Zweifel andersartigen Pathogenese werden Acne mercurialis und diese Gelenkbeugenerytheme hier nicht weiter besprochen.

3. Die Hautveränderungen können von allen möglichen Körperteilen ihren Ausgang nehmen. Ziemlich oft ist das Gesicht als Anfangsstelle beschrieben, andere Male die Genitalgegend oder die Brust und wieder andere Male die Extremitäten, besonders Hände und Füße. Aus der Literatur ist es mir aber nicht möglich, eine Prädilektionsstelle herauszufinden, an der dieses Leiden häufiger beginnen würde. Meine eigene Ansicht wird unten erwähnt. 
Bei äußerer Applikation von Quecksilbermitteln aber gehen die Hautveränderungen fast immer von der Applikationsstelle des Quecksilbermittels aus.

4. Betreffs der Ausbreitung stimmen die verschiedenen Autoren ziemlich gut überein. Man hat nämlich überall gefunden, daß die merkuriellen Hautveränderungen eine starke Tendenz haben, sich von den Ausgangsstellen über größere Hautflächen auszubreiten, und daß sie nur ausnahmsweise streng lokal bleiben; ferner daß dieses Fortschreiten in zweierlei Art stattfindet: 1. kontinuierlich längs der Hautoberfläche und 2. auf mehr oder weniger entfernte Stellen überspringend; und endlich daß sie sich ziemlich oft bis zu vollkommenerUniversalität ausbreiten.

Als eine besondere Eigentümlichkeit in der Lokalisation und Ausbreitung möchte ich zwei Beobachtungen erwähnen (Jadassohn ${ }^{122}$ ) S. 110 und Rebecka Slep$\left.j a n^{206 *}\right)$ ), in welchen die merkuriellen Hautveränderungen bei ihrer Ausbreitung gerade diejenigen Stellen vermieden hatten, wo eine lokale Quecksilberapplikation vorhanden war. Diese Eigentümlichkeit wird als erworbene „lokale Immunität“" aufgeklärt. Ferner wird sowohl von Callomon ${ }^{51}$ ) (Fall 2) wie von Hoffmann ${ }^{117}$ ) (Fall 3) erwähnt, daß sich die merkuriellen Hautveränderungen an den Stellen der Syphilitiden, oder wo solche kürzlich vorhanden gewesen waren, schwächer entwickelten oder sogar fehlten.

Ebenso wie die Ausbreitungsweise wechselt auch die Schnelligkeit der Ausbreitung. Während die Hautveränderungen in manchen Fällen nur langsam fortschreiten, können sie in anderen binnen 24 Stunden ganz universell sein.

5. Da wir außer den merkuriellen Hautveränderungen auch merkurielle Veränderungen in vielen anderen Organen kennen, so könnte man denken, daß die merkuriellen Hautveränderungen sehr oft von Veränderungen anderer Organe begleitet werden. So ist dem aber nicht. Im Gegenteil scheinen die Hautveränderungen in der Regel ganz allein aufzutreten.

Schon Fournier ${ }^{85}$ ) sagt in dieser Frage (S. 140): „Car, chose curieuse, elles ne s'accompagnent le plus souvent, d'aucune phénomene d'intolérance vers d'autres systèmes c'est à dire se produisent isolément, sans diarrhée, vomissement, gingivite, usw." Rosenthal ${ }^{191}$ ) geht noch weiter, indem er S. 524 sagt: „Ganz besondere Beachtung verdient das eigentümliche Verhalten der merkuriellen Exantheme zu den übrigen Intoxikationserscheinungen des Quecksilbers. Wunderbarerweise - und diese Tatsache ist auch von anderer Seite schon erwähnt worden - sind die letzteren neben Hauterscheinungen außerordentlich selten vorhanden, ja, es besteht sogar ein merkwürdiges Mißverhältnis zwischen diesen beiden Symptomgruppen.“ In ähnlicher Weise äußert sich L. Lewin ${ }^{150}$ (S. 273): „Sehr selten vergesellschaftet sich diese Merkurialdermatose mit anderen Nebenwirkungen des Quecksilbers z. B. mit Stomatitis und Angina."

Meine eigene Erfahrung stimmt ziemlich gut mit dieser Anschauung, doch scheint mir die Fassung Rosenthals etwas übertrieben, was mir eine genaue Durchsicht der Literatur auch bestätigt. So findet man in den

*) Sehr interessanter, experimenteller Nachweis. 
von Bossard ${ }^{41}$ ) gesammelten 34 Fällen von merkuriellen Hautverände rungen nicht weniger als 7 Fälle, welche andere Quecksilberkomplikationen aufweisen. Im großen und ganzen muß jedoch die Ansicht, daß das merkurielle Hautleiden sehr oft allein auftritt, als richtig bezeichnet werden.

Daß dieses Verhalten aber etwas besonderes Auffälliges wäre- sowohl Fournier als Rosenthal sind nach der Art, in der sie darüber berichten, von der Tatsache sichtlich befremdet — kann ich für meinen Teil nicht finden. Vielleicht hat man von alters her mit dem Ausdruck ,Vergiftung“ ein allgemeines Ergriffenwerden, ein vollkommenes Durchdrängtsein des ganzen Körpers verstanden. Dies ist aber eine mehr populäre Betrachtungsweise und hat wohl keine wissenschaftliche Begründung gefunden. Ich verstehe nicht, warum ein Gift den ganzen Körper oder mehrere Teile desselben angreifen muß, mir scheint es geradeso möglich und begreiflich, daß ein gewisses Gift nur ein gewisses Organ und nicht die übrigen Teile des Körpers schädigt. Für diese Ansicht ist, was das Quecksilber betrifft, auch Jadassohn schon 1898 und Tomasczewski $\left.{ }^{225}\right) 1904$ eingetreten. Nach der gewöhnlichen Auffassung wïd ja das Individuum im Einzelfalle deshalb ,,vergiftet", weil es gegen das betreffende Arzneimittel eine Úberempfindlichkeit oder sogar eine Idiosynkrasie hat. Nun hat aber Jadassohn im Handbuch der Inneren Medizin von EbsteinSchwalbe in der 1. Aufl., Bd. 3, I. Teil geschrieben: „Die individuelle Überempfindlichkeit ist in seltenen Fällen eine allgemeine. Der Kranke verträgt das Quecksilber überhaupt nicht, in keiner Form, in keiner wirksamen Dosis, er wird schwach, anämisch usw. Sehr viel häufiger ist die Überempfindlichkeit einzelner Organe. Je größer diese Intoleranz, um so kleiner die Dosen, auf welche die Quecksilber-Erkrankung eintritt. Und von einer bestimmten, der toxischen Dosis an werden einzelne der Organe, wie vor allem Darm und Nieren, wohl immer erkranken. Die am häufigsten gefährdeten Organe sind: Mundschleimhaut, Darm, Nieren und Haut, doch haben die einzelnen Individuen meist nur eine Empfindlichkeit eines dieser Organe." Tomasczewski findet es ferner (S. 45I) nicht richtig „, von der Idiosynkrasie eines Individuums im Sinne eines besonderen Zustandes seines Gesamtorganismus zu reden“, sondern ,richtiger, diesen besonderen Zustand in einzelne Organe zu verlegen, mit anderen Worten von Organidiosynkrasie zu sprechen". Nach meiner Meinung ist diese Ansicht Jadassohns und Tomasczewskis im großen und ganzen richtig, nur mit der Modifikation, daß diese Organidiosynkrasie bei einem Individuum manchmal auch in zwei oder sogar in mehreren Organen vorhanden sein kann.

Das Wesen der Idiosynkrasie bezüglich der nekrotischen merkuriellen Veränderungen in der Mundhöhle und im Dickdarm glaube ich erklärt zu haben (siebe meine zweite Arbeit ${ }^{9}$ ), indem ich nachgewiesen 
habe, daß bakterielle Eiweißfäulnis an der Schleimhautoberfläche der nekrotisch veränderten Teile die notwendige Bedingung dieser nekrotischen Ulcerationen ist, und daß $\mathrm{im}$ Falle einer hochgradig ausgeprägten Eiweißfäulnis sehr kleine Quecklilbermengen die Veränderungen hervorrufen können. Ǘber das Wesen der Idiosynkrasie der übrigen merkuriellen Veränderungen ist, meines Wissens, nichts bekannt.

In scheinbarem Gegensatz zu dem eben über das isolierte Auftreten der merkuriellen Hautveränderungen Gesagte, trifft man in der Literatur sehr oft Angaben über eine gewöhnliche Beteiligung der Mundschleimhaut wie anderer Schleimhäute bei Auftreten von Hautsymptomen. Die Erklärung ist aber leicht zu finden. Die hier in Frage kommende Mundschleimhautinfektion ist nicht die altbekannte Stomatitis mercurialis ulcerosa mit ihren früh auftretenden nekrotischen Geschwüren, sondern eine andere Form, welche man - im Gegensatz zu den Exanthemen der Haut - Enanthem nennt, und welche sich gewöhnlich nur als Rötung der Schleimhaut oder ab und zu außerdem in Bläschen und Hämorraghien äußert. Außer in der Mundhöhle findet man solche Enantheme auch ziemlich häufig an den Conjunctiven und im Pharynx, ferner, wenn auch weniger oft, im Larynx, in den Bronchien und der Nase und schließlich, vielleicht öfter, im Gastrointestinaltractus. Diese Enantheme sind aber von ganz derselben Natur wie die Hautveränderungen und deshalb nur als eine Fortsetzung des dermatologischen Prozesses zu betrachten. Deshalb bildet ihr Auftreten keine Ausnahme von dem oben Gesagten.

Die Enantheme wurden zuerst von Sommerbrodt $\left.t^{210}\right) 1886$ beschrieben und sind dann ziemlich oft konstatiert worden (Allgeyer und Sprecher ${ }^{6}$, Bürtzeff ${ }^{49}$ ), Caspary $\left.^{54}\right)$, Du Mesni ${ }^{65}$ ), Engelmann ${ }^{72}$ ), Hoffmann ${ }^{117}$ ) und Rosenthal $\left.{ }^{191}\right)$ ). Überall findet man die Ansicht, daß merkurielle Exantheme und Enantheme nur verschiedene Lokalisationen desselben Krankheitsprozesses darstellen. Die Enantheme können auch allein, ohne Exantheme auftreten. Rosenthal (S. 501) beschreibt 2 solche Fälle - einen mit geröteter Mundschleimhaut und Himbeerzunge und den anderen mit Blutungen im harten Gaumen - and Du Mesnil ein isoliertes Enanthem in der Mundhöhle. Hoffmann (S. 909) hat ein Enanthem gleichzeitig in der Mund-, der Rachenhöhle, an den Conjunctiven und der Genitalschleimhaut beobachtet und Fanelli da Loiano ${ }^{76}$ ) an den Conjunctiven, in der Mundhöhle, im Pharynx und in der Urethra mit Rötung und seropulurenter Sekretion.

Eine sehr gewöhnliche Begleiterscheinung der merkuriellen Hautveränderungen ist ferner das Fieber. Utber den Zusammenhàng desselben mit den Hautveränderungen äußern sich die Autoren sehr wenig. Man erhält jedoch beim Studium der Literatur dieser Frage den Eindruck, daß in vielen Fällen das Fieber nicht die Folge der Hautveränderungen ist, sondern unabhängig von diesen auftritt, also als eine selbständige, gleichzeitige Quecksilberwirkung. Für diese Auffassung spricht das Auftreten von isolierten Temperatursteigerungen ohne gleichzeitige Hautausschläge oder irgendwelche anderen merkuriellen Veränderungen 
im Körper, eine Beobachtung, die bis jetzt nur nach Injektionen von Quecksilberpräparaten gemacht worden ist.

Einen solchen Fall erwähnt Eich ${ }^{70}$ ). Sechs Stunden nach der 3. Injektion von Hydrargyrum salicylicum trat ein schwerer Schüttelfrost auf, und die Temperatur stieg bis $40,8^{\circ} \mathrm{C}$. Keine anderen Symptome; in 24 Stunden war alles vorüber.

Ferner findet man Fälle beschrieben, in denen das Fieber plötzlich und gleichzeitig mit den Hautveränderungen und nicht wie eine Folgeerscheinung nach denselben anfängt. Auch sind die Stärke des Fiebers und die Intensität der Hautveränderungen einander nicht proportional, denn man findet starke Hautveränderungen mit geringem Fieber und schwache Hautveränderungen mit hohem Fieber beschrieben.

So trat in dem Fall von Claesson ${ }^{56}$ ) mit einem binnen 24 Stunden verschwun. denen, scarlatiniformen Exanthem eine Temperatursteigerung bis $39,4^{\circ} \mathrm{C}$ auf. Ein gutes Bild von diesen Temperaturerhöhungen erhielt man durch $v$. Petersens Mitteilungen beim Deutsch. Dermatolog. Kongreß in Leipzig 1891 nebst der nachfolgenden Diskussion ${ }^{177}$ ).

Andererseits scheint jedoch das fast regelmäßige Vorkommen von Fieber bei den merkuriellen Hautveränderungen im Gegensatz zu dem selteneren Vorhandensein bei anderen merkuriellen Organleiden (Nephritis, Stomatitis usw.) Grund zur Annahme eines gewissen Kausalnexus zwischen dem Fieber und den Hauterscheinungen zu geben.

Wie häufig das Auftreten der merkuriellen Hautveränderungen ist, im Vergleich zu dem der übrigen merkuriellen Veränderungen sucht Paul Streffer ${ }^{217}$ ) in einer Statistik von $\mathbf{4 3 3}$ mit Quecksilber behandelten Fällen darzutun. Von diesen bekamen 40,2\% (= 174 Fälle) merkurielle Stomatitis, 7,9\% (= 34 Fälle) Diarrhöe und nur $0,92 \%\left(=4\right.$ Fälle) Hautveränderungen. Callomon $\left.{ }^{51}\right)$ hat aus der Klinik Hartungs nur 3 Fälle echter $\mathrm{Hg}$-Exantheme unter $1300 \mathrm{Hg}$-behandelten Fällen gefunden.

Infolge aller dieser verschiedenen Variationen bekommen die merkuriellen Hautaffektionen sehr oft eine auffallende Ähnlichkeit mit einer Reihe anderer Hautkrankheiten und sind deshalb schwer zu diagnostizieren. Von solchen Krankheiten, deren Aussehen das merkurielle Hautleiden annebmen kann, ist eine ganze Zahl beschrieben.

Es handelt sich in diesen Fällen um das Bild von: Morbilli (siehe Brouardell und Ogier ${ }^{44}$ ), Ferrand $d^{79}$ ), Hoffmann ${ }^{117}$ ) (Fall 3 u. 4), Tomasczewski225) (S. 444)), und Scarlatina (siehe u. a. Alexander 1 ), Allgeyer und Sprecher 6 )*), Blane $e^{37}$ ), Bossard ${ }^{41}$ ) (S. 57), Bürtzeff ${ }^{49}$ ), Caspary ${ }^{54}$ ), Claessen ${ }^{56}$ ), Dubreuilh $\left.{ }^{63}\right)$ ), Eich $^{70}$ ), Gaucherand $\left.{ }^{102}\right)$, Grön $\left.{ }^{106}\right)$ (Fall 1 u.87), Hallopeau $\left.{ }^{100}\right)$, (S.110), Lesser $\left.{ }^{145}\right)$, Morel-Lavallée $\left.e^{164}\right)$, Ramally $\left.{ }^{182}\right)$,

*) Der von Allgeyer und Sprecher 1895 beschriebene Fall zeigt, wie groß die Ảhnlichkeit der merkuriellen Hautveränderungen mit einer Scarlatina sein kann. Das Erythem fing an Hals und Brust an, war am folgenden Tag universell, nur Lippen und Nase waren blaß, Temperatur 39,6-40 C, Puls 130-140, reichlich Albumin, Angina mercurialis und Himbeerzunge, reichliche Schuppung nach Aufhören des Fiebers. Die gleichzeitige Gingivitis mercurialis ulcerosa und Salivation sprachen aber gegen Scarlatina. 
Rosenblatt ${ }^{190}$ ), Rosenthal(191), Saint-Germain $\left.{ }^{195}\right)$, Schnell ${ }^{198}$ ) und Spannochi $\left.{ }^{211}\right)$ ). Ferner sind beschrieben Erysipelas mercurialis (Alexander ${ }^{1}$ ), Engelmann ${ }^{72}$ ), Ascherson ${ }^{19}$ ), Fournier ${ }^{87}$ ) 1893, Kreidmann ${ }^{137}$ ) und Watson $\left.{ }^{229}\right)$ ), Pemphigus vulgaris mercurialis (Berliner $\left.{ }^{34}\right)$, Fränckel $\left.{ }^{92}\right)$, Gwalter $\left.{ }^{108}\right)$, Mouflier $\left.{ }^{166}\right)$, Petrini $\left.{ }^{178}\right)$, Rosenthal ${ }^{191}$ ) und Thimm $\left.{ }^{223}\right)$ ), Erythema exsudativum multiforme mercuriale (Rosenthal191), Callomon ${ }^{51}$ ) S. 410, Grön ${ }^{106}$ ) (Fall 10), Bonnet $\left.{ }^{40}\right)$ Du Mesnil $\left.7^{65}\right)$ ), Urticaria mercurialis (Jarusoff ${ }^{124}$ ), Du Mesnil $\left.{ }^{65}\right)$, Herxheimer113), Stern ${ }^{218}$ ) Friedheim ${ }^{95}$ ) und Spannochi $\left.{ }^{211}\right)$ ), Purpura haemorrhagica mercurialis (Bürtzelf ${ }^{49}$ ), Fournier ${ }^{90}$ ) 1898, Friedheim ${ }^{95}$ ) Rosenthal ${ }^{191}$ ), $\$$ sugen $^{220}$ ) und Wolff $\left.{ }^{233}\right)$ ), letztere Erscheinung jedoch manchmal nicht ganz ausgebildet, sondern nur als zentrale Blutungen in den erythematösen Flecken sich äußernd. Die Blutungen brauchen auch nicht in allen Flecken sondern nur an gewissen Stellen aufzutreten. Rosenthal teilt einen Fall mit, welcher Blutungen nur an den Stellen zeigte, wo das Quecksilber äuBerlich appliziert gewesen war. Von ungewöhnlicheren Fällen hat $A u^{2}{ }^{21}$ ) einen Fall von Rubeola mercurialis mitgeteilt, Friedheim ${ }^{95}$ ) einen Fall, in dem die merkuriellen Hautveränderungen nur in Ödemen bestanden, Brouardell und Ogier ${ }^{44}$ ) einen Fall mit prurigoähnlichen Veränderungen an mehreren Stellen des Körpers, Wolff $f^{233}$ ) einen Fall von lichenförmigem merkuriellem Ausschlag, Guelpa ${ }^{107}$ ) einen Fall mit sehr variolaähnlichen. Veränderungen, Wickham ${ }^{232}$ ) und Spannochi ${ }^{211}$ ) je einen Fall, der im Anfang das Bild einer Pityriasis rubra pilaris, später einer Dermatitis exfoliativa zeigte. Das letzterwähnte Bild ist aber nicht so selten, wenn die merkuriellen Hautveränderungen eine chronische Form annehmen oder sich infolge andauernder Querksilbereinwirkung schon vom Anfang an allmählich entwickeln. So z. B. Fourniers ${ }^{39}$ ) 1896 beschriebener Fall, der in quecksilberhaltiger Atmosphäre lebte, etwas Quecksilber im Urin hatte und ,une dermatite exfoliante" darbot, die sich allmählich entwickelt und keine anderen Krankheitsformen angenommen hatte. Mehr oder weniger ausgebildete Fälle von Dermatitis exfoliativa mercurialis sind ferner mitgeteilt von Milian ${ }^{160}$ ), Beck $^{29}$ ) (Fall 1), Blanc ${ }^{37}$ ), Rosenthal ${ }^{191}$ ), Hoffmann ${ }^{117}$ ) (Fall 2) und Wickham ${ }^{232}$ ). Fälle von Herpes zoster mercurialis sind von Selenew $w^{202}$ ) und Touton ${ }^{226}$ ) beschrieben.

Auch möchte ich betonen, daß die merkuriellen Hautveränderungen, wie schon oben erwähnt, gar nicht selten das Bild eines echten nässenden Ekzems annehmen. Besonders prägnante Fälle dieser Art sind von Alley $\left.y^{4}\right)$, Baron $\left.^{26}\right)$, Kahleis $^{131}$ ) (2 Fälle), Morel-Lavallée $\left.{ }^{164}\right)$, Rosenthal ${ }^{191}$ ) und Tomasczewski ${ }^{225}$ ) beschrieben.

Zum Schluß möchte ich anführen, daß Defluvium capillorum infolge Quecksilbereinwirkung von Crawfor $d^{58}$ ) (S. 38) erwähnt und sein Vorkommen auch von Kussmau ${ }^{138}$ ) angenommen wird. Letzterer teilt jedoch keine näheren Beobachtungen darüber mit. Was merkurielle Nagelveränderungen anbetrifft, so sagt Kussmaul nur, daß über solche nichts bekannt ist (S. 325). Später sind sie aber von Bossard ${ }^{41}$ ) (S. 65), Hoffmann ${ }^{117}$ ) (Fall I, S. 904), und Hans Hirschfeld ${ }^{116}$ ) beschrieben worden.

Während der letzten Jahre habe ich Gelegenheit gehabt, nicht weniger als 38 Fälle von merkuriellen Hautveränderungen bei 31 Personen zu beobachten und sowohl klinisch wie histologisch zu untersuchen. Diese kombinierten klinisch-histologischen Untersuchungen zusammen mit einigen Tierexperimenten haben mich zu einer etwas veränderten Auffassung über die besprochenen merkuriellen Hautveränderungen geführt.

Bevor ich aber zu diesen eigenen Untersuchungen übergehe, möchte ich die Frage der Benennung dieses Leidens berühren. Wie erwähnt sind bis jetzt 9 verschiedene Bezeichnungen vorgeschlagen. Von diesen finde ich die von Alley vorgeschlagene, Hydrargyra (,hydrargyrie". der Franzosen), trotz ihrer langen An- 
wendung sehr unzweckmäßig, da sie keine besondere Wirkung des Quecksilbers auf die Haut andeutet, sondern nur eine Quecksilberwirkung im allgemeinen. Ferner gibt wohl der Name Spilosis mercurialis sehr wenig Aufklärung, und der Name Eczema rubrum, der nur ein klinisches Bild und keine ätiologische Einheit bezeichnet, ist ganz ungeeignet. Dann haben wir 5 Bezeichnungen, welche alle Hautveränderungen von einer gewissen morphologischen Art. angeben, nämlich Erythema mercurialis, Eczema mercurialis, Dermatitis mercurialis, Erysipelas mercurialis und Lepra mercurialis. Von diesen ist wohl der letzterwähnte Ausdruck nichts weniger als zutreffend, da die merkuriellen Hautveränderungen kaum das Aussehen und noch weniger den Verlauf der leprösen Hautaffektion haben. Die anderen vier Namen können für gewisse Fälle geeignet sein, nämlich dann, wenn die Hautveränderungen des betreffenden Falles das Aussehen eines Erythems, Ekzems, Erysipels oder einer Dermatitis haben. Aber als eine Bezeichnung für das Leiden im ganzen, für die ganze Wirkung des Quecksilbers auf die Haut im allgemeinen taugen sie nicht. Wir müssen einen Namen haben, der alle verschiedenen morphologischen Formen der Hautveränderung, welche dieses Leiden annehmen kann (Erythem, Ekzem, Urticaria, Purpura, Dermatitis, Erysipeles usw.) in sich einschließt. Diesen Bedingungen entspricht das Wort „Dermatosis “ und so ist auch die Bezeichnung Dermatosis mercurialis als Bezeichnung für den ganzen Komplex merkurieller Hauterkranukngen vollkommen logisch und richtig, da sie nichts anderes bedeutet als merkurielle Hautveränderungen.

Gegen die 9. vorgeschlagene Bezeichnung, Exanthema mercuriale, läßt sich nichts einwenden. Die merkuriellen Hautveränderungen fangen immer mit ,eruptiven Grundformen", das heißt mit Efflorescenzen an, sind also sogenannte eruptive Dermatosen und man ist ja gewöhnt, die ganze Eruption, d. h. die Gesamtheit der Efflorescenzen Exanthem zu nennen. Daß hierdurch die merkurielle Dermatose mit den Hautveränderungen bei Scarlatina und anderen Infektionskrankheiten in eine Klasse gebracht wird, scheint mir nicht von Nachteil. Sie sind einander ja manchmal klinisch äußerst ähnlich, und über die Pathogenese der verschiedenen Hautveränderungen wissen wir nichts Sicheres. Vielleicht liegt den verschiedenen Exanthemen -- es scheint mir nicht unmöglich -- eine ziemlich gleichartige Pathogenese zugrunde. Die beiden Benennungen Exanthem und Enanthem drücken auch gut aus, wie sehr die Veränderungen der Haut und der Schleimhaut einander entsprechen. Demgemäß verwende ich als geeignete Bezeichnungen in meiner Arbeit die beiden Namen: Dermatosis mercurialis und Exanthema et Enanthema mercuriale.

Trotz der ungemein wechselnden Erscheinungsformen der merkuriellen Dermatosen ist es mir doch gelungen, 2 verschiedene Gruppen zu unterscheiden. Die eine Gruppe nenne ich Dermatosis mercurialis simplex oder Exanthema mercuriale simplex, die andere Dermatosis mercuriatis complicata seu infecta resp. Exanthema mercuriale complicatum s. infectum. Der Unterschied zwischen diesen beiden Gruppen liegt nicht so sehr in den klinischen Formen, welche ja in beiden Gruppen sehr variieren können, sondern wird vielmehr in ihrem Verlauf, der Pathogenese und den histologischen Veränderungen deutlich.

1. Exanthema mercuriale simplex ist charakterisiert durch einen regelmäßigen und ziemlich kurzen oder sogar beschleunigten Verlauf. Die Symptome können wohl in manchen Fällen sehr heftig und ausgebreitet sein (hohes Fieber, starke Hautrötung, heftiges Jucken, universeller Ausschlag), aber nachdem sie ihren Höhepunkt erreicht haben, gehen sie regelmäBig ohne neue Exacerbationen zurück, wenn nur das Quecksilber aus dem Körper ausgeschieden ist. Die Hautveränderungen, 
die man hier findet, sind Hautrötung, Urticariabildung, diffuse ödematöse Hautdurchtränkung, circumscriptes Ödem und oberflächliche Hautbläschen. Seltener sind Blutungen und eine gewisse Hautinfiltration, die sich jedoch in mäßigen Grenzen hält. Den Abschluß der Hautveränderungen bildet eine Schuppung, deren Stärke hauptsächlich der Stärke des Ödems proportional ist. und da nicht immer eine Ödembil. dung auftritt, kann auch die Schuppung fehlen. Dagegen sieht man in diesen Fällen im Gegensatz zu der anderen Gruppe keine ausgebildete Hautentzündung mit inflammatorischem Infiltrat und Exsudatbildung.

Die Dauer dieser Krankheitsformen ist sehr verschieden, geht aber gewöhnlich der Schwere der Veränderungen parallel. Leichte Fälle haben also einen entsprechend kurzen Verlauf. So sind in meinem Falle 24 die Veränderungen binnen 24 Stunden verschwunden, ebenso wie in den Fällen von Claesson und Bruck und in meinen Fällen 4 und 25 haben sie nur 2 Tage gedauert. Bei schweren Veränderungen dagegen nimmt die Rückbildung längere Zeit in Anspruch z. B. 2-3 Wochen oder noch mehr. Von meinen Fällen hat Fall 15. 28 Tage gedauert, alle anderen aber weniger als 17 Tage (siehe die Zusammenfassung S. 374). Meine histologischen und experimentellen Studien haben mich dahin geführt, diese Hautveränderungen als reine Quecksilberwirkungen anzusehen.

2. Exanthema mercuriale complicatum seu infectum ist charakterisiert durch einen unregelmäßigen, sehr langen, sich manchmal über mehrere Monate erstreckenden Verlauf, oft mit abwechselnden Verbesserungen und Exacerbationen. Die Hautveränderungen zeigen ein sehr wechselndes Bild, gewöhnlich ist jedoch die Haut an größeren und kleineren Gebieten mehr oder weniger entzündet, mit inflammatorischem Infiltrat und Exsudat, nässsend oder eitrig, hier und da mit Krusten oder Borken belegt. Vesiculäre oder sogar bullöse Abhebungen kommen nicht selten vor. Die Flüssigkeit ist sowohl in den Blasen wie auf der nässenden Hautoberfläche stark eiweißhaltig, in einigen Fällen eitrig oder übelriechend, ausnahmsweise sogar stinkend und brandähnlich. Die Haut hat manchmal eine schmutzige Farbe angenommen, und Blutungen kommen reichlicher vor als in den vorigen Fällen. Die Schuppung ist gewöhnlich sehr stark und großblättrig, die Temperatur wechselnd, zeitweise hochfebril, zeitweise niedriger oder sogar normal. Nicht selten sind schwere Allgemeinsymptome und Symptome von den inneren Organen vorhanden, und in diesen Fällen ist die Prognose quod vitam zweifelhaft oder sogar schlecht.

Da die Hautveränderungen dieser beiden Gruppen große Verschiedenheiten zeigen und nicht immer schwere Symptome darbieten und andererseits die Fälle der ersten Gruppe gleichfalls Hautentzündungen aufweisen können, so kann es manchmal ziemlich schwer sein, im Einzelfalle zu 
bestimmen, welcher Gruppe der Fall angehört. Der Unterschied liegt ja eigentlich nicht in den klinischen Veränderungen, sondern in der Pathogenese. Die Fälle der ersten Gruppe beruhen auf reiner Quecksilberwirkung; bei denen der zweiten Gruppe ist dagegen zu der Quecksilberwirkung noch eine zweites Moment dazugekommen; deshalb die Bezeichnung ,complicatum“. Der weitere Verlauf und die histologischen Untersuchungen zeigen deshalb deutlich die Natur des Krankheits. prozesses.

Es hat auch früher nicht an Versuchen gefehlt, die merkuriellen Dermatosen in verschiedene Gruppen einzuteilen.

Schon Alley ${ }^{4}$ ) hat 1810 in seiner Monographie die merkurielle Hautveränderung in 3 Gruppen eingeteilt: 1. Hydrargyria mitis oder benigna, 2. Hydrargyria febrilis und 3. Hydrargyria maligna. Die erste Gruppe sollte ohne Fieber verlaufen, mehr lokale Veränderungen zeigen und nur in einem Erythem oder einem Erythem mit kleinen Bläschen bestehen. Die zweite Gruppe sollte sich durch Vorhandensein von Fieber, stärker ausgebildeten Hautveränderungen mit Krusten und unerträglichem Jucken auszeichnen. Sehr oft sollte ferner Angina und Stomatitis mercurialis auftreten. Die dritte Gruppe käme nach Alley kaum unter anderen Bedingungen zur Beobachtung als bei Fortsetzung der Queeksilberbehandlung nach dem Auftreten der ersten Bläschen. Aus Alleys langer Beschreibung dieser letzten Gruppe möchte ich besonders hervorheben, daß einerseits die Hautaffektionen sehr schwer waren, u. a. mit Veränderungen großvesiculären oder sogar bullösen Charakters, die Blasen von einer ,scharfen" Flüssigkeit erfüllt, manchmal außerdem mit oberflächlichen Abscessen, Furunkeln und sogar gangränösen Ulcerationen, und daß andererseits außer dem Fieber sowohl schwere Allgemeinsymptome wie Komplikationen innerer Organe vorhanden waren. Finige Fälle waren unter Delirien und Koma gestorben. Von dieser Gruppe hat Alley in seiner Monographie 14 Fälle beschrieben, von welchen $8(=57 \%)$ tödlich endeten.

Ferner beschrieb Faierman ${ }^{75}$ ) (1897) 2 Formen von Hautveränderungen in folgender Weise: a) „L'hydrargyrie spécifique commune, apyrétique, à localisation (spécialement le scrotum, la face interne des cuisses et la partie inférieure de l'abdomen), développement en forme anatomique (érythemato-vesiculeuse), plus ou moins détérminée.

b) L'hydrargyrie cutanée anormale, accidentelle, pyrétique, sans caractères bien nets, à éléments éruptifs polymorphes à manifestations septicémiques."

Schließlich möchte ich auch die Ansicht Juliusbergs ${ }^{128}$ ) erwähnen, der 1911 sagt: „Die Quecksilberintoxikationen im allgemeinen gehören 2 verschieden zu bewertenden Gruppen an, Bei der einen Gruppe sind es die direkten toxischen Einflüsse auf die der Quecksilberschädigung besonders ausgesetzten Organe, speziell Niere und Darm, die den unglïicklichen Verlauf veranlassen. Bei anderen. Fällen sind es von der geschädigten Mundhöhle aus erfolgende Infektionen, die zu dem letalen Ausgang führen. Fälle dieser letzteren Art sind also als Sepsis nach Quecksilberstomatitis aufzufassen."

Den Unterschied zwischen diesen Einteilungen und meinen beiden Gruppen kann ich erst richtig auseinandersetzen, nachdem ich die histologischen Veränderungen beschrieben habe. Auch ist eine kurze Mitteilung der Krankengeschichte meiner Fälle nötig, weil es sonst nicht möglich ist, meine beiden Gruppen genau klarzulegen. 


\section{Exanthema mercuriale simplex.}

Fall 1. Schneider, geboren 1888. Hat sich wegen Pediculi pubis mit Unguentum cinereum behandelt. Am folgenden Tage trat eine Hautrötung in der Genitalgegend auf. In die Klinik aufgenommen am 18. I. 1913 mit einem Erythem an Genitalien, Oberschenkeln und Bauch. Außerdem bedeutende ödematöse Anschwellung des Präputiums und zerstreute rote Flecken an Brust, Hals und Extremitäten. Unter Behandlung mit Boecks Liniment*) Genesung in 11 Tagen. Schuppung nur an den Genitalien.

Fall 2. Schuhmacher, geboren 1883. In die Klinik aufgenommen am 10. X. 1913 wegen Syphilisrezidivs. Behandlung: Hydrargyrum salicylicum $0,05 \mathrm{~g}$, am 12. X. und 15. X. Finige Stunden nach der letzten Injektion bemerkte Pat. an den Rü̈ckseiten der Oberschenkel, den Knien und den Glutealregoinen eine Menge stecknadelkopfgroßer bis linsengroßer Effloreszenzen von erythematös turticariellem Aussehen, mit zentralen Blutungen. An der rechten Glutealregion waren die Urticariaquaddeln zu einer kindshandgroßen Partie zusammengeschmolzen. Unter Behandlung mit Ichthyolpinselung gingen die Efflorescenzen ziemlich schnell zurück, so daB am 25. X. nur kleine Reste zu sehen waren und die Behandlung am 28. X. wieder aufgenommen werden konnte. Bis zum 4. XI. hatte Pat. kein Rezidiv bekommen; seit diesem Tage hat er sich nicht mehr vorgestellt.

Fälle 3 und 4. Schaffner, geboren 1884. Wegen Syphilis recens am 22. X. 1915 in die Klinik aufgenommen, erbielt er sofort eine Injektion von $0,05 \mathrm{~g}$ Hydrargyium salicylicum. Am folgenden Tage war ein scharlachrotes Erythem an den Oberschenkeln, am Nabel, in den Leisten und in den Kniekehlen zu sehen. AuBerdem erythematöse Papeln in den Ellenbeugen. Unter Behandlung mit Boecks Liniment binnen 3 Tagen gesund. Am 26. X. eine zweite Injektion von $0,05 \mathrm{~g}$ Hydrargyrum salicylicum; am folgenden Tage war wieder ein Erythem zu sehen, ganz ähnlich wie das vorige, genau an denselben Stellen, nur etwas schwächer ausgebildet. Heilung nach 3 Tagèn. Am 29. X. zum 3. Male Hydrargyrum salicylicum 0,05 g: Danach kein Erythem. Erhielt in der Folge 7 Injektionen von Hydrargyrum salicylicum und 2 von Oleum cinereum ohne Hautveränderungen zu bekommen.

Fälle 5 und 6. Schmied, geboren 1891. Am 7. III. 1916 wegen Syphilis recens in die Klinik aufgenommen. Behandlung: Injektionen von Hydrargyrum salicylicum 8. III. 0,05, 11. III. 0,07, 14. III. 0,08, 17. III. 0,09 g. An diesem Tage trat an den Händen ein Erythem auf, das sich an diesem und den nächsten Tagen. über Arme und Stamm ausbreitete. Es blaßte aber rasch ab und am 20. III. war die Haut normal, so daß Pat. an diesem Tage eine Injektion von 0,05 g Hydrargyrum salicylicum bekommen konnte und am 23. III. eine zweite von der gleichen Dosis. Kurz danach trat wieder ein ähnliches Erythem auf, welches binnen 5 Tagen abgeblaßt war. Dann Salvarsanbehandlung.

Fälle 7 und 8. Dienstmädchen, geboren 1894. Wegen Syphilisrezidivs am 29. IV. 1916 in die Klinik aufgenommen. Vom 30. IV. Injektionen von $0,05 \mathrm{~g}$ Hydrargyrum salicylicum jeden 3. Tag. Bei der 6. Injektion am 18. V. wurde an der Brust und dem größten Teil des Rückens ein kleinpapulöser, follikulärer, lebhaft roter Ausschlag beobachtet. Unter Behandlung mit Boecks Liniment and Ichthyol ging der Ausschlag schnell zuriuck und war am 21. V. beinahe verschwunden. An diesem Tag erhielt Pat. eine 7. Injektion von derselben Dosis wie die früheren, und am folgenden Tage war an den erwähnten Stellen neuerlich ein Ausschlag vom selben Aussehen wie der erste aufgetreten. Derselbe war unter der gleichen Behandling am 29. V. wieder abgeheilt. Die Quecksilberbehandlung wurde aber nicht wieder aufgenommen.

*) Hat gewöhnlich folgende Zusammensetzung: Amylum triticum und Talcum ana partes $100 \mathrm{~g}$, Bleiwasser $200 \mathrm{~g}$ und Glycerin $50 \mathrm{~g}$. 
Fall 9. Klempner, geboren 1890. Am 29. V. 1916 wegen Syphilis recens in die Klinik aufgenommen. Behandlung: Injektionen von Hydrargyrum salicylicum 29. V. 0,05 , 1. VI. 0,07 , 4. VI. 0,08 , 7. VI. 0,10 und 10. VI. 0,10 g. Am 13. VI. morgens, als Pat. sich wieder zur Injektionsbehandlung einstellte, zeigte er an den Streckseiten der Arme und Beine und an den Glutealregionen ein diffuses Erythem, welches sich nachmittags über den ganzen Körper ausgebreitet hatte. Er fühlte sich sehr schwach und konnte nichts essen. Nach der letzten Injektion war Fieber aufgetreten. Temperatur jetzt $38,1^{\circ} \mathrm{C}$. Unter Behandlung mit Boecks Liniment wurde das Erythem schon am folgenden Tage etwas besser und war am 17. VI. ganz verschwunden, doch trat jetzt eine nekrotische Gingivitis auf. Da sich diese schnell besserte wurde die Behandlung am 19.VI. wieder aufgenommen, und Pat. erhielt an diesem 'Tag 0,05 und am 22.VI. 0,10 g Hydrargyrum salicylicum, ohne neue Hautsymptome zu zeigen.

Fall 10. Heizer, geboren 1896. Am 11. X. 1916 wegen Syphilis recens in die Klinik aufgenommen. Erhielt am 12. X. eine Injektion von Hydrargyrum salicylicum $0,05 \mathrm{~g}$. Am folgenden Tage bemerkte Pat. Hautrötung in den Ellenbeugen, und am 14. X. fand sich bei der Untersuchung ein Frythem ïber dem größten Teil der Arme, über den Schuitern, den Seitenteilen der Brust, dem ganzen Bauch und an gewissen Teilen des Rückens und der Glutealregion. An einigen Stellen war das Erythem ein wenig urticariell. Keine Symotome seitens der inneren Organe. Temperatur $38,2^{\circ} \mathrm{C}$. Unter Behandlung mit Boeks Liniment gingen Erythem und Temperatursteigerung zurïck und am 18. X. war die Haut ziemlich normal. Am 20. $X$. wurde die Behandlung wieder aufgenommen, und trotzdem Pat. bis zum 31. X. 5 Injektionen à $0,05 \mathrm{~g}$ Hydrargyrum salicylicum erhalten hatte, waren keine Hautsymptome mehr aufgetreten.

Fall 11. Dienerin, geboren 1894. Am 28. XI. 1916 wegen Syphilis recens in die Klinik aufgenommen. Behandlung: Injektionen mit $0,05 \mathrm{~g}$ Hydrargyrum salicylicum am 28. XI., 1. XII. und 4. XII. Am 6. XII. Kopfschmerzen, Temperatur $38,4^{\circ} \mathrm{C}$, rotfleckiger Ausschlag an den Beugeseiten derUnterarme und Handgelenke, bestehend aus stecknadelkopfgroßen, lebhaft roten, etwas erhöhten und teilweise urticariellen Flecken. Einige solche auch in den Palmae manuum, zwischen den Fingern und an den Dorsalseiten der Hände. Das Quecksilber wurde ausgesetzt und der Ausschlag mit Ichthyol bepinselt. Am 7. XII. waren die roten Flecke schon bedeutend geringer, am 9. XII. die Temperatur normal und am 11. XII. vom Ausschlag nichts mehr zu sehen. Am 12. XII. wurde Neosalvarsanbehandlung eingeleitet und Pat. erhielt bis zum 27. XII. 5 Injektionen mit einer Totaldosis von 2,1 g Salvarsan. Am 28. XII. wurde die Quecksilberbehandlung wieder aufgenommen und bis zum 12. II. 1917 fortgesetzt, ohne daß der Ausschlag wiederkam.

Fall 12. Arbeiter, geboren 1887, bemerkte am 20. I, 1917 Pediculi pubis und behandelte sich mit Unguentum cinereum. Am 27. I. Hautrötung in der Genitalgegend und 2 Tage später Paraphimosis. Aufgenommen in die Klinik am 30. I. Der Ausschlag, der nun auch in den Axillen und Cubitalregionen aufgetreten war, bestand aus urticariell-erythematösen Flecken, teilweise konfluierend. Penis ödematös mit Paraphimosis. Unter Behandlung mit Resorcinumschlägen war der Ausschlag am 14. II. geheilt.

Fälle 13 und 14. Knabe, geboren 19. VI. 1918: Syphilis congenita. In die Klinik aufgenommen am 12. X. 1918. Behandelt mit 6 Injektionen Neosalvarsan 15. X. bis 9. XI. Sodann am 12. XI. 0,008 g Hydrargyrum salicylicum intramuskulär. Da Pat. an einer Lungenentzündung erkrankte, wurde die nächste Injektion erst am 30. XI. gegeben. An diesem Tage bekam Pat. dieselbe Dosis, $0,008 \mathrm{~g}$ Hydrargyrum salicylicum. Als man ihm am 3. XII. eine weitere Injektion geben wollte, wurde aber ein follikuläres rubeolaähnliches Erythem über Gesicht und 
Stamm konstatiert. Diese Hautveränderungen waren am 17. XII. abgeheilt. Infolge einer Rhinitis und Angina lacunaris konnte die Behandlung erst am 29. XII. wieder beginnen. Pat. erhielt dann $0,007 \mathrm{~g}$ Hydrargyrum salicylicum 29. XII, 5. I. 1919, 8. I., 11. I. und 14. I. Am 17. I. trat ein Ausschlag von roten Flecken im Gesicht auf, und am folgenden Tag war ein Erythem von lebhaft roten, etwas: urticariellen, bis linsengroßen Flecken diffus über Gesicht und Capillitium, Brustund Rücken ausgebreitet; die Extremitäten waren frei. Nach 5 Tagen war das Erythem unter Behandlung mit Ichthyolpinselung verschwunden. Salvarsan. behandlung begonnen.

Fall 15. Kassiererin, geboren 1880. Am 8. I. 1919 wegen Syphilisrezidivs in die Klinik aufgenommen. Frhielt 5 Injektionen Neosalvarsan, 9. I. bis 28. I. und darauf folgende Injektionen von Hydrargyrum salicylicum: 31. I. 0,05, 3. II. 0,06 und 6. II. $0,08 \mathrm{~g}$. Am letzten Tage zeigten sich einige Stunden nach der Injektion an den Streck- und Beugeseiten der Oberarme zerstreute, unregelmäßige, juckende, bis talergroße, rote Flecken und an den Streckseiten der Unterschenkel dichte, rote follikuläre PapeIn. Am 7. II., 8. II. und 9. II. traten neue Flecken an den Händen, an Kinn, Brust und Vorderarmen auf. Die Ausbreitung des Ausschlages nahm stets zu, so daß er am 10. II. beinahe universell war. Temperatur normal. Etwas Jucken, sonst keine subjektiven Symptome. Am folgenden Tage nahm das Jucken bedeutend zu, und es zeigten sich an vielen Stellen Massen von miliären Bläschen. Die Entwickiung machte dann aber halt, und am 14. II. konnte man die ersten Zeichen der Besserung sehen. Diese machte zuerst ziemlich schnelle, dann langsamere Fortschritte. Am 5. III. begann Pat. eine Salvarsankur, welche bis zum 2. IV. fortgesetzt wurde, ohne eine Spur von Hautveränderungen hervorzurufen, was deutlich zeigte, daß die früheren Hautveränderungen nicht von Salvarsan herrühren konnten.

Fall 16. Ziseleur, geboren 1890. Nachdem er wegen einer Epididymitis vom 25.-30. III. 1919 Quecksilber-Karbol-Pflaster-Mull appliziert hatte, bekam er einen Ausschlag am Scrotum und an den Innenseiten der Oberschenkel. Dieser Ausschlag wurde mit Unguentum cinereum behandelt. Nach 24 Stunden entstand an der betreffenden Stelle eine. Hautrötung, welche sich sowohl lokal ausbreitete als auch an anderen Stellen auftrat. In die Klinik aufgenommen am 4. IV. 1919. Universelles Erythem, teils fleckenförmig, teils konfluierend, spärlich am Rücken und Hals; an den Oberschenkeln und am Skrotum war die Haut außerdem etwas ödematös, nässend und schuppend. Temperatur 39,1 ${ }^{\circ}$. Unter reichlicher Schuppung ging dann der Ausschlag ungewöhnlich schnell zurück, so daß Pat. nach 12 Tagen beinahe geheilt das Krankenhaus verlassen konnte.

Fälle 17 und 18. Köchin, geboren 1891. Wegen Syphilis recens am 25. IX. 1919 in die Klinik aufgenommen. Behandlung: 10 Injektionen Neosalvarsan 27. IX. bis 11. XI., dann Injektionen von Hydrargyrum salicylicum, 13. XI., 0,05, 16. XI. 0,06, 19. XI. 0,08, 22. XI. 0,10. Nach der letzten Injektion wurde am selben Tage ein feinpunktiertes Erythem an den Streckseiten der Oberarme, an Waden und Brust beobachtet. Am folgenden Tage hatte es sich über den ganzen Körper ausgebreitet. Gleichzeitig waren die Flecken hier und da urticariell geworden und konfluierten stellenweise. Temperatur $39^{\circ}$ C. Kein Jucken oder andere subjektive Symptome. Die Veränderungen gingen unter Behandlung mit Adrenalininjektionen und Boecks Liniment sehr schnell zurück. Am 25. XI. Temperatur afebril, am 26. XI. das Exanthem beinahe verschwunden.

Die Behandlung mit Hydrargyrum salicylicum wurde wieder anfgenommen: 28. XI. 0,06, 1. XII. 0,05 und 4. XII. 0,05 g. Bis zum 6. XII. hatte Pat. die Be. handlung gut vertragen; an diesem Tage klagte sie aber über Blasen in der Mundhöhle und an der Zunge, über Kopfschmerzen und schlechten Appetit. Bei der 
Untersuchung zeigte sich an der Vorderseite des Stammes, an den Hüftregionen und den Streckseiten der Arme ein feinpunktiertes Erythem, in der Mundhöhle waren aber keine deutlichen, Veränderungen zu entdecken. Temperatur 38,5 . Am 11. XII. was dar Erythem fast universell, teilweise konfluierend; Faeces weich, aber kein ausgesprochener Durchfall. Temperatur afebril. Am 12. XII. war die Zunge rot, geschwollen, mit unregelmäßigen, grauen Massen belegt. Bei der Untersuchung der Mundhöhle zeigten sich an diesem Tage reichliche, unregelmäBige Erosionen am Gaumen und eine starke Rötung der ganzen Mund- und Rachenschleimhaut. Das Zahnfleisch jedoch normal, ohne nekrotische Beläge. Pat. klagte über Schluckbeschwerden. Nach 5 Tagen waren diese Veränderungen um vieles besser und am 23. XII. ganz verschwunden. Auch das. Frythem war nun schon bedeutend abgeblaßt und zurückgegangen. Kleine Reste des Erythems hielten sich aber bis 14. I. 1920. Pat. hat später vom 18. II. bis 18. III. 1920 eine Salvarsankur von 9 Injektionen mit einer Totaldosis von $4,95 \mathrm{~g}$ durchgemacht, ohne irgendwelche Ausschläge zu bekommen.

Fall 19. Dienerin, geboren 1896. Wegen Syphilisrezidivs am 29. X. 1919 in die Klinik aufgenommen. Behandlung: Silbersalvarsan, vom 1. XI. bis 29. XI. 7 Injektionen von insgesamt 2,1 g. Dann Hydrargyrum salicylicum 3. XПI. 0,05, 6. XII. 0,06, 9. XII. 0,08 g. Abends nach der letzten Injektion kJeine rote Knötchen an den Vorderarmen und Unterschenkeln. Am 10. XII. Kopfschmerzen, Übelkeit und Fieber bis 38,6. Die roten Knötchen nahmen zu, und am 12. XII. waren die ganzen Beine, die Glutealregionen und die Arme bis zu den oberen Hälften der Oberarme dicht mit roten, follikulären, teilweise konfluierenden Knötchen besetzt. Schon am folgenden Tage begann aber das Erythem abzublassen, war aber erst am 22. XII. mit Hinterlassung zerstreuter Pigmentflecken ganz verschwunden. Behandlung: Boecks Liniment.

Fall 20. Seemann, geboren 1900. Syphilis seit 1918. Hat mehrere Quecksilberbehandlungen durchgemacht; im Jahre 1918 eine Kur von 9 Quecksilberinjektionen, im Februar 19198 Quecksilberinjektionen, im Mai 19194 Quecksilberinjektionen, 30 Einreibungen und im Juli-August 32 Einreibungen. Pat. erhielt in der Poliklinik des Krankenhauses St. Göran am 6. II., 12. II. und 18. II. 1920 je eine Injektion von Oleum hydrargyrum à $0,06 \mathrm{~g}$ Hydrargyrum. Am Tage der letzten Injektion trat ein Ausschlag im Gesicht, an Hals und Brust auf. Als er am 20. II. 1920 in die Klinik aufgenommen wurde, zeigte er im Gesicht, am ganzen Stamme, an Hals, Armen und Oberschenkeln ein Exanthem von stecknadelkopfgroßen und größeren, dichten, teilweise zusammenfließenden, roten Flecken, an einigen Stellen follikulär lokalisiert. Ein Teil der Flecken zeigte eine kleinere und größere Schuppung. Unter Behandlung mit Ichthyol ging der Ausschlag in 3 Tagen so weit zurück, daß Pat. auf seinen Wunsch das Krankenhaus verließ. Der Aufforderung, dem Krankenhaus weiter. Nachricht über seinen Zustand zukommen zu lassen, folgte er nicht, so daß über den späteren Verlauf nichts bekannt ist.

Fall 21. Tabaksarbeiterin, geboren 1899. Am 3. III. 1920 wegen Syphilis recens in die Klinik aufgenommen. Vom 4. III. bis 6. IV. mit 7 Neosalvarsaninjektionen behandelt, ohne Hautveränderungen zu bekommen. Dann Injektionen von Hydrargyrum salicylicum 7. IV. 0,05, 10. IV. 0,06 und 13. IV. 0,08 g. Als Pat. sich am 16. IV. zur 4. Injektion einstellte, wurde ein Ausschlag an Händen und Füßen entdeckt. Der Ausschlag bestand aus zerstreuten, kleinen, follikulären, roten, nicht juckenden Papeln, welche sich von den Dorsalseiten der Hände und Füße, immer spärlicher werdend auf die Vorderarme und Unterschenkel erstreckten. Temperatur seit gestern, d. i. seit dem Tage vor Erscheinen des Ausschlages $38,3^{\circ} \mathrm{C}$. Behandelt mit Pyroleum lithantracis. Nach 5 Tagen war der Ausschlag bedeutend besser, und am 23. IV. waren die Hautveränderungen vollständig verschwunden. 
Am selben Tage wurde mit Salvarsan begonnen, welches Pat. gut vertrug. Eine neue Quecksilberkur nicht versucht.

Fall 22. Dienerin, geboren 1895. Wegen Syphilis tertiaria (Ulcera gummosa anticruris) mit 3 Quecksilberinjektionen behandelt: am 19. VII. 1920, 23. VII. 26. VII. Am 30. VII. bemerkte Pat. Rötung des Gesichts und später rote Flecken am Körper. Wurde am selben Tage in die Klinik aufgenommen. Sie bot da folgendes Bild: Die Haut des Gesichts stark gerötet, mit Ödem an den Lippen und unter den Augen. Am Stamm und an den Streckseiten der Extremitäten zahlreiche rotviolette Flecken, an den Beugeseiten dagegen nur sehr spärliche. Nach Behandlung mit Ichthyol war der Ausschlag am 10. VIII. ganz verschwunden und nur noch Schuppung im Gesicht zurückgeblieben. An diesem Tage Beginn einer Salvarsanbehandlung. Sowohl diese wie eine nachfolgende Quecksilberkur wurde gut vertragen.

Fall 23. Näherin, geboren 1889. Wegen Syphilis recens vom 27. IX. bis 28. X. 1919. in der Klinik behandelt mit 6 Injektionen von Neosalvarsan und 3 Injektionen von Hydrargyrum salicylicum und später wegen Syphilisrezidivs vom 22. XII. 1920 bis 25 . I. 1921 mit 8 Injektionen Neosalvarsan und 9 Injektionen von Hydrargyrum salicylicum. Die letzterwähnten Injektionen wie folgt: 31 . I. 0,05, 3. II. 0,05, 6. II. 0,06, 9, II. 0,08, 12. II. 0,08, 15. II. 0,08, 18. II. 0,10, 21. II. 0,10 und 24. II. $0,10 \mathrm{~g}$. Am Abend des letzten Tages bemerkte Pat. rote Flecken an den Armen. Bei der Untersuchung am 26. II. zeigte sich ein kleinpapulöser, lebhaft roter, juckender Ausschlag an den Streckseiten der Arme, den Dorsalseiten der Hände und den Kniescheiben. Der Ausschlag wurde mit Tchthyol bepinselt und war am 1. III. verschwunden. Die Quecksilberbehandlung wurde nicht wieder aufgenommen.

Fälle 24 und 25. Dienstmädchen, geboren 1897. Wegen Syphilisrezidivs am 11. VII. 1921 in die Klinik aufgenommen. Bis 30. VII. mit 4 Neosalvarsaninjektionen behandelt und dann mit folgenden Dosen Hydrargyrum salicylicum: 4. VIII. 0,05, 7. VIII. 0,05, 10. VIII. 0,06 und 13. VIII. 0,06 g. Als Pat. sich am 16. VIII. zur 5. Injektion einstellte; wurde ein Erythem an beiden Hüftregionen, an den Außen- und Rückseiten der Oberschenkel, an Knien und Waden konstatiert. Der Ausschlag bestand aus lebhaft hellroten, unregelmäßigen Flecken, welche teilweise konfluierten. Kein Fieber, keine subjektiven Symptome. Das Erythem wurde mit Ichthyol bepinselt und war nach 24 Stunden ganz verschwunden. Am 24. VIII. bekam Pat. um $11 \mathrm{Uhr}$ vormittags eine Injektion von Hydrargyrum salicylicum $0,03 \mathrm{~g}$. Am selben Tage um $4 \mathrm{Uhr}$ nachmittags fühlte Pat. Jucken an den Stellen, wo sich letzthin das Exanthem gezeige hatte, und wurde eines Ausschlags gewahr, der ganz so aussah und so lokalisiert war wie der vom 16. VIII. Um $8 \mathrm{Uhr}$ abends des gleichen Tages wurden Ichthyolpinselungen vorgenommen. Der Ausschlag war am folgenden Tage abgeblaßt, doch konnte man an denselben Stellen wie neulich blasse erythematöse Flecken sehen, einige etwas urticariell geschwellt. Später zeigten sich mehrere urticariell-erythematöse Flecken an Ster* num, Schultern und der linken Submaxillarisregion. Am 26. VIIT. war der Ausschlag verschwunden. Es wurde dann Salvarsanbehandlung eingeleitet, nach welcher keine Hautveränderungen auftraten.

Fall 26. Frau, geboren 1896. Wegen Syphilis recens mit 4 Injektionen Neosalvarsan in einer Gesamtdosis von $1,8 \mathrm{~g}$ behandelt. Am 10. XI. $1916 \mathrm{mu}$ Bte aber diese Behandlung wegen Erbrechens und Durchfalls sistiert werden. Am 18. XI. erhielt sie eine Injektion von $0,05 \mathrm{~g}$ Hydrargyrum salicylicum, kam jedoch am 20. XI. wieder zu ihrem Arzt, weil sie an den Dorsalseiten der Hände und Vorderarme einen Ausschlag bemerkt hatte. Die Untersuchung ergab da zerstreute erythematöse Papeln an den erwähnten Stellen. Am folgenden Tage waren auch 
an den Streckseiten der Oberarme und den Vorder- und Hinterseiten der Beine rote Papeln zu finden, teilweise zu diffusen erythematösen Hautpartien konfluiert. Die Haut der Hände außerdem etwas ödematös. Nach Behandlung mit Ichthyolpinselung war Pat. am 26. XI. geheilt.

Fall 2\%. Frau, geboren 1882, behandelt wegen Syphilis recens mit 2 Injektionen Hydrargyrum salicylicum à $0,02 \mathrm{~g}$ am 20. X. und 21. X. 1917. Am folgenden Tage rote Flecken an den Armen, die sich ausbreiteten und zusammenflossen, so daß am 24. X. ein ziemlich diffuses scarlatiniformes Erythem an den Extremitäten, am Halse und Stamme ausgebildet war. Am Halse außerdem ein wenig Ödem. Kein Fieber, dagegen Übelkeit, leichtes Erbrechen und Unruhe. Am 28. X. war der Ausschlag unter Behandlung mit Boecks Liniment abgeblaßt und nur etwas Schuppung zu sehen. Die Quecksilberbehandlung wurde nicht wieder aufgenommen, sondern die Pat. bis 5. VI. 1918 nur mit Neosalvarsan bèhandelt.

Fall 28. Ingenieur, geboren 1881. Wegen Syphilisrezidivs mit Injektionen von Hydrargyrum salicylicum behandelt wie folgt: 12. II, 15. II. und 18. II. 1919 je 0,05 g. Als Pat. sich am 21. II. zu einer neuerlichen Injektion einstellte, wurden rote, etwas violette Flecken an der Brust bemerkt. Die Behandlung wurde ausgesetzt und Ichthyol ordiniert, welche Verordnung der Pat. aber nicht befolgte. Nach 2 Tagen mußte er sich ins Bett legen und zeigte bei der Untersuchung am 23. II. rote Flecken nebst kleineren und größeren erythematösen Hautpartien am ganzen Stamme, an den Armen, den Kniebeugen und den Innenseiten der Hände und. Füße. Die Mundschleimhaut war gerötet, auf der Zunge vereinzelte Blasen. Fr konnte nichts essen, klagte über Übelkeit und hatte erhöhte Temperatur, $39,8^{\circ}$. Unter Behandlung mit Digitalis, Diuretin und Ichthyol gingen die Symptome in 3 Tagen zurück, so daß Pat. am 26. II. nur eine lamellöse Schuppung an den ergriffenen Hautpartien zeigte.

\section{Exanthema mercuriale complicatum seu infectum.}

Fall 29. Dienstmädchen, geboren 1895. Am 10. XII. 1915 wegen Syphilis recens in die Klinik aufgenommen. Behandelt mit 10 Injektionen von Hydrargyrum salicylicum und nach dem Verlassen des Krankenhauses bis 15. II. 1916 mit 7 Injektionen Oleum mercurioli. Jede Injektion von Oleum mercurioli enthielt $0,067 \mathrm{~g} \mathrm{Hg}$. Wieder aufgenommen am 24. II. (also 9 Tage nach Schluß dieser Behandlung) wegen Stomatitis mereurialis, an welcher sie seit einigen Tagen litt. Zeigte bei der Untersuchung außer der Veränderung in der Mundhöhle an den Hinten- und Außenseiten der Arme zerstreute, blaß rosagefärbte, kleine follikuläre Flecken, welche Pat. früher nicht bemerkt hatte. Sonst kein Ausschlag. Unter Behandlung mit Ichthyolpinselung waren diese Flecken jedoch nach 5 Tagen verschwunden. Am 6. III. traten einige gruppierte urticarielle Quaddeln am Bauch auf. 3 Tage später hatte sich ein Erythem über beide Arme und das ganze Gesicht entwickelt. Das Gesicht außerdem etwas ödematös angeschwollen. Während der folgenden Tage sah man, wie das Erythem sich mehr und mehr ausbreitete, bis es am 15. III. ganz universell war. Starkes Jucken. Unter Behandlung mit Atropin, Ichthyol und Boecks Liniment war der Zustand am 23. III. bedeutend gebessert und das Erythem nur an den Streckseiten der Arme, den Glutealregionen und den unteren Extremitäten zu finden. Die Haut war hier otwas cyanotisch, mit roten follikulären Anschwellungen.

Während einiger 'Tage, welche Pat. außerhalb der Klinik zubrachte (23. III. bis 27. III.) hatte sich der Ausschlag verschlechtert. Stamm und Extremitäten zeigten jetzt starke Sehuppung, rote geschwollene Follikel und teilweise nässende Hautpartien. Das Gesicht war etwas geschwollen, mit mehreren Pusteln und einigen Borken. Unter gewöhnlicher Ekzembehandlung mit Umschlägen und 
Salben ging der Ausschlag sehr langsam zurück, und Pat. war, als sie am 17. IV. in ein anderes Krankenhaus transferiert wurde, wenn nicht ganz, so doch beinahe geheilt.

Ich muß zu diesem Fall bemerken, daß man nicht ganz sicher sein kann, daß wir es hier mit einem Falle von Exanthema mercuriale complicatum zu tun haben, denn der langsame Verlauf kann auch eine Folge der jlangsam resorbierenden Quecksilberdepots sein, welche die Behandlung mit Oleum mercurioli zurückläßt.

Fall 30. Dienstmädchen, geboren 1. I. 1900. Am 14.VIII. 1916 wegen Syphilisrezidivs in die Klinik aufgenommen. Behandlung mit Hydrargyrum salicylicum 0,05 jeden dritten Tag, beginnend am 15. VIII., kombiniert mit Neosalvarsan intravenös, in folgender Weise: Am 16. VIII. 0,3, 19. VIII. 0,3 und 20 . VIII. $0,4 \mathrm{~g}$ Salvarsan. Am 1. IX. bekam sie ihre 6. Injektion Hydrargyrum salicylicum von $0,05 \mathrm{~g}$. Im Laufe desselben Tages hatte sie dann Übelkeit und Krankheitsgefühl, und entdeckte einen Ausschlag an den Extremitäten. Die Temperatur abends $40^{\circ} \mathrm{C}$. Bei Untersuchung am 2. IX. zeigte sich ein fleckförmıges, teilweise zusammenfließendes Erythem an Extremitäten und Brust. Temperatur 39,6 ${ }^{\circ} \mathrm{C}$. Am 4. IX. war das Exanthem beinahe über den ganzen Körper, - auch über das Gesicht ausgebreitet, sehr lebhaft gerötet, hier und da quaddelartig erhaben oder öclematös geschwellt, nicht aber infiltriert und ohne Blasen oder deutliche Ödeme. Morgens Temperatur $39^{\circ}$, abends $40,0^{\circ}$ C. Behandlung Zinksalbe. Am 5. IX. Temperaturabfall bis $37,6^{\circ} \mathrm{C}$ abends. Gleichzeitig begann das Exanthem abzublassen und war am 11. IX. beinahe verschwunden. Immerhin hatte die Körpertemperatur während dieser Tage um $38^{\circ} \mathrm{C}$ geschwankt. Trotzdem fühlte sich Pat. gesund.

Am 12. IX. wieder Temperatursteigerung (morgens 39,5, abends $40,1^{\circ} \mathrm{C}$ ) und gleichzeitig Beginn einer neuerlichen Erythemeruption. Am folgenden Tage plötzlich ein Anfall von hochgradiger Dyspnöe und schwerem Seitenstechen ohne nachweisbare objektive Veränderungen. Unter Behandlung mit Digitotal, Campher und Panthopon ging der Anfall in 2 Stunden vorüber. Am 14. IX. war der ganze Körper diffus rot, die ödematöse Anschwellung ausgeprägter als vorher, sogar in der Subcutis. Am stärksten war das Ödem im Gesicht, wo Lippen und Augenlider stark angeschwollen waren. Feinlamellöse Schuppung am Halse, Kinn und um den Mund. Hyperkeratotische Verdickungen an Palmae manuum, Plantae peduum und an mehreren Stellen der Streckseiten der Extremitäten (Knie-, Handgelenk, Oberarme). An den Fußsohlen und den Innenseiten der Hände punktförmige, teilweise zusammenfließende, schwarzrote Hämorrhagien. Am 15. IX. vermehrte Schuppung an den Vorderarmen und Beinen in Form von kleinen blasenähnlichen, lamellösen Erhebungen. AuBerdem waren auch an den Dorsalseiten der Blase Blutungen aufgetreten. Zustand im übrigen unverändert.

Die Blutungen, die hyperkeratotischen Verdickungen und die Schuppung nahmen weiterhin immer mehr zu. Eine besonders starke Schuppung hatte sich am 18. IX. an den Palmae manuum und Plantae peduum ausgebildet. Zwischen den Fingern und Zehen und in den Axillen hatte die Haut zu nässen begonnen. Die Temperatur hatte während der letzten Tage zwischen 39,0 und $40,3^{\circ} \mathrm{C}$ geschwankt. Puls 110. Pat. ist ein wenig benommen. Ein brauner Farbenton hat sich während der letzten Zeit, jeden Tag deutlicher, über den ganzen Körper ausgebreitet. Ein eigentümlicher Geruch geht von der Kranken aus. Am 20. IX. waren über den ganzen Körper massenhaft kleine, weiße, blasenförmige Erhebungen zu sehen, welche nichts anderes waren als begrenzte Ansammlungen von Epidermisschuppen. Durch Konfluieren dieser Ansammlungen ist an mehreren Stellen eine diffuse Schuppung entstanden. An Knien, Händen und Füßen sieht man hyperkeratotische Verdickungen. Plantae peduum und Palmae manuum dunkelrot cyanotisch infolge verschmelzender Blutungen. An den Lippen und Augen- 
lidern hämorrhagische Krusten. Am 21. IX. war die Temperatur bis $38^{\circ}$ gesunken. Pat. fühlte sich etwas besser. Die Haut an allen Beugestellen nässend und schmerzhaft. Am 22. IX. zeigte sich die Schuppung an vielen Stellen sehr großlamellös. Man konnte große Lamellen abblättern. Die Hornlamellen des Gesichtes gaben der Pat. einen eigentümlichen steifen Ausdruck, was besonders an den Augenlidern hervortrat, welche durch die Lamellen in halbgeschlossenem Zustand fixiert waren. Wenn Pat. die Augen schlieBen wollte, rotierte sie die Augäpfel aufwärts, die einzige Weise, in der sie den Lichteinfall verhindern konnte. Entnahme von Hautstückehen von mehreren Stellen zur mikroskopischen Untersuchung. Am 23. IX. sah man unter den losesitzenden Schuppen und größeren Lamellen dünne rosagefärbte Haut hervorscheinen. Wenn man von den dicken großen Hautlamellen an den Händen und den Füßen welche abhob, sah man sie an ihrer Innenseite dicht mit punktförmigen Blutungen besät. Temperatur 37,0. Am 25. IX. hatte die Schuppung enorm zugenommen. Vom Stamme konnten meterlange Hornlamellen abgetragen werden und von der Planta pedis dextra stie $B$ sich die ganze Hornhaut zusammenhängend in einem großen überschuhähnlichen Stück (siehe Abb. 1) ab. Die Innenflächen dieser Hautlamellen waren stellenweise ganz voll mit punktförmigen Blutmassen (siehe Abb. 2). Temperatur wieder gestiegen bis ungefähr $38^{\circ} \mathrm{C}$. Am 26. IX. war die Körperoberfläche infolge dieser Abstoßung der Hautlamellen an vielen Stellen mit einer dünnen normalen Haut bedeckt. Die Blutmassen und die braune Pigmentierung waren mit den abgestoßenen Hornlamellen weggefallen. An diesem Tag stellte sich jedoch nachmittags Erbrechen und schwerer Durchfall ein. Abends Temperatur 38,5. Pat. fühlt sich sehr krank. Am 27. IX. war die Temperatur ungefähr 39,0 und der Allgemeinzustand sehr schlecht. Puls schwach, 115, Erbrechen, Durchfall, Seitenstechen, Atemnot, Außerdem Klagen über Schmerzen beim Schlucken. Es sind aber weder stomatische Veränderungen noch Veränderungen an den Tonsillen zu konstatieren. Am 28. IX. gleich schlechter Zustand, mit denselben Erscheinungen. Pat sehr unruhig. Äußert Todesahnungen. Exitus um 4,45 Uhr nachmittags.

Die Sektion wurde am 29. IX. um 12 Uhr mittags, also 19 Stunden nach dem Tode des Pat. von Prof. G. Hedrên ausgeführt. Aus dem ausführlichen Sektionsprotokoll finde ich folgendes besonders erwähnenswert:

Weicher Gaumen, Tonsillen und Pharynx belegt mit einer diphtherieähnlichen, weibgrauen, meistenteils festsitzenden Pseudomembran (Diphtheritis faucium pharyngis). Die Schleimhaut des Kehlkopfes überall belegt mit einer weißgrauen, ïberall ganz festsitzenden Pseudomembran. Ödem in der Schleimhaut (Laryngitis diphtherica + oedema glotlidis). Aus dem Kehlkopf setzte sich die Pseudomembran in die Trachea fort, in deren oberem Teil sie stark festsaß, während sie unten leicht, in großen zusammenhängenden Stücken losgetrennt werden konnte. Unter den Membranen ist die Schleimhaut stark gerötet ( Tracheitis diphtherica et crouposa). Die Lymphdrüsen des Halses gesehwollen bis Mandelgröße, weich, mit grauroter, feuchter Schnittfläche (Lymphadenitis acuta). Ferner: Oedema pulmonum amborum Dilatatio et Degeneratio cordis + Myocarditis acuta, Hypertrophia et Degeneratio adiposa hepatis, Degeneratio parenchymatosa et adiposa acuta renum amborum, Hypertrophia acuta lienis. Bemerkenswert ist, daß trotz der Symptome vom Magendarmkanal hier keine Veränderungen vorhanden waren. Der Magen enthielt ein wenig dünne, braungraue Flüssigkeit. Die Schleimhaut rotgrau, sonst normal. Der Dünndarm enthielt eine geringe Menge braungelber Flüssigkeit, die Schleimhaut rotgrau, sonst normal. Im Dickdarm fand sich ein wenig von einer dickflüssigen, graubraunen Masse; die Schleimhaut normal.

Fall 31. Frau, geboren 1898. Am 4. VII. 1917 wegen Syphilisrezidiv + Graviditas in die Klinik aufgenommen. Behandlung: Injektionen mit Hydrargyrum 
salicylicum $0,05 \mathrm{~g}$ am 6 . VII., 9. VII. und 12. VII. Sodann Injektionen von Neo* salvarsan 4. VII. 0,3, 19. VII. 0,3, 24. VII. 0,4 und 29. VII. 0,5 g. Nach der letzten Injektion Kopfschmerzen und Erbrechen ohne Fieber. Nach 2 Tagen wieder normales Befinden. Die Salvarsanbehandlung wurde ausgesetzt und Pat. erhielt am 3. VIII. und 6. VIII. je 0,05 g Hydrargyrum salicylicum. Am 9. VIII. berichtet Pat., daß sie am vorhergehenden Tage rote Flecke an den Händen bemerkt hätte und daß während der Nacht ein Ausschlag an den Armen und am Stamm aufgetreten sei. Bei der Untersuchung fanden sich stecknadelkopfgroße, lebhaft gerötete Knötchen an den Armen, besonders an den Streckseiten, wo sie teilweise konfluierten sowie am Bauche sehr dicht, an den übrigen Teilen des Stammes und an den Oberschenkeln mehr zerstreut. Temperatur normal. Das Quecksilker wurde ausgesetzt und der ganze Körper mit Boecks Liniment behandelt. Der Ausschlag blieb lange ziemlich unverändert, bis am 18. VIII. ein Ödem ringsum die Augen und in der Vulva auftrat. Die Temperatur begann zu steigen und hielt sich nach dem 22. VIII. ungefähr um $39^{\circ} \mathrm{C}$. Am 21. VIII. kleine Mengen Albumin im Urin. Beginnende großlamellöse Schuppung um die Angen herum. Von anderen Organen keine Symptome. Wurde am 24. VIII. avf die Gebäranstalt transferiert.

Am 5. IX. wieder in die syphilidologische Klinik aufgenommen, zeigte sie eine universelle Schuppung, stark und großlamellös im Gesicht und besonders an den Händen und Füßen, geringer, feiner und teilweise kleieartig an den übrigen Körperregionen. Temperatur normal. Die Schuppung ging allmählich zurück und die Haut war am 5. X. ganz normal. Hat dann zwischen dem 5. X. und 4. XI. 10 Injektionen Hydrargyrum salicylicum à $0,04-0,05 \mathrm{~g}$ bekommen, ohne da $B$ irgendwelche Beschwerden auftraten.

Fall 32. Kellnerin, geboren 1891. Am 22. I. 1918 wegen Syphilis recens in die Klinik aufgenommen. Behandelt mit 5 Injektionen Neosalvarsan, 24. I. bis 12. II., mit einer Totaldosis von 2,1 g Salvarsan. Erhielt dann am 14. II., 17. II. und 20. II. Injektionen von je 0,05 g Hydrargyrum salicylicum. Am folgenden Tage verließ sie die Klinik um ambulatorisch behandelt zu werden, und bekam ihre 4. Injektion am 23. II. Als sie sich am 26. II. zur 5. Injektion einstellte, zeigte sie einen rotfleckigen Ausschlag am Halse und Stamme, welcher am Abend des 23. II. unter hohem Fieber zum Ausbruch gekommen war. Die Behandlung wurde ausgesetzt und Boecks Liniment verordnet. Am 1. III. war an der Haut nichts mehr vom Exanthem zu sehen. Kopfschmerzen und verminderter Appetit aber noch anhaltend. Am 4. III. trat wieder ein ähnlicher Ausschlag am Hals und Stamm auf. Pat. bekam wieder Fieber, fühlte sich krank und der Ausschlag nahm zu. Sie wurde am 7. III. wegen dieser Hauterkrankung wieder in die Klinik aufgenommen und zeigte da folgendes Bild: Das Gesicht zum größten Teil ödematös geschwollen, besonders die Lippen, welche außerdem einen mehr oder weniger starken Belag von gelben Schuppen und Krusten haben. Der Ausschlag erstreckt sich über den Hals, die Brust, den Bauch und den Rücken, teils in Form von lebhaft roten, follikulären Papeln, teils konfluierend, mitunter schuppend oder mit kleinen Bläschen besät. Temperatur 38,5. Die Veränderungen gingen auf die Schleimhaut der Mundhöhle und der Vulva über, welche beide gerötet und mit Erosionen und Bläschen besetzt waren. Behandlung Resorcinumschläge, Boecks Liniment und Suprarenininjektionen.

Am 8. III. hatte das Ödem im Gesicht zugenommen und der Ausschlag hatte sich über Oberschenkel und Hände verbreitet. An den Innenseiten der Hände waren die Flecken ganz konfluierend. Husten, Atemnot und UUbelkeit. Über den Lungen nichts objektiv Nachweisbares. Blutdruck: Systol. 105, Diastol. 55. Am 9. III. war der Ausschlag ganz universell und am Stamme konfluierend.: Die 
Haut hatte eine starke braune Farbe angenommen, an mehreren Stellen, besonders an allen Beugeflächen und am Nabel war sie nässend und hatte ein ganz ekzematöses Aussehen. In der Mundhöhle war der Zustand unverändert. Am 11. III. hatte sich eine bedentende Schuppung ausgebildet, besonders im Gesicht. Auch Atembeschwerden und Husten waren noch vorhanden, wenn auch etwas vermindert; nichts Objektives seitens der Lungen. Puls 104, etwas weich. Temperatur hat seit der Aufnahme in das Krankenhaus zwischen 38,9-37,5 geschwankt. Am 14. III. konnte man eine beginnende Besserung konstatieren. Das Ödem des Gesichts etwas vermindert, die Haut hier und da blaß, die Schuppung hat zugenommen. Der Blutdruck wie vorher, steigt nach Suprarenininjektion wie folgt:

13. III. 1,30 Uhr $100-40$.

14. III. 12,30 Uhr $105-55$ (danach Suprarenin).

14. III. 2,30 Uhr $115-65$.

Gleichzeitig mit der beginnenden Besserung der Hautveränderungen traten aber andere Symptome auf. Am 17. III. klagte Pat. über Magenschmerzen und hatte Durchfall. Außerdem waren weiche Nebengeräusche über der rechten Lunge zu hören. Am 18. III. Schmerzen im rechten Ohre und eitriger Ausfluß aus demselben. Temperatur $39,5^{\circ} \mathrm{C}$. Unter entsprechender Behandlung war aber das rechte $\mathrm{Ohr}$ am 21. III. wieder normal und die Temperatur afebril. Dann Schmerzen im linken Ohr. Hier trat aber keine Eiterbildung auf. Am 26. III. war auch dieses Ohr ganz gesund und die Temperatur normal (morgens 36,4, abends 37,2).

Einige Tage später begann die Haut wieder rot zu werden, besonders im Gesicht und an der Brust. Am 31. III. Temperatur 38,5, reichlich weiche Krusten im Gesicht, hier und da am Körper erythematöse Hautveränderungen und ein nässendes Ekzem an den Vorderarmen. Der Hautausschlag nahm zu, die ganze Körperoberfläche war am 2. IV. lebhaft rot und an vielen Stellen nässend. Auf diesen Partien hatten sich am 10. IV. große Massen stinkender Krusten von einem eigentümlichen Geruch gebildet. Die Temperatur schwankte etwas unter oder uiber $38^{\circ} \mathrm{C}$. Durch ungefähr einen Monat hielt dieser Zustand, bald etwas hesser, bald etwas schlechter doch im ganzen unverändert an. Mitte Mai aber begann er sich zu bessern und am 21. V. war die Haut nirgends mehr nässend und ziem. lich abgeblaßt, aber doch noch etwas rot und schuppend. Am Kopf, in den Axillen und in der Pubisregion hatte sich in der letzten Zeit starker Haarausfall eingestellt. Am 31. V. waren von den Hautveränderungen nur hyperkeratotische Verdickungen in den Plantae peduum und eine gewisse Lividität an den Beinen zu finden.

Anfang Juni eine Angina phlegmonosa der linken Tonsille, welche Erkrankung in 10 Tagen abgelaufen war. Als Pat. das Krankenhaus am 18. VI. verlieB, war die Haut vollständig normal.

Am 30. VIII. wurde neuerlich ein Versuch mit Quecksilberbehandlung gemacht. Pat. fühlte sich um diese Zeit ganz gesund und hatte seit dem Verlassen des Krankenhauses keine Hautveränderungen bemerkt. Sie erhielt an diesem Tage 0,03 Hydrargyrum salicylicum. Am folgenden Tage erythematöse Flecken im Gesicht, Ödem unter den Augen, Jucken über den ganzen Körper und eine allgemeine Unruhe, welch letztere vielleicht rein psychisch war, da Pat. große Angst vor einer Wiederkehr der schweren Hautaffektion hatte. Die erwähnten Hautveränderungen waren am 4. IX. vorüber. Pat. erklärte, sie wolle niemals wieder einen Versuch mit Quecksilberbehandlung machen. Es wurde eine Neosalvarsanbehandlung eingeleitet und Pat. erhielt vom 20. IX. bis 26. X. 7 Injektionen mit einer Gesamtdosis von $3,6 \mathrm{~g}$ Neosalvarsan ohne irgendwelche Hautsymptome zu zeigen, weder im unmittelbaren Anschluß noch in einer Folgezeit von $3^{1} / 2$ Monaten, aus welchem Verhalten deutlich hervorgeht, da $\beta$ die oben beschriebenen Hautveränderungen vom Quecksilber und nicht vom Salvarsan herrührten. 
Fall 33. Eisenarbeiter, geboren 1883. Syphilis 1916. Therapie: zuerst Neosalvarsan, sodann chronisch-intermittierende Quecksilberbehandlung. Hat die letztə Quecksilberkur (6 Injektionen von Oleum cinereum) vom 30. IX. bis 25. X. 1919 durchgemacht. Mitte Oktober waren kleine rote Flecken an den Vorderarmen aufgetreten. Da der behandelnde Arzt anfangs nicht die richtige Diagnosis stellte, setzte er die Behandlung fort, hörte aber am 25. X. mit derselben auf, das sich der Ausschlag später auch an den Oberschenkeln zeigte. Pat. wurde dann von verschiedenen Ärzten behandelt, und war auch durch 10 Tage in Spitalbehandlung. Da der Ausschlag sich nicht besserte, lieB er sich am 20. XII. in die Klinik aufnehmen. Die Hautveränderungen waren da über Brust, Bauch, Arme, Oberschenkel,Hüftregionen undWaden ausgebreitet. Die Flecke teilweise zu größeren und kleineren diffusen, ödematösen Hautpartien zusammengeschmolzen, einige schuppend oder mit Krusten belegt, andere nässend und ekzematös entzündet. Temperatur 38,2. Appetit sehr schlecht, sonst keine Symptome seitens der inneren Organe.

Durch mehr als 2 Monate zeigten die Hautveränderungen ungefähr das gleiche Aussehen bald etwas besser, bald etwas schlechter, mit Auftreten von Bläschen oder sogar größeren Blasen an der infiltrierten Haut. Erst am 8. III. konnte Pat. als geheilt das Krankenhaus verlassen.

Fall 34. Knabe, geboren 3. VII. 1905 (der Vater Arbeiter). In der Klinik vom 4. III. bis 12 . VII. 1911 behandelt, wegen einer universellen Dermatitis unbekannter Ursache. Seitdem keine Ausschläge. Anfangs Januar 1919 erhielt Pat. wegen eines Ausschlags am Capillitium und in der linken Axillarhöhle eine 10 proz. weiße Präcipitatsalbe. Nachdem er dieselbe etwas über einen Monat verwendet hatte, trat ein roter, juckender und teilweise nässender Ausschlag an den beiden erwähñten Stellen auf.

Zeigte bei der Aufnahme in die Klinik am 24. II. 1919 ekzemähnliche, nässende Hautveränderungen am Capillitium, in der linken Axillarhöhle und in deren Umgebung. Sehr schnell breiteten sich die Hautveränderungen weiter aus, teils kontinuierlich, teils nach anderen Stellen überspringend, bis der Ausschlag ganz universell war und über große Hautflächen das Bild eines nässenden, teilweise krustösen Ekzems zeigte. Temperatur wechselnd, 38-40,5 $5^{\circ} \mathrm{C}$. Keinerlei Symptome von inneren Organen. Am 10. III. Besserung und Temperaturfall bis $37^{\circ} \mathrm{C}$. Während der Abheilungszeit teilweise großlamellöse Schuppung. Kurze Zeit darnach zeigte sich eine neue Eruption von Hautefflorescenzen und die Temperatur stieg bis $39,5^{\circ} \mathrm{C}$. Nach einem sehr wechselnden Verlauf konnte Pat. am 17. V. das Krankenhaus geheilt verlassen.

Fail 35. Dienerin, geboren 1893. Am 4. VI. 1919 wegen Syphilisrezidiv in die Klinik aufgenommen. Behandlung: 4. VI. bis 21 . VI. 5 Injektionen von Neosalvarsan. Dann Injektionen mit Hydrargyrum salicylicum 21. VI. 0,05 g und 24. VI. 0,06 g. Wurde am 25. VI. entlassen, um ambulatorisch behandelt zu werden, kehrte aber am folgenden Tage zurück mit einer Eruption von zerstreuten, roten, follikulären, juckenden Papeln am linken Vorderarm, die am 25. VI. nachmittags begonnen hatte. Pat. erhielt eine Adrenalininjektion und Ichthyolpaste. Am 28. VI. war das Erythem über Arme, Hals, Brust und Rücken ausgebreitet. Temperatur 39,4. Pat. erhielt wieder Adrenalin, wurde aufgefordert sich sofort in die Klinik aufnehmen zu lassen, stellte sich aber erst am 1. VII. ein. Sie hatte da über den 'ganzen Körper dichte, vielfach konfluierende, erythematöse etwas schuppende Flecken. Um die Augen herum war die Haut deutlich ödematös. Temperatur 39,4. Sonst nichts Abnormes. Am 5. VII. sank die Temperatur bis $37^{\circ} \mathrm{C}$, war vom 8 . VII. bis 12 . VII. etwas höher, bis 38,1 , blieb aber von da ab afebril. Der Ausschlag ging sehr langsam unter Schuppung zurück. Am 26. VII. war nur an Armen, Händen und Füßen eine großlamellöse Schuppung zu sehen. 
Auch diese Reste verloren sich sehr langsam, so daß sich am 14. VIIT. noch dünne Schuppung an den Plantae peduum und Palmae manuum vorfanden. Später hat Pat. Salvarsanbehandlung gut vertragen.

Fall 36. Dienerin, geboren 1892. Am 3. XII. 1919 wegen Syphilis recens in die Klinik aufgenommen. Infiziert September 1919; hatte am 29. XI. einen Abort im 6. Monat durchgemacht und wurde von der Gebäranstalt direkt nach der dermatologischen Klinik transferiert. Behandlung: Silbersalvarsan, 10 Injektionen mit einer Gesamtdosis von $2,75 \mathrm{~g}$ vom 4. XII. 1919 bis 9. I. 1920, sodann Hydrargyrum salicylicum folgendermaßen: 20. I. 0,05, 23. I. 0,06, 26. I. 0,08, 1. II. $0,06 \mathrm{~g}$. Einige Stunden nach der letzten Injektion Übelkeit, Schüttelfrost und Fieber bis $39,4^{\circ} \mathrm{C}$. Am 2. II. die gleichen Symptome, das Fieber stieg bis 40,0 und an den Vorderund Rückseiten der Beine, an den Glutäen und den Rückseiten der Arme zeigte sich ein rotes, feinpunktiertes, follikuläres Erythem. Außerderr am Stamme rote Flecke. Unter Behandlung mit Adrenalin und Boecks Liniment ging das Erythem ziemlich schnell zurück und war am 10. II. nicht mehr zu sehen. Die Temperatur war am 6. II. afebril, begann aber trotz des Zurücktretens des Erythems bald zuzunehmen und hielt sich ungefähr bei $38^{\circ} \mathrm{C}$, um am 11. II. bis zu 39,5 und am 12 . II. auf $40^{\circ}$ zu steigen. Um diese Zeit traten auch rote Flecken am Bauch auf, und am letzterwähnten Tage bot sich folgendes Bild. Über große Teile des Körpers, hauptsächlich im Gesicht, an Rücken und Bauch, an den Armen, besonders an deren Streckseiten, ein follikuläres, teilweise konfluierendes, teilweise knötchenartiges Erythem, hier und da von leicht urticariellem Charakter. Am folgenden Tage war der Ausschlag fast universell und entweder vollständig oder teilweise konfluierend, im letzteren Falle wie marmoriert. Die Schleimhaut der Mundhöhle gerötet, mit kleinen Blasen und Erosionen. Die Temperatur ging nach dem I2. II. zurück und hielt sich nach dem 16. II. etwas unter $38^{\circ} \mathrm{C}$.

Der Zustand blieb dann durch 12 Tage ziemlich unverändert, nur der Ausschlag wurde vollständig universell und mehr konfluierend, und ab und zu trat Durchfall auf. Am 28. IT. war die Temperatur 38, an den Händen waren große Blasen aufgetreten und die Haut wurde an mehreren Stellen, besonders in den Beugeflächen ekzemähnlich nässend. An den folgenden Tagen nahmen die Blasen an den Händen zu, konfluierten zu größeren bullösen Abhebungen mit stinkendem Inhalt, und an dem kleinen Finger trat ein grauschwarzer, brandähnlicher Fleck auf. Hier und da zeigten sich Blutungen in die Haut, sehr reichlich im Gesicht und in der Schamgegend. Die ganze Haut nahm eine schmutzig graubraune Farbe an, war in großer Ausbreitung, besonders im Gesicht, ödematös und mit Bläschen besetzt. Am 3. III. starb Pat. unter zunehmender Herzschwäche.

Die Sektion wurde von Privatdozent Hilding Bergstrand ausgeführt. Dem ausführlichen Protokoll entnehme ich folgendes:

Die Tonsillen waren angeschwollen, dunkelrot mißfarbig, mit Belägen, und diese Veränderung setzte sich nach unten bis zu den Stimmbändern fort, welche angeschwollen und gleichfalls mißgefärbt waren und einen kleinen pseudomembranösen Belag aufwiesen. Zahnfleisch ohne nekrotische Veränderungen. Die Milz beträchtlich vergröBert, weich graurot. Nieren, Leber und Herzfleisch zeigen parenchymatöse Degenerationen, vereinzelte Blutungen unter der Serosa des Darmes und reichliche subpleural. Das Knochenmark der Diaphyse des rechten Oberschenkels teilweise rot. Unbedeutende alte Veränderungen der Valvulae aortae. Diagnose: Dermatitis universalis + Pharyngitis et Stomatitis pseudomembranacea + Splenitis septica + Degeneratio organorum + Endocarditis chronica fibrosa valvularum aortae.

Fall 3\%. Kassiererin, geboren 1900. Am 15. I. 1920 wegen Syphilisrezidiv in die Klinik aufgenommen. Behandelt mit 4 Injektionen Hydrargyrum salicylicum 
und zwar am 16. I. 0,05, 19. I. 0,06, 22. I. 0,08 und 25. I. 0,10 g. Da Pat. aber über Appetitmangel und Übelkeit klagte, wurde das Quecksilber ausgesetzt und Sulfoxylatsalvarsan verordnet. Nach 6 solchen Injektionen erhielt Pat. wieder Hydrargyrum salicylicum, aber jetzt nicht mehr als $0,05 \mathrm{~g}$ pro dosi, was sie bis zu der neunten Injektion am 25. III. gut vertrug. Am folgenden Tage, 26. III., zeigte Pat. an den Dorsalseiten der beiden Hände und der Finger, ferner an den Ellbogen rotgelbe, juckende, stecknadelkopfgroße Papeln. Die Interdigitalräume aber frei und keine Milbengänge zu finden. Der Ausschlag breitete sich aus und am 29. III. fanden sich ähnliche PapeIn, dicht gestellt auch am Stamme und im Gesicht, die Ohren inbegriffen, jedoch spärlicher als an den Armen. Am folgenden Tage waren die Papeln am Stamm und Becken zu einem Erythem zusammengeflossen. Leichtes Ödem unter den Augen. Seit dem 30. III. wurde Pat. mit 10 proz. Ichthyolpaste, Ichthyolpinselungen, Pyroleum litanthracis und an verschiedenen Stellen mit Umschlägen von essigsaurer Tonerde behandelt. Die Hautveränderungen gingen im Anfang zurück, nahmen aber dann, besonders im Gesicht, etwas zu. Die Blutuntersuchung am 5. IV. zeigte $75 \%$ Hämoglobin und 300000 Leukocyten, davon $50 \%$ Neutrophile, 17\% Eosinophile, 23\% kleine Lymphocyten, 6\% Basophile und $4 \%$ Übergangszellen. Keine pathologischen Blutkörperchenformen.

Der weitere Verlauf ziemlich wechselnd bis 24. IV. Die Haut zeigte während dieser Zeit an mehreren Stellen ein ekzemähnliches nässendes Aussehen. UnregelmäBige Temperatursteigerungen bis $39^{\circ} \mathrm{C}$. Behandlung mit Digitalis und Diuretin. Ende Mai war die Haut ziemlich normal, nur etwas schuppend. Am 11.VI. wurde eine Neosalvarsaninjektion von $0,45 \mathrm{~g}$ versucht. Da aber Pat. nach derselben Jucken in der Haut fühlte, wurde die Salvarsanbehandlung nicht weiter fortgesetzt.

Am 16. VII., nachdem die Haut $1^{1 / 2}$ Monate ganz normal gewesen war, erhielt Pat. eine Injektion von Hydrargyrum salicylicum $0,05 \mathrm{~g}$. Am folgenden Tage Jucken, besonders im Gesicht und an den Beinen. Es bildete sich nun ein ähnliches Exan. them aus wie früher, das jedoch nur im Gesicht und in den Axillen zu einem diffusen Erythem zusammenfloß. An diesen Stellen war die Haut auch etwas nässend. Unter Behandlung mit Resorcinumschlägen, Boecks Liniment und Ichthyol ging aber der Ausschlag ziemlich schnell zurück. Am 27. VII. war die ganze Haut fast normal und am 30. VII. verließ Pat. vollständig geheilt das Krankenhaus.

Fall 38. Frau, geboren 1894. Bekam vom 3. II. bis 24. II. wegen Syphilisrezidivs 5 Neosalvarsaninjektionen von insgesamt $2,8 \mathrm{~g}$, sodann 5 Injektionen von Hydrargyrum salicylicum, insgesamt 0,25 g. Am 27. II. eine universelle Urticaria mit lokalem Ödem der Hände und Füße. Nach mehr als einer Woche, während welcher Zeit eine erythematöse Hautrötung hinzukam und Fieber bis über $39^{\circ} \mathrm{C}$ bestand, begann eine reichliche Schuppung. Pat. wurde am 17. III. 1920 in die Klinik aufgenommen. Die ganze Haut war nun etwas gerötet und schuppend, eigentümlicherweise mit Ausnahme der Plantae peduum und Palmae manuum. Am ausgebreitetsten war die Schuppung am Stamme. Die Rötung größtenteils konfluierend, an den Extremitäten teilweise follikulär. Im Gesicht Ödem unter den Augen, die übrige Haut an mehreren Stellen, besonders aber an den Ohren nässend und teilweise infiltriert. Am Capillitium die Haut nässend mit gelben Krusten. Gerötete Konjunktiven. Unbedeutende Gingivitis. Temperatur afebril. Puls 116, regelmäßig, gut. Behandlung: Infusum digitalis, Umschläge mit essigsaurer Tonerde, Ichthyolpasta und Pyroleum litanthracis. Am 20. III. waren die Krusten verschwunden und der Ausschlag abgeblaßt. Am 26. III. Symptome einer Otitis externa. Temperatur $39,1^{\circ} \mathrm{C}$. Am 29. III. waren die Ohrensymptome verschwunden, Temperatur normal und von der Hautrötung über dem ganzen Körper nichts mehr zu sehen. Blutuntersuchung: Hämoglobin 90\%, Leukocyten 
300 000, davon 45\% Neutrophile, 35\% Eosinophile, 14\% kleine Lymphocyten, $4 \%$ große Lymphocyten, $1 \%$ Übergangsformen und 1\% basophile Zellen.

Am 1. IV. zeigte sich wieder Hautrötung unter den Mammae, an denAxillarfalten und in der Schamgegend, an welchen. Stellen die Haut sehr schnell ekzemähnlich, etwas braungefärbt und teilweise nässend wurde. Am 3. IV. traten dieselben Veränderungen auch im Gesicht auf. Rötung und „Blasen“ in der Mundhöhle. Unter der oben angegebenen Behandlungsweise ließen die Hautveränderungen aber wieder nach. Am 20. IV. war die Haut bedeutend besser und am 7. V. war von allen Hautveränderungen nur eine Licheninfizierung der Axillarfalten $\mathrm{zu}$ sehen.

Wenn wir nun diese Fälle überblicken, so finden wir in bezug auf:

\section{I. die Applikationsweise des Quecksilbers,}

daß in diesen Fällen die Hautveränderungen im Gefolge von 4 verschiedenen Arten der Quecksilbermedikation aufgetreten sind, und zwar durch:

1. äußere Anwendung grauer Quecksilbersalbe in den Fällen 1, 12, 16.

2. äußere Anwendung weißer Präcipitatsalbe in dem Falle 34.

3. intramuskuläre Injektionen von Hydrargyrum salicylicum in den Fällen \%. $3,4,5,6,7,8,9,10,11,13,14,15,17,18,19,21,22,23,24,25,26,27$, $28,30,31,32,35,36,37,38$.

4. intramuskuläre Injektionen von Oleum cinereum in den Fällen 20, $\mathbf{2 9 ,} 33$.

\section{II. die schädigende Quecksilbermenge:}

Beträchtliche Verschiedenheiten in der Größe der Dosen, die eine Schädigung bewirkten und der Zeit, in der sie sie bewirkten, indem die Dermatosis bei den beschriebenen Fällen aufgetreten ist:

a) nach einem Intervall (vom Beginn der Quecksilberbehandlung gerechnet) von 1 Tag in den Fällen $1,3,4,10,25$,

\begin{tabular}{|c|c|c|c|c|}
\hline 2 & agen & ", & " & 26,27 , \\
\hline 3 & ,, &, & ," & $2,6,13$ \\
\hline 4 & , &,$"$, & ," & $8, \mathbf{3 5}$, \\
\hline 5 & , & , dem & Falle & $\mathbf{3 1}$ \\
\hline 6 &, & , den & Fällen & $15,16(?), 19$, \\
\hline 8 & , &, & , & $11,12,18$ \\
\hline 9 & , &,$\quad$, &, & $5,17,21,28, \mathbf{3 2}$ \\
\hline 11 & 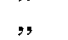 &, & , & $20,22,36$, \\
\hline 12 & , & $"$ dem & Falle & 24 \\
\hline 15 & $"$ & , den & Fällen & 9, 33 (ungefähr), \\
\hline 17 & ", & , dem & Falle & 30, \\
\hline 18 & $\eta$ & $"$, & ", & 7 , \\
\hline 19 & ", & $"$, & ", & 14 , \\
\hline 24 & ", & , den & Fällen & 23,38 \\
\hline 98 & , & , dem & Falle & 38, \\
\hline & $"$ & $"$ & , & 34 \\
\hline & , & , & , & \\
\hline
\end{tabular}

b) nach Anwendung folgender Quecksilberdosen:

Einschmieren in der Pubisgegend mit Unguentum cinereum in den Fällen 1, 16. 
Einige (unbekannt wie viele) solche Einschmierungen im Falle 12.

Anwendung von weißer Präcipitatsalbe im Falle 34.

1 Injektion von Hydrargyrum salicylicum à $0,008 \mathrm{~g}$ (Kind von $5000 \mathrm{~g}$ ) im Falle 13.

1 Injektion ", 1

$10,26$.

2 Injektionen,

$2 \quad, \quad$,

Fällen 2, 6, 8, 30.

2 Injektionen,

$3 \quad, \quad$,

$3 ", "$

len 112228.

3 Injektionen ,

Fällen 15, 19, 21.

4

$4-\quad, \quad$,

$4 \quad " \quad$,

$4 \quad, \quad$,

$4 \quad, \quad$,

len 5 und 17 .

5 Injektionen, $6000 \mathrm{~g})$ im Falle 14.

5 Injektionen von

5

6

Fällen $7, \mathbf{3 0 .}$.

9

"

(")

3 ,

4,

7

$\begin{array}{ll}, & \quad, \\ & \end{array}$

$"$

,

"

",

, ,

, ,

", "

,"

,",

2

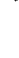

$\because$

,

" à $0,03 \mathrm{~g}$ im Falle 25 .

à $0,05 \mathrm{~g}$ in den Fällen 3,4 ,

von insges. 0,04 $\mathrm{g}$ im Falle 27.

von insges. $0,10 \mathrm{~g}$ in den

von insges. $0,11 \mathrm{~g}$ im Falle 35 . von insges. $0,11 \mathrm{~g} \mathrm{im} \mathrm{Falle} 18$. von insges. $0,15 \mathrm{~g}$ in den Fäl-

von insgesamt $0,19 \mathrm{~g}$ in den

von insges. $0,20 \mathrm{~g}$ im Falle 32. von insges. $0,22 \mathrm{~g}$ im Falle 24 . von insges. $0,25 \mathrm{~g}$ im Falle 36 . von insges. $0,29 \mathrm{~g}$ in den Fäl-

von insges. $0,035 \mathrm{~g}$ (Kind von

von insges. $0,25 \mathrm{~g}$ im Falle 38. von insges. $0,40 \mathrm{~g}$ im Falle 9. von insges. $0,30 \mathrm{~g}$ in den von insges. $0,45 \mathrm{~g}$ im Falle 37. von insges. $0,70 \mathrm{~g}$ im Falle 23.

"von Oleum Hydrargyri im Falle 20.

, "Oleum mercurioli im Falle 33.

" $, \quad, \quad, \quad, \quad, 29$.

\section{Die Anfangsformen der Hautveränderungen:}

a) Gewöhnlich Beginn mit erythematösen Flecken und zwar in den Fällen 1, $3,4,5,6,9,10,11,12,14,15,16,17,18,20,20,22,23,24,25,27,28,29$, 30, 31, 32, 33, 34, 36; seltener mit roten follikulären Papeln wie in den Fällen 7, 8, 13 (zuerst die Diagnose Rubeola? gestellt), 15, 19, 21, 26, 35, 3\%; und ausnahmsweise mit urticariellen Quaddeln wie im Falle 30 oder mit einer Kombination von erythematösen Flecken und urticariellen Quaddeln wie in den Fällen 2, 11. Wenn man von dem Ausnahmsfalle 2 absieht, wo in den Anfangsefflorescenzen Blutungen vorhanden waren, finden sich zu Beginn der Hautveränderungen niemals andere Erscheinungen als Rötung, Urticariabildung und Ödem, was ich besonders hervorheben will;

b) Lokalisation der Ausgangsstellen: Beginn an vielen verschiedenen Körperregionen und zwar in den besprochenen Fällen folgenderweise:

1. an den peripheren Teilen der Extremitäten in den Fällen 5, 6, 11, 15, 17, $18,19,21,23,24,25,26,27,29,30,31,33,35,36,37$;

2. an den nicht peripheren Teilen der Extremitäten in den Fällen 2, 3, 4, 9, $10,15,17,18,24,25,27,29,30,36$.

3. im Gesicht in den Fällen $13,14,20,22$.

4. am Halse in den Fällen 20, $\mathbf{3 2}$. 
5. an der Brust in den Fällen 7, 8, 13, 17, 18, 20, 28, 30, 32 .

6. am Bauch in den Fällen $3,4,13,18,32$.

7. am Rüicken in den Fällen 7, 8, 13, 32;

8. an den Hüft- und Glutealregionen in den Fällen 2, 9, 18, 24, 25, 36 ;

9. in der Genitalgegend in den Fällen 3, 4;

10. an der Applikationsstelle in den Fällen 1, 12, 16, 34;

11. am ganzen Körper im Falle 38 .

\section{Die Entwicklung der Hautveränderungen.}

a) Räumliche Ausbreitung in den fraglichen Fällen, wie folgt:

1. Keine oder nur unbedeutende Ausbreitung von den Anfangsstellen in den Fällen 2, 3, 4, 7, 8, 11, 13, 21, 23, 24, 25.

2. Eine weitgehende Ausbreitung über verschiedene Teile des Körpers, nicht aber bis zur Universalität in den Fällen 1, 5, 6, 10, 12, 14, 19, 20, 22, 26, 27, 28, 33, 3\%.

3. Ausbreitung über den ganzen Körper in den Fällen 9, 15, 16, 17, 18, 29, 30, 31, 32, 34, 35, 36, 38 (vom Anfang an universell).

b) Auftreten folgender verschiedener Hauterkrankungsformen im Laufe der Entwicklung des Leidens:

1. Lokales Ödem in den Fällen $1,12,16,22,26,27, \mathbf{2 9}, \mathbf{3 0}, \mathbf{3 1}, \mathbf{3 2}, \mathbf{3 6}, \mathbf{3 7}, 38$.

2. Urticaria in den Fällen $10,12,14,17,25,29,30,35,36,38$.

3. Blutungen in den Fällen 30, 36.

4. Braunfärbung der Haut in den Fällen 30, 32, 36, 38.

5. Bildung kleiner Blässchen in den Fällen 15, 30, 32, 33, 36.

6. Blasenbildung in den Fällen 33, 36.

7. Pustelbildung in den Fällen 29, 36.

8. Hautinfiltration in den Fällen $30,32,33,34,36,37,38$.

9. Eikzematöse Hautentzündung in den Fällen 16, 29, 30, 32, 33, 34, 36, 37, 38.

10. Krustenbildung in den Fällen 2, 29, 30, 32, 33, 34, 38.

11. Schuppung in den Fällen $1,16,20,22,27,28, \mathbf{2 9}, 30,31,32,33,34,35$, $3 \%, 38$.

12 Hautgangrän im Fälle 36.

\section{Die Dauer der Hautveränderungen.}

Ein ungemein wechselndes Verhalten; in den genannten Fällen wie folgt:

1 Tag im Falle 24,

2 Tage in den Fällen 4, 25,

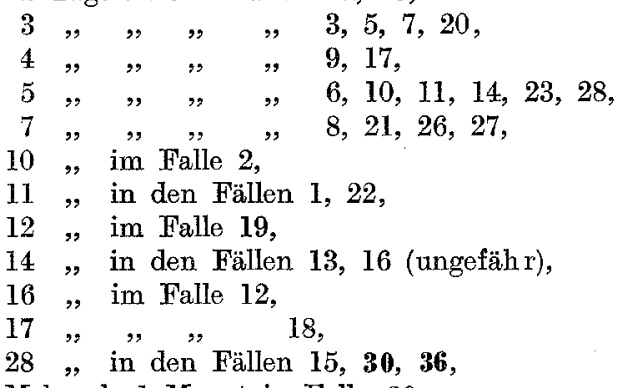

Mehr als 1 Monat in Falle 29,

$1 \frac{1}{2}$ Monate im Falle a1,

49 Tage im Falle 35, 
2 Monate in den Fällen $\mathbf{3 r}, \mathbf{3 8}$,

3 Monate im Falle 34,

4 Monate und 23 Tage im Falle $\mathbf{3 3}$.

VI. Das gleichzeitige Vorkommen anderer mercurieller Veränderungen im Körper; folgende Komplikationen:

1. Fieber in den Fällen 9, 10, 11, 13, 14, 16, 17, 18, 19, 21, 26, 28, 29, 30, $31,32,33,34,35,36,3 \%, 38$,

2. Enanthem in den Fällen $18,28, \mathbf{3 0}, 32,36,38$,

3. Gastritische Symptome in den Fällen 9, 18, 19, 27, 28, 30, 32, 33, 36,

4. Kolitische Symptome in den Fällen 18, 30, 36,

5. Stomatitis oder Angina mercurialis in den Fällen 9, 29, 30, 36, 38,

6. Nephritis im Falle 31 (Graviditas).

Meine Fälle weichen also von den früher in der Literatur beschriebenen Fällen nicht wesentlich ab. Die Variationen sind im großen und ganzen die schon bekannten. Als abweichend möchte ich die Fälle 32 und 37 erwähnen, welche eine Ausnahme von der Regel der Gewöhnung an das Quecksilber bilden. Sie waren nämlich nach der Behandlung ungemein empfindlich gegen Quecksilber, deutlich mehr als vor derselben. Doch will ich keineswegs - wie dies Zigler-New-York tut in solchen Fällen von einer Anaphylaxie sprechen.

Bemerkenswert finde ich ferner die großen Unterschiede in der Zeit, welche von Anfang der Quecksilberbehandlung bis zum Auftreten der Hautsymptome vergeht, ein Umstand, der jedoch schon früher konstatiert worden ist. Schon Bossard hat dies durch seine Tabellen deutlich klargestellt. In den von ihm beschriebenen Fällen sind nicht weniger als $14 \mathrm{am} 1$. Tage der Behandlung aufgetreten, und unter diesen sind in 3 Fällen 12 Stunden, in einem Falle 11 Stunden, in 2 Fällen ,einige “ Stunden, einmal 4 Stunden und einmal 2 Stunden angegeben, und einmal soll der Ausschlag , sofort" nach dem Anfang der Behandlung begonnen haben. In manchen Fällen kann man sich über die Länge dieser Zeit infolge unbestimmter Angaben wie z. B.: „Nach der 150. Pille“", ,im Anschlu $B$ an die letzte Dosis" schwer ein Urteil bilden. Zweimal ist diese Zeit zu 18 Tagen angegeben, und als längste Zeit sind 5 Wochen nach der letzten Einreibung angeführt.

In meinen 38 Fällen ist diese Zeit von dem Anfang der Quecksilberbehandlung bis zum Ausbruch der Hautsymptoje, welches Intervall man mit der Inkubationszeit der Infektionskrankheiten vergleichen und demgemäß als ,toxische Inkubationszeit" bezeichnen könnte, in 5 Fällen höchstens 24 Stunden; in 5 anderen Fällen ist sie länger als 20 Tage und die längste Zeit wahrscheinlich 39 Tage.

$\mathrm{Ob}$ dieser bedeutende Unterschied nur eine Folge verschiedener Empfindlichkeit ist oder andere Ursachen hat, scheint mir unmöglich zu entscheiden. Ein Zusammenhang zwischen der Dauer dieser ,to- 
xischen Inkubationszeit" und der Schwere oder Dauer der Intoxikationserscheinungen habe ich in keiner Weise feststellen können. Ebensowenig ist es mir gelungen, ein bestimmtes Verhältnis zwischen den Quecksilberdosen und den Hautveränderungen zu finden.

Die Lokalisation dieser Dermatosen ist in der Literatur meist nur als sehr wechselnd charakterisiert. Eine Zusammenstellung der Anfangserscheinungen meiner Fälle deutet doch auf eine gewisse Prädilektion hin. Von meinen 28 Fällen haben 4 die ersten Veränderungen an den Applikationsstellen der angewandten Quecksilbersalbe gehabt. In den übrigen 34 Fällen haben die mercuriellen Hautveränderungen an verschiedenen Körperstellen angefangen, und zwar:

An den peripheren Teilen der Extremitäten 20 mal und nur an diesen Stellen 11 mal,

den zentralen Teilen der Extremitäten 14 mal und nur an diesen Stellen 1 mal, im Gesicht 4 mal und nur an diesen Stellen 2 mal, am Halse $2 \mathrm{mal}$ und nur an diesen Stellen $0 \mathrm{mal}$, an der Brust 9 mal und nur an diesen Stellen 1 mal, am Bauch $5 \mathrm{mal}$ und nur an diesen Stellen $0 \mathrm{mal}$, am Rücken 4 mal und nur an diesen. Stellen 0 mal, an den Hüft- und Glutealregionen $6 \mathrm{mal}$ und nur an diesen Stellen $0 \mathrm{mal}$, in der Genitalgegend 2 mal und nur an diesen Stellen 0 mal, über den ganzen Körper $1 \mathrm{mal}$ und nur an diesen Stellen $0 \mathrm{mal}$.

Diese Zusammenstellung widerspricht in keiner Weise der alten Erfahrung über das Wechselvolle der Ausgangsstellen der mercuriellen Dermatosen, denn in meinen 33 Fällen sind nicht weniger als 9 solche Stellen zu finden. Die Hautveränderungen haben teils nur an einer von diesen Stellen, teils gleichzeitig an 2 oder mehreren angefangen. Sehr deutlich geht aber auch aus diesen Zahlen hervor, daß die peripheren Teile der Extremitäten so bedeutend über die anderen Ausgangsstellen überwiegen, daß sie wohl als eine besondere Prädilektionsstelle des Anfanges der mercuriellen Dermatosen angesehen werden können. Ferner habe ich häufig gefunden, daß mehr oder weniger cyanotische Hautstellen an einem Körperteil eher und stärker von dem mercuriellen Exanthem angegriffen werden als Hautstellen mit normaler Blutverteilung. Hierdurch wird die Lokalisation der mercuriellen Exantheme derjenigen der syphilitischen Exantheme nahezu entgegengesetzt. Die letzterwähnten Exantheme vermeiden nämlich hauptsächlich cyanotische und kalte Hautstellen, was Verfasser früher beschrieben hat [s. Literaturv. ${ }^{17}$ )].

Von Interesse scheint mir ferner das Vorkommen von derartigen Hautaffektionen gleichzeitig mit anderen Quecksilberveränderungen. Die Ansichten Fourniers und Rosenthals habe ich bereits berührt, und meine Fälle bestätigen deutlich die oben ausgesprochene Ansicht von der Übertriebenheit ihrer diesbezüglichen Äußerung, denn wenn man vom Fieber absieht, so zeigten von diesen 34 Fällen nicht weniger als 
11 (also ungefähr $1 / 3$ ) auch andere Quecksilberveränderungen. Betrachtet man aber die Zusammenstellung meiner Fälle etwas näher (S. 375), so findet man, daß in diesen 11 Fällen nicht weniger als 9 mal gastritische Symptome aufgetreten sind; danach kommen die Enantheme, d. h. die Veränderungen im Munde und Rachen mit 6 Fällen. Tomasczweski (S. 443) und andere rechnen aber gastro-intestinale merkurielle Veränderungen, wie entsprechende bronchielle, ebenfalls zu den Enanthemen, und wir werden unten sehen, wie gute Gründe für eine solche Ansicht vorliegen. Wir kommen deshalb zu dem Schluß, daß diejenigen Quecksilberveränderungen, welche am häufigsten neben dem Exanthem auftreten, eigentlich eine Fortsetzung der Hautveränderungen repräsentieren oder mit anderen Worten: in ähnlicher Weise wie die mercuriellen Hautveränderungen sich auf der Körperoberfläche ausbreiten, teils kontinuierlich, teils springend, setzen sie sich ziemlich häufig auch auf die Schleimhäute fort. Diese Veränderungen im Mund, Rachen, Kehlkopf, Ventrikel, Jejunum und auf anderen Schleimhäuten betrachte ich deshalb nicht als andersartige Mercurialveränderungen, sondern nur als Ausbreitung der Hautveränderungen.

Quecksilberveränderungen anderer Art oder in anderen Organen sind deutlich seltener als diese Enantheme. Sie treten jedoch unter meinen 38 Fällen in 7 Fällen auf (also ungefähr in $1 / 5$ ), davon ulceröse Stomatitis oder Angina 5 mal, Colitis 3 mal und Nephritis einmal. Das gleichzeitige Vorkommen anderer Quecksilberveränderungen (Enanthema ausgenommen) möchte ich deshalb ziemlich ungewöhnlich, nicht aber eine seltene Ausnahme nennen.

Das histologische Studium der mercuriellen Dermatosen ist bedeutend jüngeren Datums als das klinische.

Die ersten histologischen Untersuchungen, die ich gefunden habe, stammen aus dem Jahre 1895, in dem Beck ${ }^{29}$ ) bei Beschreibung von 3 Fällen mercurieller Hautinfektionen auch histologische Untersuchungen erwähnt. In einem seiner Fälle konnte er „nichts Auffallendes" finden, und in einem anderen, komplizierten, bei dem die Untersuchung 5 Tage vor dem Tode des Pat. ausgeführt wurde, waren ziemlich viele kernhaltige rote Blutkörperchen neben reichlichen Leukocyten in der Cutis zu sehen.

Zwei Jahre später beschreibt Fisichella ${ }^{81}$ ) in Reforma medica (14 VIII. 1897, S. 46I) einen Fall, der unter merkuriellen Hautveränderungen letal verlief. Fr fand Verdickungen und Desquamation der Hornschicht, Verminderung des Stratum granulosum und der Eleidinkörnchen, sowie Ansammlung von Rundzellen in der Cutis längs der Gefäße, der Talg- und Schweißdrüsen und der Nervenen digungen.

Im Jabre 1902 berichtete Ehrmann ${ }^{69}$ ) in Mračeks Handbuch der Hautkrankheiten über die histologischen Veränderungen bei den merkuriellen Dermatosen. 
Er betont hierbei die Hyperämie der Gefäße des Papillarkörpers und des subepithelialen Gefäßnetzes bisweilen auch der tieferen Gefäße, ebenso das stets vorhandene mehr oder weniger ausgeprägte Ödem des Papillarkörpers, kenntlich durch geringe Färbbarkeit und Verwisehtsein der Bindegewebsfasern. Ferner fand er um die dilatierten Gefäße herum immer eine Ansammlung von mono- und polynukleären Leukocyten. An den vesikulösen Stellen konstatiert er eine vollständige Abhebung der gesamten Epidermis mit Ansammlung von Ödemflüssig. keit. Im Blaseninhalt wie im ödematösen Gewebe konnte er häufig Fibrinausscheidung nachweisen.

Im selben Jahre erschien ferner $E$. Hoffmann s $^{117}$ ) Mitteilung über Quecksilberdermatitis, in der er seine histologischen Untersuchungen von 4 Fällen beschreibt. Er fand in einem Falle mit hauptsächlich erythematösen Veränderungen in Übereinstimmung mit Ehrmann eine starke Dilatierung und Blutfüllung der Gefäße des Papillarkörpers und des oberen Coriumnetzes, nebst einem Infiltrat von Rundzellen um diese Gefäße herum und einem leichten Ödem im benachbarten Gewebe, wodurch eine Verschmälerung der Retezapfen zustande kam. Er erwähnt ferner Kernteilungsfiguren in den Endothelien der erweiterten Gefäße und polymorphkernige eosinophile Granulationen in die ZellhüJlen der Gefäße oder auch in das Innere der erweiterten Gefäße hinein. Die Hornschicht fand er verdickt und aufgelockert, mit einzelnen Leukocyten. In den Fällen, wo die Haut das Bild eines Ekzzems oder einer Dermatitis exfoliativa darbot, konstatierte er außer den gleichen Veränderungen in stärkerem Ausmaß, also stärkerem Ödem, stärkerer Gefäßdilation und stärkerem Zelleninfiltrat mit größerem Reichtum an eosinophilen Zellen, auch eine bedeutende Wucherung der Retezapfen mit zahlreichen Kernteilungen, eine Verminderung oder ein Verschwinden des Stratum granulosum, in der Hornschicht kernhaltige Zellen und eine albuminöse, stellenweise zu kleinen Krusten verdickte Einlagerung, eine Leukocytenansammlung in der ganzen Epidermis, besonders aber in den Krusten der Hornschicht, aus den Gefäßen ausgetretene Erythrocyten sowie eine Vergrößerung und Wucherung der fixen Zellen der Cutis. In einem Falle fand er entsprechend der Atrophie der Haut, welche auf die Entzündung gefolgt war, hauptsächlich regressive Veränderungen.

Aus der Zeit nach den Arbeiten $E$. Hoffmanns habe ich in dieser Frage nur Untersuchungen von Jutiusberg ${ }^{128}$ ) (1911) gefunden, über ein scarlatiniformes mercurielles Exanthem. Seine Ergebnisse stimmen in der Hauptsache mit denjenigen Ehrmanns und Hoffmanns überein und widersprechen denen Hoffmanns nur insoweit, als „Leukocyten mit eosinophilen Granulationen gänzlich fehlen“. Ferner spricht er von diffusen Zellenhäufungen in den obersten Schichten des Corium, was Hoffmann nicht erwähnt.

Keine von diesen histologischen Untersuchungen hat ein für dieses Leiden spezifisches Merkmal gefunden; alle haben nur ein mehr oder weniger gewöhnliches Bild ergeben. Denn das Vorkommen eosinophiler Zellen ist nichts Merkwürdiges. Diese Zellen kommen bei einer Menge von Haut- und Schleimhautveränderungen vor. Sie sind z. B. in gonorrhoischem Sekret so gut wie konstant vorhanden, wenn auch in sehr wechselnder Menge, bald nur vereinzelt, andere Male in einer Zahl bis $2 / 3$ sämtlicher Leukocyten, besonders bei Prostatitis oder anderen Formen der Drüsengonorrhöe. Eosinophile Zellen treten auch bei vielen anderen Entzündungen auf und sind überhaupt nichts weniger als spezifisch. 
Auch ich habe zu Beginn meiner histologischen Untersuchungen bei diesen Gewebsveränderungen den anscheinenden Mangel an charakteristischen Zügen konstatiert und deshalb gefürchtet, daß sie keine Anhaltspunkte für die Frforschung der mercuriellen Dermatose gewähren würden. Die ekzematösen Stellen der mercuriellen Dermatose zeigten ja Veränderungen ganz ähnlich denjenigen eines gewöhnlichen Ekzems, die erythematösen Stellen ungefähr die gleichen wie ein anderes Erythem usw.

Im Laufe meiner Untersuchungen bin ich jedoch zu einer anderen Auffassung gekommen, und zwei Methoden waren es, die mich zum Resultate führten, nämlich 1. Bakterienfärbungen, gleichzeitig mit Gewebsfärbungen und 2. ein genaues Studium der Reihenfolge der verschiedenen Gewebsveränderungen. Schließlich habe ich die mercuriellen Hautveränderungen mit mercuriellen Veränderungen anderer Organe, wie der Magen- und Darmschleimhaut, der Nieren, der Leber, der Speicheldrüsen usw. verglichen und dadurch einige Schlüsse auf die Wirkung des Quecksilbers auf das Gewebe ziehen können. Meine Studien der verschiedenen mercuriellen Organveränderungen habe ich in mehreren früheren Arbeiten beschrieben (siehe das Literaturverzeichnis ${ }^{9-16}$ ), und die vorliegenden Untersuchungen stellen also nur ein Glied in der Reihe jener Arbeiten dar, in welchen ich in den letzten 16 Jahren immer wieder auf das Thema der Quecksilbervergiftung zurückgekommen bin, um die durch dieselben bedingten Veränderungen der verschiedenen Organe $\mathrm{zu}$ studieren.

Um zu konstatieren, mit welchen Veränderungen der mercurielle Prozeß in der Haut tatsächlich beginnt, ist es nicht hinreichend, einen ziemlich frischen Erythemfleck zu untersuchen, denn auch hier können sich schon vielerlei Veränderungen ausgebildet haben und man kann nicht ablesen, welche von diesen der ursprünglichen sind. Da sich die Erythemflecken peripher vergrößern, muß gerade die Peripherie eines Fleckes die jüngsten Veränderungen zeigen, und wenn man außerhalb der Peripherie, in makroskopisch normaler Haut Veränderungen findet, so müssen diese noch jünger sein. Die am meisten peripher liegenden Veränderungen müssen die Anfangsveränderungen darstellen. Ich habe deshalb nicht nur Efflorescenzen, sondern auch die makroskopisch normale Umgebung und oft zwei Efflorescenzen mit zwischenliegender normaler Haut excidiert und histologisch untersucht. So habe ich feststellen können, daß die Anfangsveränderung der mercuriellen Dermatose in einer Dilatation der kleinen Blutgefäße besteht. Man kann sogar hochgradige Gefäßdilatationen in sonst ganz normalem Hautgewebe finden (vgl. meine experimentellen Tieruntersuchungen und Abb. 12). In diesen Fällen findet man keine Zellvermehrung um die erweiterten Gefäße herum, nirgends Leukocyten, die Papillen und Retezapfen von gewöhn- 
licher Form, die Zellen des Rete Malpighii mit gut ausgebildeten Intercellularbrücken und normalen Saftspalten, Stratum granulosum und. Stratum corneum von normalem Aussehen, und auf der Hautoberfläche keine Bakterienentwicklung. In einigen Fällen habe ich auch in den am meisten peripher gelegenen Veränderungen neben diesen GefäBdilatationen ein wenig ödem im Gewebe gefunden. Die Gewebsspalten der Cutis waren in diesen Fällen durch die ausgetretene Transsudatflüssigkeit ein wenig ausgedehnt und die Zwischenräume der Retezellen etwas dilatiert. Diese beiden Veränderungen, GefäBdilatation und Transsudation, bilden deshalb die Anfangserscheinungen der mercuriellen Dermatose, hauptsächlich und konstant die GefäBdilatation, welche man oft allein antrifit, auBerdem aber, in einigen Fällen, eine Transsudatbildung.

In denjenigen Fällen, wo man beide Anfangserscheinungen trifft, sind sie durchaus nicht immer proportional entwickelt. So kann man starke Ödembildung zusammen mit schwacher GefäBdilatation oder das Umgekehrte sehen, wenn ich auch das Ersterwähnte sehr selten fand.

Die Ausbreitung der Gefäßerweiterungen ist verschieden. Gewöhnlich findet man die erweiterten Gefäße um die Talg- und Schweißdrüsen herum, im Gefäßnetz des Korpus papillare und in den Gefäßschlingen der Papillen. Bald sind die Gefäßdilatationen an einer von diesen drei Stellen stärker susgebildet, bald verhalten sie sich an allen Stellen ungefähr gleich. Sehr oft trifft man aber die stärkste Gefäßdilatation in den Spitzen der Cutispapillen.

Die geschilderten Anfangserscheinungen habe ich als das erste Stadium der mercuriellen Dermatosen bezeichnet.

Diesem Stadium stelle ich ein zweites gegenüber, welches, wenn auch mit sehr großen Variationen, in der Regel ungefähr folgende Veränderungen zeigt. Das Ödem hat zugenommen, aber in sehr verschiedenem Ausmaße, manchmal sehr hochgradig, ein anderes Mal mäßig und wieder andere Male in sehr spärlicher Entwicklung. Die Cutispapillen sind beträchtlich verlängert und verbreitert, bei stärkerer Ödembildung oft sogar in ihren Spitzen keulenförmig angeschwollen (siehe Abb. 4 und 5), die Bindegewebsbündel sind durch das Ödem stark auseinandergezerrt, manchmal und besonders in stark angeschwollenen Papillenspitzen so hochgradig, daB das Bindegewebe wie ein Netz aussieht (Abb. 5). Etwas tiefer in der Cutis ist das Gewebsödem meist geringer und verschwindet allmählich, je tiefer hinab man geht.

Auch die Epidermis wird vom Ödem verändert. Das Rete Malpighii ist infolge ödematöser Anschwellung mehr oder weniger breiter geworden, und das Leistensystem springt nach abwärts vor. Die Saftspalten sind gut ausgebildet, geräumig oder sogar auffallend erweitert. Die Epithelzellen scheinen vergrößert und zeigen sehr oft zentrale Vakuolen- 
bildung. Das Stratum granulosum ist meist kaum zu sehen. Die Körnelung fehlt oder ist ungemein fein und schwer zu entdecken. Die basale Hornschieht zeigt mehr oder weniger erhaltene Zellenkonturen und Zellkerne in Form von stark gefärbten Stäbchen (Abb. 4, 5 und 11). Die Ausbreitung dieser kernhaltigen Zellen ist sehr verschieden, manchmal sind die Zellkerne schwer zu entdecken, manchmal finden sie sich im ganzen Stratum corneum gut ausgebildet. Außerdem ist die Hornschicht zerteilt, und zerklüftet und in den unregelmäßigen, vielgestaltigen Hohlräumen und Gängen sieht man Ansammlungen einer gelben Flüssigkeit (ungewöhnlich reichlich in Abb. 4, s. auch Abb. 5 und 11), in welcher man oft massenhaft kleine, unregelmäßige Koagula findet. In einigen Fällen kann man kernhaltige Zellen noch in einer oberflächlicheren Schicht als diese Hohlräume finden. Die obersten Schichten bestehen aus lockeren, unregelmäßigen Schollen und Lamellen (Abb 4). Diese oben besprochenen Veränderungen der Epidermis entsprechen also eigentlich dem, was man unter dem Namen Parakeratose versteht.

Außer diesen gewöhnlich gut ausgeprägten, ödematösen Erscheinungen finden wir in diesem Stadium eine andere Art von Veränderungen, nämlich eine Zellenvermehrung sowohl in der Cutis wie in der Epidermis. Jene zeigt sich zuerst in den Endothelien der Gefäße, der Cutispapillen und des subpapillaren Gefäßnetzes (siehe Abb. 5, wo das erweiterte Gefäß mit rosenkranzförmig angeordneten Epithelien besetzt ist). Später findet man eine dünnere oder dickere perivaskulöre Zellinfiltration um die Gefäße herum (siehe die tieferen Gefäße Abb. 4). Diese perivasculäre Zellvermehrung ist manchmal im subpapillaren Gefäßnetz stärker entwickelt als in den Papillen.

Bei näherem Studium dieser perivasculären Zellanhäufung findet man hauptsächlich eine Vermehrung der Perithelien, welche oft in konzentrischen oder zwiebelförmig angeordneten, linear begrenzten Reihen liegen, mit kleineren oder manchmal ziemlich großen Hohlräumen dazwischen (siehe Abb. 6 und 8). Die Hohlräume waren ohne Zweifel intra vitam von Transsudatflüssigkeit aus den Gefäßen ausgefüllt. Außer diesen proliferierenden Perithelien findet man in den perivasculären Zellschläuchen: 1. mehr oder weniger eckige Plasmazellen von verschiedener Form, nur ausnahmsweise gut ausgebildete, mit großem stark gefärbtem Protoplasmaleib, in der Regel mehr oder weniger fragmentarisch entwickelt (siehe Abb. 6) ; 2: Mastzellen (Abb. 3) langgestreckt oder eckige mit Ausläufern oder ohne solche, ab und zu große mit massenhaften Körnchen, öfter mit sehr spärlichen und 3. eosinophile Zellen. Diese trifft man sowohl innerhalb (Abb. 7 und 8) wie außerhaib der Blutgefäße (Abb. 3, 7, 8, 9, 10 und 11). Im ersteren Fall haben sie gewöhnlichen Typus mit unregelmäßigem oder geteiltem Kern und einem runden rot granulierenden Protoplasma (s. Abb. 7); außerhalb der Ge- 
täße zeigen sie aber teils die gleichen (Abb. 7), teils andere, wechselnde Formen (Abb. 3, 8, 9 und 11). So sieht man hier und da den Kern rund oder oval, das Protoplasma spindelförmig oder langgestrckt, oder selbst mit Protoplasmaausläufern versehen, jedoch mit Körnchen, gerade so deutlich wie in den anderen normalentwickelten (Abb. 3 u. 9). Einige Male habe ich eosinophile Zellen in unmittelbarer Nachbarschaft von Mastzellen und von derselben Form wie diese gesehen (s. Abb. 3). Unwillkürlich drängt sich deshalb die Frage auf, ob nicht derartige eosinophile Zellen umgebildete Bindegewebszellen sein könnten, so daß die eosinophilen Zellen einen doppelten. Ursprung hätten, d. h. sowohl aus Leukocyten wie aus Bindegewebszellen stammten. Auf diese Frage hier näher einzugehen, würde zu weit führen. An der Möglichkeit dieses doppelten Ursprunges möchte ich doch jedenfalls festhalten und gewisse Gründe, welche hierfür sprechen können, erwäbnen. Meine Studien über die Plasmazellen vom Jahre 19017) führten mich zur Annahme eines doppelten Ursprunges der Plasmazellen, sowohl aus Leukocyten wie aus Bindegewebszellen, weshalb eine ähnliche Annahme für die eosinophilen Zellen mir sehr möglich scheint.

Ferner glaubt Herzog in Leipzig ${ }^{115}$ ) in einer vor kurzem erschienenen Arbeit den Nachweis geliefert zu haben, daß pseudo-eosinophile und eosinophile Granulocyten aus Abkömmlingen von Gefäßwandzellen entstehen und sich bei der Entzündung weiter vermehren und zu typischen Leukocytenformen heranreifen. Nach dieser Ansicht könnten also selbst die leukocytenähnlichen eosinophilen Zellen in den fixen Gewebszellen und nicht in den Blutzellen ihren Ursprung haben. Endlich behauptzt Häggqvistio9), bei seinen Studien über die Stellung der Blutlymphdrüsen direkt gesehen zu haben, wie Retikelzellen, also eine besondere Art von Bindegewebszellen, rote Blutkörperchen in sich aufnehmen, die dann zerfallen, und wie hierdurch eosinophile Zellen entstehen.

In 3 Fällen mit ungewöhnlich starker Dilatation der Blutgefäße habe ich schon in diesem ziemlich frühen Stadium rote Blutkörperchen in den Geweben gefunden. Sie liegen nicht in Haufen oder Gruppen, sondern vereinzelt und zerstreut, so daß sie wahrscheinlich nicht durch eine Berstung der Gefäßwand, sondern durch Diapedese ausgetreten sind (s. Abb. 8).

Die Zellenvermehrung im Rete Malpighii zeigt sich in Form von Mitosen, die man sowohl in den Basalzellen als in etwas höheren Zellschichten fintet. Die Volumzunahme der Retezapfen beruht also nicht nur auf der oben besprochenen Ödemdurchtränkung, sonđern außerdem auf einer Akanthose. Manchmal aber sind die Mitosen sehr spärlich, und in manchen. Fällen, besonders in frischen, kann man keine Mitosen finden, trotzdem die Retezapfen größer geworden, weshalb die Akanthose nicht die einzige Ursache der Volumvermehrung sein kann.

Von einem dritten Stadium spreche ich, sobald eine Bakterienentwicklung hinzugetreten ist. Auf dieses neue Moment lege ich ein besonders 
großes Gewicht, weil ich glaube, daß es gerade dieser Vorgang ist, der den Unterschied zwischen Exanthema mercuriale simplex und Exanthema mercuriale complicatum seu infectum ausmacht, denn die Bakterienentwicklung zieht ihre besonderen Folgen nach sich, welche nicht mehr direkte Quecksilberwirkungen sind.

Diese Bakterienentwicklung beginnt immer an der Oberfläche der Epidermis und verbreitet sich dann allmählich nach abwärts in die Zwischenräume der Hornlamellen und in die erwähnten Höhlen und Gänge der Hornschicht. Die Bakterien sind gewöhnlich in Haufen angeordnete Kokken, sehr selten Stäbchen (s. Abb. 11).

Als Folge dieser Bakterienentwicklung treten polynucleäre Leukocyten in größeren Mengen auf. Bis dahin waren nur vereinzelte solche Zellen außerhalb der Gefäße zu sehen. Jetzt kann man aber von einer Anhäufung dieser Zellen sprechen. Unter diesen Leukocyten findet man mehr oder weniger reichliche eosinophile Zellen von typischer Form (Abb. 10). Außerdem findet man in diesem Stadium, sogar in seinem allerersten Anfang, in der kernhaltigen Hornschicht eosinophile Zellen von langgestreckter Form mit langem, stäbchenförmigem oder ovalem Kern ${ }^{1}$ ) (s. Abb. 11). Ob diese Zellen gewöhnliche eosinophile Zellen sind, welche diese Form durch Eindringen in die schmalen Spalten zwischen den kernhaltigen Hornlamellen erhalten haben, oder ob sie in der Hornschicht entstanden sind, möchte ich dahingestellt sein lassen.

Die ersten Leukocytenansammlingen trifft man gewöhnlich unmittelbar unter der basalen Hornschicht, in dem durch die Abhebung der Hornschicht gebildeten Zwischenraum zwischen Hornschicht und Rete Malpighii (s. Abb. 10). Die Anzahl dieser kleinen Abszesse wechselt sehr beträchtlich. Bei fortschreitender Entwicklung des Prozesses sieht man Leukocyten vereinzelt oder in Haufen von den erwähnten Abscessen nach abwärts ins Rete Malpighii hinabdringen. Sie werden um so spärlicher, je tiefer man ins Rete hinabkommt, und in der Cutis kommen sie nicht oder nur sehr spärlich vor. Nach oben breiten sich die Leukocyten in den erwähnten Hohlräumen und Gängen der Hornschicht aus, wenn diese Schicht nicht zum größeren oder kleineren Teil abgestoßen wird.

Besonders reichliche Anhäufung von Leukocyten findet man sehr oft in den Talgdrüsen und ihren Ausführungsgängen, und. zwar kommen sie hier teils mehr diffus ausgebreitet vor, teils in dichteren Anhäufungen, in welch letzterem Falle sie kleine Pseudoabscesse bilden. Mehrmals habe ich in den Mündungen der Ausführungsgänge solche Pseudoabscesse mit ausgebuchteten Wänden gesehen. Diese Veränderungen der

1) Das Protoplasma dieser Zellen sieht bei schwacher Vergrößerung ganz homogen aus, und erst bei Vergrößerung mitImmersion kann man eine feineKörnelung warhnehmen. 
Talgdrüsen entsprechen der klinisch ziemlich oft zu beobachtenden follikulären Lokalisation, und schon im ersten Stadium kann man, wie ich erwähnt habe, sehr häufig reichliche Gefäßerweiterungen um die Talgdrüsen herum finden. Merkwürdig scheint mir aber, daß ich in diesen ziemlich abgeschlossenen Hohlräumen auffallend wenig Balzterien nachweisen konnte, regelmäßig weniger als in der Hornschicht der Epidermis. Eine Erklärung hierfür kann ich nicht geben.

Die Schweißdrüsen fand ich immer frei von Leukocyten wie von Bakterien.

Durch die zunehmende Eiterbildung und die erwähnte Abstoßung von Hornlamellen wird die Reteschicht mehr oder weniger oder sogar ganz freigelegt.

Außer durch diese Bakterienentwicklung mit ihrer Leukocytenanhäufung ist das dritte Stadium durch eine Zunahme der Veränderungen des zweiten Stadiums gekennzeichnet. So nimmt die Zellenproliferation zu. Das Zelleninfiltrat des Bindegewebes war im zweiten Stadium hauptsächlich längs der Blutgefäße lokalisiert, während die dazwischen liegenden Gewebspartien verhältnismäßig frei waren. Im dritten Stadium füllen sich aber diese Gewebspartien durch eine zunehmende Zellinfiltration aus, so daß die gesamte Cutis ziemlich gleichmäßig von Zellen durchsetzt werden kann. Diese diffuse Infiltration finden wir am stärksten in der horizontalen Schichte des Papillarkörpers und um die Talgdrüsen herum ausgebildet, sie steigt jedoch mehr oder weniger hoch in die Papillen hinauf und ebenso den Gefäßen entlang tiefer in die Cutis hinab.

Die Natur dieses Zelleninfiltrates stimmt im großen und ganzen mit der Natur der oben beschriebenen perivasculären Zellenansammlungen überein. Man findet also proliferierende Endothel- und Bindegewebszellen, ferner sehr reichlich ziemlich große vielgestaltige Zellen mit rundem, gut tingiebelm Kern und verschieden großem Protoplasmaleib, welcher sich mehr oder weniger stark färbt, also mehr oder weniger entwickelte Plasmazellen. Mastzellen sind in manchen Fällen häufig, in anderen sehr selten. Außerdem mehr unbestimmte, uncharakteristische Zellen von runder Form.

Leukocyten und Lymphocyten sind nur spärlich, mitunter aber auch im Bindegewebe und nicht nur in der Epidermis vorhanden. Von anderen Blutzellen trifft man rote Blutkörperchen öfter und reichlicher als im vorigen Stadium. Wie in diesem, sind sie aber auch hier nicht angehäuft, sondern zerstreut, mitunter an manchen Stellen so dicht, da $B$ sie beinahe ein Bild geben wie die Sterne auf einer Himmelskarte, an anderen Stellen mehr spärlich wie auf Abb. 10, wieder an anderen nur sehr vereinzelt, und nicht selten findet man in diesem Stadium überhaupt keine roten Blutkörperchen in dem Bindegewebe. In der Epidermis habe ich nie welche gesehen. 
Mehrmals habe ich konstatieren können, daß in einer Partie, in der die roten Blutkörperchen zahlreich sind, auch reichlich eosinophile Zellen auftreten. Außerdem habe ich ab und zu Bilder gesehen, wie eines in Abb. 8 wiedergegeben ist, wo die roten Blutkörperchen mehr oder weniger zerfallen scheinen oder geschrumpit und in Kontakt mit den eosinophilen Zellen. Solche Bilder scheinen mit die Möglichkeit der oben erwähnten Ansicht Häggqvists ${ }^{109}$ ) zu stützen, daß die eosinophilen Körnchen aus roten Blutkörperchen entstehen können. Meine Zeit hat mir aber nicht erlaubt, dieses Verhalten näher zu studieren.

Auch das Ödem kann zunehmen und eine Steigerung der früher beschriebenen Veränderungen hervorrufen. Auf diese Weise kann es auch Blasenbildung in der Epidermis oder nach Abstoßen der Hornschicht eine nässende Oberflä.che verursachen.

Die jetzt beschriebenen Veränderungen können sich aber noch weiter entwickeln, und man kann dann ein viertes Stadium unterscheiden. Die Leukocytenansammlung ist in eine richtige Eiterbildung übergegangen. Wenn die Hornschicht abgestoßen ist, kommt es zu eitriger Sekretion auf die Oberfläche, in anderen Fällen entstehen eitrige Blasen. Diese können ziemlich groß und pemphigusähnlich werden oder endlich sich zu großen mit Eiter gefüllten Abhebungen entwickeln. Die Natur dieser Eiterbildung hängt von der Art der wirksamen Bakterien ab. Man sieht dementsprechend bald eine sehr akute Eiterbildung, bald eine langsam verlaufende; ferner kann der Eiter übelriechend werden oder das Sekret kann stinkend werden, mehr dünn und braungefärbt und die Blasen mehr oder weniger gangränähnlich. Die Art der Bakterienflora, welche gerade im Anfangsstadium der mercuriellen Hauterkrankung auf der Hautoberfläche lebt, hat deshalb eine große Bedeutung für den Verlauf der mercuriellen Dermatose.

Die Eiterbildung kann auch das Rete Malpighii reichlich.durchtränken und selbst in der Cutis können polynucleäre Leukocytenmassen auftreten.

Auch ist in der Cutis ein bedeutend reichlicheres Auftreten der roten Blutkörperchen möglich, entweder in diffusen Ansammlungen oder in Blutungen. Wenn die Blutungen ungewöhnlich stark entwickelt sind, erhält man ein purpuraähnliches Bild.

Wenn wir nun diese Hautveränderungen mit den Veränderungen vergleichen, die im Magen und Dünndarm bei Quecksilbervergiftung zustande kommen, so finden wir in dem Krankheitsprozeß dieser beiden Stellen eine große Übereinstimmung. Eine Beschreibung der histologischen Magen- und Dünndarmveränderungen bei Quecksilbervergiftung. habe ich 1918 veröffentlicht ${ }^{15}$ ) (S. 286-339). Gerade wie in der Haut habe ich auch bei den mercuriellen Veränderungen des Dünndarms im 
Anfang eine Gefäßerweiterung und eine ödematöse Durchtränkung gefunden. In einem zweiten Stadium tritt im Dünndarm und Magen ein Zellinfiltrat hinzu, und zwar mit einem sehr reichlichen Gehalt an Plasmazellen.

In der folgenden Entwicklung sind wohl die Hautveränderungen den Magen- und Darmveränderungen nicht mehr so ganz ähnlich. Der Unterschied ist jedoch mehr scheinbar und bedingt durch die verschiedene Struktur der beiden Gewebe. Sowohl in der Haut wie in der Darmschleimhaut finden wir aber im dritten Stadium Zeichen einer Entzündung. Es versteht sich, daß im Darm, wo die Blutgefäße nach Abstoßung des einschichtigen Zylinderepithels ganz frei liegen, das Transsudat in viel größerer Menge an die Oberfläche austreten wird als in der Haut, wo die oberflächlichsten Gefäße auch nach Abstoßung der Hornschicht von einer mächtigen Reteschicht und etwas Bindegewebe bedeckt sind. Übereinstimmend ist aber, daß wir an beiden Stellen ein Transsudat finden und daß in diesem reichlich Fibrin nachzuweisen ist. Natürlich ist ferner, daß die regressiven Veränderungen, welche im weiteren Verlaufe des Prozesses in der Darmschleimhaut auftreten, keine analogen Veränderungen in der Haut haben können. Die regressiven Veränderungen treten nämlich hauptsächlich in den Drüsen auf, welche sowohl in der Magen- wie Darmschleimhaut sehr zahlreich vorkommen. Entsprechende Drüsen vermissen wir ja in der Haut. Andererseits ist die Eiterbildung an der Haut reichlicher entwickelt, was wohl eine Folge der reichlicheren Bakterienflora der Haut im Vergleich zur Magen- und Dünndarmschleimhaut ist.

Für mich ist es deshalb außer Zweifel, daß wir bei Quecksilbervergiftung im Prinzip denselben Krankheitsprozeß in der Haut wie in der Magen- und Dünndarmschleimhaut haben. Diese Anschauung ist auch in voller Übereinstimmung mit der oben angeführten Ansicht von Tomasczews $k i^{225}$ ) und anderen, nach der die Veränderungen im Magen und Dünndarm bei Quecksilbervergiftung nichts anderes sind, als ein Enanthem, d. h. daß sie die gleiche Veränderung wie das Exanthem und nur ein Übergreifen desselben auf die Schleimhäute vorstellen. Ich betrachte deshalb das mercurielle Exanthem und das mercurielle Enanthem an allen. Schleimhäuten, wo mercurielle Veränderungen vorkommen, ihrem Wesen nach als denselben Krankheitsprozeß, nur mit Variationen infolge der verschiedenen anatomischen Struktur des Substrates.

Ich habe ferner in meiner Arbeit von 1918 nachgewiesen, wie in mehreren anderen Organen (Leber, Nieren, Pankreas, Speicheldrüsen und anderen) die Quecksilberwirkung mit denselben Gefäßdilatationen anfangen, wie in der Darmschleimhaut. Es sind demnach die Gefäßdilatationen der mercuriellen Hautveränderungen nicht etwas diesen Eigentümliches, sondern nur ein Beispiel der gewöhnlichen Quecksilberwirkung. 
Makroskopisch wahrnehmbare Hautveränderungen experimentell an Tieren hervorzurufen, ist mir nicht geglückt. Seit 1901 habe ich über 100 Kaninchen, 24 Katzen und 5 Hunde mit Quecksilber vergiftet, ohne makroskopische Veränderungen der Haut beobachten zu können. Bei 7 Fällen aber, deren Haut ich mikroskopisch untersucht habe, ist es mir 5 mal gelungen, mehr oder weniger ausgeprägte mikroskopische Veränderungen zu finden, und zwar 3 mal bei Katzen und 2 mal bei Kaninchen.

Bei den Katzen sind es hauptsächlich jene Hautstellen, die mit Schweißdrüsen versehen sind, also die Fußsohlen, an denen ich Hautveränderungen gefunden habe. Diese Veränderungen entsprechen eigentlich dem oben beschriebenen ersten Stadium, zeigen aber denUnterschied, daß sie im Gegensatz zu den entsprechenden Veränderungen beim Menschen um die Schweißdrüsen herum auftreten. Außerdem finden sie sich auch im Corpus papillare, ganz ähnlich wie beim Menschen. Die Veränderungen bestehen (s. Abb. $12 \mathrm{u} .13$ ) an manchen Stellen nur aus Gefäßdilatationen. Die Gefäße können sogar sehr hochgradig dilatiert und strotzend mit Blut gefüllt sein, ohne daß man in den Geweben oder in der Gefäßwand eine Spur von Veränderungen entdecken kann. An anderen Stellen findet man eine Vermehrung der Endothelkerne der Gefäßwand, aber nichts anderes, und endlich kann es sein, daß ein unbedeutendes Zellinfiltrat um die Gefäße herum zu sehen ist. Wie Abb. 13 zeigt, kommen auch tiefer in der Cutis hochgradige Gefäßdilatationen vor. Es scheint sehr eigentümlich, daß man am lebenden Tier trotz der hochgradigen Gefäßerweiterung keine Zeichen eines Erythems sehen kann. Möglicherweise beruht dies darauf, daß die Hornschicht beträchtlich höher ist als in der Haut der Menschen und infolgedessen die Farbe des Erythems deckt. An jenen Hautteilen, wo keine Schweißdrüsen vorhanden sind, habe ich nur unbedeutende oder häufig gar keine Veränderungen gesehen.

Gerade das Studium dieser experimentell hervorgerufenen mercuriellen Hautveränderungen hat mir Bilder gegeben, welche die Gefäßdilatationen als die erste, die primäre Veränderung der mercuriellen Dermatose deutlich hervortreten ließen.

Im Anschluß an die Besprechung dieser Hautveränderungen möchte ich - wenn es auch außerhalb des Rahmens meines Themas fällt erwähnen, daß ich manchmal ähnliche Bilder in den Lungen meiner Versuchstiere gefunden habe. Die Tiere haben bei Lebzeiten überhaupt keine Lungensymptome gezeigt, und bei der Sektion fand man nur eine etwas mehr hellrote Farbe als normal. Bei der mikroskopischen Untersuchung aber trifft man auf reichliche Gefäßdilatationen, ganz wie im Corpus papillare, und manchmal genau so hochgradig wie dort. Auch an mehreren anderen Organen kann man dasselbe Verhalten feststellen, 
also makroskopisch negativer oder fast negativer Befund, mikroskopisch deutliche oder sogar sehr starke Gefäßdilatationen und keine anderen Veränderungen. Hat man diese Untersuchungen genau durchgeführt, so fühlt man sich fest überzeugt, daß die primäre Veränderung wirklich die Gefäßerweiterung ist.

Die oben besprochene Übereinstimmung zwischen verschiedenen mercuriellen Organveränderungen bezieht sich, wie erwähnt, vor allem auf die Anfangserscheinungen. Später entstehen infolge der verschiedenen Struktur der einzelnen. Organe verschiedene Variationen. Dasjenige Moment, welches den Hautveränderungen im späteren Verlauf ihren besonderen Charakter gibt, ist die Bakterienentwicklung mit der Leukocytenansammlung oder gar der Eiterbildung, d. h. mit anderen Worten das Hinzutreten einer Hautinfektion zu den im Anfang nur toxischen Erscheinungen. Auch bei dem mercuriellen Dünndarmprozeß spielen ohne Zweifel Bakterien eine gewisse Rolle, aber wie ich S. 28915) angegeben habe, sicher nicht eine so große wie in der Haut. Ebenso handelt es sich hier um eine andersartige Bakterienflora als in der Haut. Infolgedessen bildet diese Hautinfektion ein für die mercuriellen Dermatosen eigentümliches und wichtiges Moment, und ich finde sie gerade deshalb sehr dazu geeignet, als Einteilungsprinzip der mercuriellen Dermatosen zu dienen, das ich auch beim Aufstellen meiner beiden Arten, Exanthema mercuriale simplex und complicatum seu infectum, in diesem Sinne verwendet habe. Der Verlauf einer mercuriellen Dermatose nach dem Eintreten dieser Hautinfektion beruht dann hauptsächlich darauf, welche Bakterienarten auf der Hautoberfläche leben und in welcher Weise sie sich entwickeln. Je nach den Eigenschaften dieser Bakterien können sie eine unbedeutende oder eine schwere Entzündung, eine Nekrose oder eine brandige Zerstörung hervorrufen oder sie können eine Allgemeininfektion - evtl. mit zweifelhafter Prognose - hervorrufen. Selbst wenn dann alles Quecksilber aus dem Körper ausgeschieden ist und keine Quecksilberwirkung mehr besteht, so kann diese Infektion doch fortbestehen. Dadurch haben wir eine natürliche Erklärung für die Tatsache, daß3 durch eine kurzdauernde Quecksilberwirkung hervorgerufene Hautveränderungen mehrere Monate nach der Ausscheidung des Quecksilbers, nachdem sie sich gebessert hatten oder sogar verschwunden waren, wieder aufflackern können (s. meine Fälle 29-38). Wenn die Hautveränderungen nur eine direkte Folge der Quecksilberwirkung wären, so müßten sie nach der Elimination des Quecksilbers sehr schnell aufhören. Dem ist aber nicht so. Auch bei Injektion von Quecksilber- 
verbind ungen, welche nicht lange im Körper bleiben, z. B. Hydrargyrum salicylicum, halten die Hautveränderungen manchmal sehr lange, oft sogar, wie meine Fälle zeigen, mehrere Monate an. Schon bevor ich die histologischen Untersuchungen ausgeführt hatte, war es mir klar, daß - wie ich manchmal bei Demonstration der Fälle von mercuriellem Exanthem in der Klinik mich ausgedrückt habe - das Quecksilber den Anstoß zu Hautveränderungen gibt, welche nach dem Verschwinden des Quecksilbers aus dem Körper noch lange Zeit anhalten und sich weiter entwickeln können. Nach meinen histologischen Untersuchungen scheint es mir nun ganz verständlich, wie dieser primäre Anstoß des Quecksilbers die Bakterienentwicklung fördert und wie diese nach dem Verschwinden der Quecksilberwirkung eine bakterielle Hautentzündung durch lange Zeit unterhalten kann.

Ich habe oben (S. 358) die früheren Einteilungen der mercuriellen Dermatosen von Alley ${ }^{4}$ ) und Faierman ${ }^{75}$ ) erwähnt. Diese beiden Einteilungen sind aber eigentlich klinische. Da aber die klinischen Symptome der mercuriellen Dermatosen sogar in einem und demselben Falle außerordentlich wechselnd sind, so ist es kaum möglich, mit einem klinischen Prinzip eine gute Einteilung zu erreichen.

Wir sehen auch, wie unbestimmt diese Einteilungen sind. Alley sucht für seine dritte Klasse ein gewisses ätiologisches Moment hinzuzufügen, nämlich die fortgesetzte Anwendung des Quecksilbers nach dem Auftreten der Hautveränderungen. Da wir aber jetzt wissen, welche große Rolle die individuelle Idiosynkrasie spielt im Vergleich zu den größeren oder kleineren Quecksilbermengen, scheint ein solches ätiologisches Moment, mir wenigstens, sehr unwahrscheinlich. Aus dem, was ich oben von Alleys Beschreibung wiedergegeben habe, geht jedoch ziemlich deutlich hervor, daß seine dritte Klasse wenigstens teilweise meinem Exanthema mercuriale complicatum s. infectum entspricht. Von seinen 42 Fällen sind auch 8 unter Allgemeinerscheinungen, die auf eine Allgemeininfektion hindeuten, gestorben.

Faierman scheint bei seiner Einteilung nur klinischen Erscheinungen zu folgen. Möglicherweise stimmt wohl seine Gruppe 2 mit meiner zweiten Klasse überein. Er legt jedoch deutlich das größte Gewicht auf die klinischen Erscheinungen, wenn man auch aus dem Ausdruck „,manifestations septicémiques" entnehmen kann, dab er das Dazutreten einer septischen Infektion annimmt.

Juliusberg ${ }^{128}$ ) spricht von einer Einteilung der Quecksilberintoxikation im allgemeinen in zwei Gruppen, von welchen die zweite eigentlich eine Sepsis nach Quecksilbervergiftung ist. Seine Einteilung, welche - wie aus dem auf S. 359 Angeführten hervorgeht - mit der meinen durchaus nicht identisch ist, deutet doch auf die Bedeutung einer septischen Infektion hin.

Auch andere Autoren, welche keine Gruppeneinteilung der mercuriellen Dermatosen angeben, haben doch Fälle veröffentlicht, die deutlich meiner zweiten Gruppe angehören.

Folgende Beispiele möchte ich aus der Literatur erwähnen:

1. Den $\mathrm{z}$ weiten Fall von $\left.B e c k^{29}\right)$, in dem nach einer leichten Schmierkur ein fleckiger universeller Ausschlag auftrat, der bald in ein nässendes Ekzem überging. Später großlamellöse Schuppung und Tod unter sekundärer Sepsis.

Archiv f. Dermatologie u. Syphilis. O. Bd. 141. 
2. Den Fall von Berliner ${ }^{34}$ ), eine 42 jährige Frau bei der sich nach Inunktion von $30 \mathrm{~g}$ grauer Salbe im Verlaufe von 10 Tagen ein Hautausschlag neben Stomatitis entwickelte. Das ganze Gesicht wurde infolge ödematöser Hautdurchtränkung unförmig gedunsen, mit diffuser blauschwarzer Verfärbung, Schuppen, honiggelben Borken und nässenden Rhagaden in den Falten. Auch das Capillitium gerötet. Blutungen in die Conjunctivae bulbi. Die Haut des ganzen Stammes blaurot infolge dichter Petechien und schuppend. Die Haut der Extremitäten ähnlich verändert, zeigt außerdem große Blasen und flache Hautabhebungen. Die Hautfarbe der Füße fast schwarz. Temperatur bis $38,9^{\circ} \mathrm{C}$. Der Urin enthielt Zylinder, aber kein Eiweiß. Pneumonie, Durchfall, Stomatitis, Funrunkulosis und Hautabscesse. Allmähliche Besserung. Bei ihrer Entlassung aus der Klinik war die Hautfarbe der Pat. so dunkel wie die einer Mulattin.

3. Fall von Fisichella ${ }^{81}$ ). Ein 20 jähriger Mann bekam infolge von 10 Injektionen à $0,01 \mathrm{~g}$ Sublimat ein scarlatiniformes universelles Erythem mit $39^{\circ} \mathrm{C}$. Später Auftreten kleinerer und größerer Blasen und Krusten. Werterhin Schuppung und Hautabscesse. Tod nach 2 Monaten. Die Sektion zeigte eine Bronchitis purulenta mit Bronchopneumonien, Enterocolitis, Fettdegeneration der Leber und der Nieren und braune Atrophie des Herzens.

4. Fall von Fournier ${ }^{90}$, 1898, in dem sich ein diffuses Exanthem von Flecken und Papeln über den größten Teil des Körpers entwickelte, von welchen ungefähr die Hälfte Blutungen aufwiesen, die in den Palmae manuum zu einer sehwarzroten Verfärbung zusammenflossen. Heilung erst nach 5 Monate währender Erkrankung.

5. Fall von Gwalter $\left.{ }^{108}\right)$. Nach dreiwöchentlichem Einschmieren mit roter Präcipitatsalbe zuerst eine Stomatitis, und dann Auftreten von zunächst weißen Blasen an verschiedenen Stellen des Körpers, welche sich aber später schwarz verfärbten und gangränös wurden. Blutige Stühle und Exitus letalis.

6. Fall von Issersohn ${ }^{121}$ ). Hier waren breite Kondylome mit etwas Kalomel eingestaubt worden. Nach 6 Tagen entwickelte sich von diesen Stellen aus ein scharlachähnliches Exanthem. Unter septischen Erscheinungen, Durchfällen und Erbrechen verlief der Fall letal.

7. Fall von Crippa und Feichtinger ${ }^{59}$ ), in dem nach dem dritten Turnus einer Schmierkur eine unbedeutende Stomatitis und Hautrötung der Arme auftraten. Nach 4 Tagen war die ganze Körperoberfläche vollkommen ziegelrot. Temperatur 38,1, dann schwankend zwischen 36,8-38,0 . Geringe Menge Albumen im Urin. Später Blutungen und Blasen auf der Haut, Allgemeinsymptome, Temperatursteigerung bis 40,5 und Exitus letalis.

8. Fall von Kaposi ${ }^{132}$ ). Eine 26 jährige Pat., die mit 16 Einreibungen behandelt worden war und einige Tage danach im Gesicht und auf dem ganzen Körper rote juckende Flecken bekam, die bald konfluierten, so daß der Körper vom Scheitel bis zur Sohle gleichmäßig gerötet war. Stellenweise Schuppen, an anderen Stellen Borken. Unter der Behandlung Nachlassen der Erscheinungen. Später Auftreten von frischen Erythemen, gleichzeitig Diarrhöe und Decubitus. Kräfteverfall, Kollaps, Exitus.

Diese Beispiele scheinen mir zur Genüge zu beweisen, daß solche Fälle, welche ich als Exanthema mercuriale complicatum sive infectum bezeichne, seit längerer Zeit beobachtet worden sind, und daß die Beschreibungen sehr oft auf eine Hautinfektion mit Eiterung, Abscessen und Furunkeln oder auch auf eine septische Allgemeininfektion mit Degeneration innerer Organe deuten. Die Literatur liefert also eine gute Stütze für meine Einteilung der mercuriellen Dermatosen in eine 
einfache Form (Exanthema mercuriale simplex) und eine Form, kompliziert durch eine Infektion (Exanthema mercuriale infectum sive complicatum).

Fragen wir uns nun zum Schlusse, $o b$ wir etwas darüber wissen können, in welcher Weise das Quecksilber diese Hautveränderungen hervorruft, so will ich versuchen, diejenigen Schlüsse darzulegen, welche sich aus meinen histologischen Bildern ziehen lassen.

Da die primären Veränderungen, wie ich immer wieder betont habe, in einer Dilatation der kleinen Gefäße bestehen, ohne irgend welche Veränderungen des benachbarten Gewebes, so muß man die Ursache dieser Dilatazion in der Einwirkung des Quecksilbers auf die Gefäßnerven suchen. Seit Claude Bernard wissen wir, daß durch eine Sympathicuslähmung Gefäßdilatationen entstehen können. Die Annahme, daß das Quecksilber durch Einwirkung auf die sympathischen Ganglien eine solche Erweiterung hervorrufen kann, mag wohl als sehr wahrscheinlich bezeichnet werden können. Daß ferner eine Sympathicuslähmung auch eine vermehrte Transsudation aus den Gefäßen begünstigen kann, scheint mir ebenfalls sehr wahrscheinlich oder wenigstens möglich. Eine vermehrte Transsudation nimmt ja unter anderen Formen auch das Bild einer Urticaria an. Da Urticaria durch verschiedene Vergiftungen oder durch Resorption giftiger Darmgase entstehen kann, ist wohl anzunehmen, daß ebenso auch das Quecksilber infolge seiner Einwirkung auf die sympathischen Ganglien diese Transsudatausscheidung (diese lymphatische Reaktion) erzeugen kann.

Ist diese Annahme, daß die toxische Wirlkung des Quecksilbers durch Sympathicuslähmung eine Gefäßdilatation mit Ödembildung hervorruft, richtig, so lassen sich dann die anderen Veränderungen sehr plausibel aus dieser Prämisse herleiten. Die erste Gewebsveränderung, welche auch Hoffmann hervorhebt, die Vergrößerung und Vermehrung der Capillarendothelien, scheint eine Folge des vermehrten Blutzuflusses zu sein, denn man sieht diese Veränderung nur in den erweiterten Gefäßen. $\mathrm{Ob}$ sie auf den vermehrten Blutzufluß an und für sich oder auf eine Veränderung des Blutdruckes in den erweiterten Gefäßen zurückzuführen ist oder auf eine durch den größeren Blutzufluß und die vermehrte Transsudation eines quecksilberhaltigen Blutplasmas verstärkte Quecksilberwirkung, möchte ich unentschieden lassen. Ich begnüge mich damit feststellen zu können, daß diese Endothelienproliferation sich unmittelbar nach den Gefäßerweiterungen entwickelt.

Die nächste Veränderung, die danach auftritt, ist die Proliferation der Perithelien. Diese findet, wie ich oben beschrieben habe (siehe 
Abb. 6 und 8), in konzentrischen Ringen um das Blutgefäß statt, und zwischen diesen Ringen sieht man ziemlich große Räume, welche durch das Transsudat ausgedehnte perivasculäre Lymphräume darstellen. Es scheint mir deshalb, daß auf die Perithelien ähnliche kausale Momente einwirken, wie sie eben bezüglich der Gefäßendothelien beschrieben worden, und zwar können wir uns, wie in den Gefäßen dreierlei Ursachen denken, entweder verbesserte Ernährungsverhältnisse infolge Anhäufung von transsudiertem Blutplasma oder Reizung durch das in diesem Transsudat enthaltene Quecksilber oder endlich die Druckveränderung. Welches von diesen Momenten oder ob vielleicht noch andere, die ich nicht berücksichtigt habe, als Ursachen wirksam sind, auf diese Frage möchte ich nicht eingehen, ich will nur festhalten, daß die Perithelienproliferation in irgendeiner Weise als eine Folge der vermehrten Blutplasmatranssudation in die perivasculären Lymphräume und deren Erweiterungen auftritt.

Wenn dem so ist, so muß man auch ähnliche proliferierende Prozesse im Bindegewebe sehen, wenn die Transsudation von den perivasculären Lymphräumen in die Bindegewebsspalten fortschreitet. Auf diese Weise scheinen mir die Proliferationsprozesse sowohl im Rete Malpighii wie im Bindegewebe der Cutis als eine Folge des mercuriellen Ödems natürlich erklärt werden zu können. Zwar ist diese Proliferation im Bindegewebe beträchtlich geringer als die perivasculäre Proliferation, welche wie besonders Hoffmann ${ }^{117}$ ) beschreibt — eine bedeutende Stärke erreichen kann, aber gerade unter der besprochenen Annahme ist dies ganz erklärlich, da auch das Ödem im Bindegewebe immer beträchtlich geringer ist.

Von den verschiedenen Zellarten, den eosinophilen Zellen, den mehr oder weniger ausgebildeten Plasmazellen und drittens den Mastzellen, scheint besonders das Auftreten der letzteren sehr erklärlich, da sie auch bei anderen ödematösen Hautveränderungen, die nicht zu schnell zurückgehen, z. B. bei länger bestehender Urticaria immer auftreten und deshalb als eine Folge des Ödems in den Geweben angesehen werden können. Daß die eosinophilen Zellen gleichzeitig mit der vermehrten Transsudation aus den dilatierten Gefäßen, wo sie regelmäßig vorhanden sind, emigrieren können, ist als selbstverständlich anzunehmen. Den supponierten doppelten Ursprung dieser Zellen habe ich oben besprochen. Über die Bedingungen des Auftretens der Plasmazellen wissen wir eigentlich nichts. Sie kommen bei einer Menge von verschiedenen Prozessen vor und es ist deshalb nichts Eigentümliches, wenn man hier Vorstufen oder bereits entwickeltere Plasmazellen findet.

Wenn ferner das Ödem so reichlich ist und so lange bestanden hat, daß es nicht nur das Bindegewebe der Cutis und die Reteschicht durchtränkt, sondern auch die Hornschicht allmählich bis zur Oberfläche durch- 
dringt, so müssen die Bakterien, welche hier vegetieren durch die hinzugetretene eiweißhaltige Ödemflüssigkeit ein viel besseres Nahrungssubstrat bekommen. Daß hierdurch in manchen Fällen eine stärkere Entwicklung der Hautbakterien und vielleicht auch eine Erhöhung ihrer Virulenz bedingt wird, scheint mir ganz natürlich. Welche Fälle sind es also, wo eine solche Bakterienwucherung stattfindet? Da die Durchfeuchtung der Hornschicht natürlich eine gewisse Zeit in Anspruch nimmt, so müssen alle in sehr kurzer Zeit ablaufenden Fälle von dieser Bakterienwucherung ausgeschlossen sein. Tatsächlich habe ich in allen kurzverlaufenden Fällen von nur einigen Tagen weder klinisch noch histologisch Anzeichen einer stärkeren Bakterienentwicklung sehen können. Ich habe auch einige Fälle von etwas längerer Dauer - 14 bis 28 Tage - welche ebenfalls keine Bakterienentwicklung zeigen. Es muß deshalb noch ein anderes Moment außer der Länge der Zeit mitspielen, und ein solches muß selbstverständlich die Menge der transsudierten Ödemflüssigkeit sein. Nicht alle Fälle lassen dieselben Menge Blutplasma transsudieren. U̇berhaupt müssen Gefäßerweiterung und Transsudation einander nicht ganz proportional sein, was ich schon oben (S. 380) besprochen habe, denn das Quecksilber kann natürlich das sympathische Nervensystem bei verschiedenen Individuen in verschiedener Weise angreifen. Diejenigen Fälle, bei welchen eine starke Transsudation während einer nicht zu kurzen Zeit anhält, müssen wir uns demnach als geeignet für diese Bakterienwucherung vorstellen. Doch kommt ohne Zweifel noch ein drittes Moment hinzu. Nicht alle versehiedenen Bakterienarten können durch die Ödemflüssigkeit in derselben Weise in ihrer Entwicklung befördert werden. Für manche Arten ist diese Durchtränkung der Hornschicht ohne Zweifel ein stärkerer Anstoß als für andere, weshalb auch die Zusammensetzung der Hautflora für das Ausmaß ihrer Entwicklung maßgebend sein muß.

Die Wirkung dieser Bakterienwucherung ist ferner in verschiedenen Fä̈llen sehr verschieden. Je nach der Art und der Virulenz der sich entwickelnden Bakterien können die sekundär auftretenden Hautveränderungen verschiedene Bilder annehmen, wie das eines Erysipels, eines Ekzems, einer Pyodermie in verschiedenen Formen usw. oder selbst das nekrotischer oder brandiger Veränderungen gewisser Stellen. Schließlich kann die Infektion in gewissen Fällen in den Kreislauf übergehen und eine Allgemeininfektion hervorrufen. Dies habe ich oben mehrfach auseinandergesetzt und finde es unnötig, nochmals darauf einzugehen. Ebenso habe ich erwähnt, wie diese schweren und lange dauernden Formen der merkuriellen Dermatosen in früheren Zeiten bekannt und beschrieben waren.

Meine histologischen Untersuchungen haben mich also bezüglich der Pathogenese des merkuriellen Exanthems zu der Ansicht geführt, 
daß Quecksilbemwirkung - durch Sympathicuslähmung oder vielleicht auf andere Weise - zuerst Gefäßerweiterungen mit Ödembildung und Zellenvermehrung hervorruft, und daß die hinzutretende Bakterienentwicklung später entzïndliche Veränderungen von wechselndem Aussehen hervorrufen, je nach den Bakterienarten, die sich entwickelt haben. Diese Ansicht ist nun auch in bester Übereinstimmung mit meinen klinischen Beobachtungen und Experimenten an Tieren. Wie verhalten sich aber die bisherigen Angaben in der Literatur zu dieser Auffassung? Finden sich frühere Aussprüche in ähnlichem oder entgegengesetztem Sinn über diese Frage?

Die erste Äußerung, die ich über die Pathogenese der merkuriellen Dermat ose gefunden habe, stammt von $E$. Lesser ${ }^{155}$ ) aus dem Jahre 1888. Nach Beschreibung eines Falles von Quecksilbererythem infolge einer Kalomelinjektion, sucht er die Hautveränderungen zu erklären und geht (S. 266) ,,auf die Ursachen der Arzneiexantheme im allgemeinen“ ein. Er setzt dann fort: „Wenn wir berücksiohtigen, daß die große Mehrzahl der Arzneiexantheme unter Ausschlagsformen auftritt, die wìr durch Störungen der Gefäßinnervatıon erklären können, nämlich unter dem Bilde von Erythemen, Quaddeleruptionen, diffusen und serösen Durchtränkungen, Bläschen- und Blasenbildungen und von Blutungen, so ist die wohl auch von der Mehrzahl der Autoren geteilte Ansicht gerechtfertigt, da. $B$ es sich bei den Arzneiexanthemen um Siörungen der vasomotorischen Nerven, und zwar wahrscheinlich der Zentralorgane, durch das im Blute zirkulierende Medikament handelt.

Diese eigentümliche Wirkung auf die Gefäßnerven, welche die verschiedenen Medikamente bei den prädisponierten Individuen ausüben, kann nun - ich möchte diese Ansicht zunächst nur als Hypothese aufgefaßt wissen - auch lokal, durch direkte Applikation und Findringen des Medikamentes in die Haut zur Entfaltung kommen, und der vergleichsweise stärkeren Konzentration, in welcher das Mittel in diesen Füllen zur Wirkung gelangt, entspricht auch der stärkere Effekt. Es ist dieser Vorgang nicht ohne Analogien, und ich erinnere hier nur an die Erweiterung der Pupille bei interner Atropinaufnahme und bei Finträufelung in den Conjunctivalsack." Er erwähnt dann einige Experimente mit Jodkaliumlösung, die ihm aber nicht glückten, und fügt abschließend hinzu: „Dieses negative Resultat beweist natürlich nichts gegen meine oben ausgesprochene Vermutung, da $ß$ Arzneiexantheme sowohl durch zentrale wie durch lokale Einwirkung entstehen können. Jedenfalls für die Quecksilbererytheme glaube ich, daß das Nebeneinanderbestehen beider Entstehungsarten durch den zuerst angeführten Fall bewiesen ist."

Diese 1888 ausgesprochene Ansicht Lessers stimmt vollikommen mit meinen histologischen Untersuchungen überein. Doch kann ich aus diesen nicht entscheiden, ob die Gefäßerweiterungen auf zentraler oder peripherer Einwirkung auf das Sympathicusnervensystem beruhen. Die von Lesser ,als Hypothese" ausgesprochene Ansicht ist wohl nicht bewiesen, scheint mir aber sehr wahrscheinlich.

Im Jahre 1895 spricht sich Rosentha ${ }^{191}$ ) bezüglich der Pathogenese folgenderweise (S. 525) aus: „Suchen wir nun dem ursächlichen Moment für die Entstehung derartiger Ausschlagsformen näher zu treten, so muß als Causa efficiens eine $\mathrm{Be}$ einflussung des vasomotorischen Nervenapparates betrachtet werden. Man muß annehmen, daß, wie L. Lewin schon ausgeführt hat, das Quecksilber als solches, respektive die Produkte, welohe dasselbe in der Haut erzeugt, oder die Veränderung, 
welche es daselbst erleidet, auf chemischem Wege einen Finfluß auf dieses System ausiubt. Die Verschiedenheit in der Intensität, der Ausbreitung und der Dauer beruht auf dem physiologischen Unterschied in den Funktionen der Nervenzentren und der Nervenendigungen, die Differenzen in der Art der einzelnen Efflorescenzen auf dem verschiedenen Grad der Resistenzfähigkeit und des Verhaltens der anatomischen Elemente der Haut. Muß man sich mithin die örtlichen Erscheinungen in der Weise erklären, daß das Quecksilber als solches resp. seine Produkte auf die peripherischen in den GefäBwandungen liegenden Ganglien eine lokale Wirkung ausübt, so kann man die Exantheme, die an den nicht mit Quecksilber direkt in Berührung gekommenen Stellen auftreten, entweder auf das Vasomotorenzentrum in der Medulla oblongata resp. die untergeordneten Zentren im Grau des Rückenmarks, welche als solche die Nervenendapparate beeinflussen, oder auf einen reflektorischen Akt, durch welchen die lokal hervorgerafenen Erscheinungen an anderen Stellen in gleicher Weise hervorgebracht werden, zurückzuführen. Fs erscheint aber, wenn das Exanthem nicht universell ist, einfacher, sich die Entstehungsart so vorzustellen, daß man annimmt, daß dieselbe Schädlichkeit, die lokal die beobachteten Folgeerscheinungen hervorgerufen hat, durch die BIutbahn auf andere Teile, ,übertragen wird und dort gleiche Veränderungen erzeugt". Die Übereinstimmung mit der Anischt Lessers ist ziemlich deutlich, wenn auch Rosenthal eine lokale Einwirkung direkt durch das im Blute kreisende Quecksilber annimmt.

Im Gegensatz zu diesen beiden Ansichten glaubt Tomasczewski225) (1. c. S. 465), daß wir in den Zellen der Gewebe oder der Gefäßwände (oder in beiden) den Angriffspunkt für die Wirkung des Quecksilbers zu suchen haben, oder wie er sich unmittelbar darnach ausdrückt: „Organidiosynkrasie ist also im letzten Grunde Idiosynkrasie der ein Organ zusammensetzenden Zellen, zum mindesten eines Teiles derselben." Es scheint mir jedoch, daß eine solche Ansicht unvereinbar ist mit den histologischen Veränderungen der merkuriellen Dermatose, denn man müBte die ersten Veränderungen in diesem Falle in den Gewebszellen oder Gefäßwandzellen (oder in beiden) konstatieren können. Die ersten Veränderungen bestehen aber im Gegenteil in einer Dilatation der Gefäße, wie ich immer wieder betont habe, und die Gewebsveränderungen kommen erst später.

In Übereinstimmung mit den Ansichten Lessers und Rosenthals und im Gegensatz zu der Ansicht Tomasczewskis sprechen meine histologischen Untersuchungen für die Auffassung, daß die merkurielle Idiosynkrasie ihren Sitz in den sympathischen Nerven und ihren Ganglienzellen hat, und zwar in denjenigen Zellen, die zu einem gewissen Organ gehören, entweder zentral oder peripher oder an beiden Stellen, da die Idiosynkrasie niemals im ganzen Körper, sondern nur in einem Organ oder sogar nur in einem Teile desselben lokalisiert ist.

Die Ansicht, daß es gewisse Teile des sympathischen Nervensystems sind, welche die Angriffspunkte für die Quecksilberwirkung auf die Haut und mehrere andere Organe darstellen, findet ferner Stütze in den Untersuchungen von Merings ${ }^{159}$ ), der eine deletäre Wirkung des Quecksilbers auf die vasomotorischen Apparate experimentell nachgewiesen hat. 
Whe ich diese meine Darstellung abschließe, möchte ich betonen, daß meine Untersuchungen außer ihrer Bedeutung für die Erklärung der mercuriellen Dermatosen auch eine mehr allgemeine Bedeutung für die Pathologie besitzen können. Es scheint mir nämlich wichtig, da $\beta$ nach meinen Untersuchungen zu einem bestimmten Zeitpunkt eine Bakterienwirkung mit schweren, ja sogar zum Tode führenden Folgen sich entwickeln kann, ohne daß eine Infektion von außen eingetreten ist. Die Bakterien waren hier nämlich schon vorher an der Stelle, wo später ihre Wirkung auftrat, vorhanden, entwickelten sich aber erst bei dem gewissen Zeitpunkt infolge Eintretens der günstigen Veränderungen derart, daß sie pathogen wurden. Zwar ist es wohl bekannt, daß eine Infektion eine Zeitlang nach dem Eindringen der Erreger im Körper latent bleiben kann, um erst nach einer Herabsetzung der Körperkräfte zum Ausbruch zu kommen, aber hier liegt die Sache doch anders, denn hier ist überhaupt keine Infektion eingetreten, sondern die Bakterien lebten an der Hautoberfläche, ohne das Gewebe zu schädigen, und durch gewisse Veränderungen kam es zu einer Entwicklung dieser Bakterien, wodurch sie für das benachbarte Gewebe pathogen wurden und sogar eine Allgemeininfektion verursachen konnten.

Es scheint mir infolgedessen möglich, daß manche bis jetzt nicht erklärte, krankhafte Veränderungen im Körper vielleicht eine ähnliche Pathogenese haben könnten, nämlich Bakterienwirkung im Gefolge von Gefäßerweiterungen, die ihrerseits durch Sympathicusschädigung hervorgerufen sind. Da viele Schleimhaute eine reichliche Bakterienflora haben, so könnte z. B. ein Katarrh derselben in ähnlicher Weise, wie es oben beschrieben ist, durch eine Sympathikuseinwirkung entstehen. Ebenso könnte eine nicht medikamentöse Hautentzündung entstehen, denn die nötige Sympathicuswirkung kann ohne Zweifel nicht nur durch ein Arzneimittel, sondern auch durch viele andere Substanzen und in verschiedener anderer Weise zustande kommen.

Zum Schlusse möchte ich die Frage berühren, ob man auf diese Pathogenese der mercuriellen Dermatose eine rationelle Therapie aufbauen kann. Es sind hauptsächlich zwei Veränderungen, welche schwere Folgen haben können, nämlich die Gefäßerweiterungen und die Bakterienentwicklung, und gegen diese muß deshalb die Behandlung besonders gerichtet sein. Außerdem muß man rationeller Weise versuchen, das Quecksilber so rasch wie möglich aus dem Körper zu entfernen. Ich suche also in meiner Therapie drei verschiedene Ziele zu erreichen:

1. Die Ausscheidung des Quecksilbers möglichst zu befördern, 
2. den Gefäßerweiterungen in der Haut entgegenzuwirken und

3. die Bakterienentwicklung in der Haut zu verhindern.

Betreffs dieser drei Momente möchte ich noch folgendes hinzufügen:

1. Die Ausscheidung des Quecksilbers hängt wohl im wesentlichen von dem Zustand der Nieren ab, kann jedoch mehr oder weniger durch die bekannten Mittel, welche die Herz- und Nierentätigkeit steigern, befördert werden.

2. Wenn die Gefäßerweiterungen auf Sympathicuslähmung beruhen, wie ich angenommen habe, so sollten wir sie surch sympathicusreizende Mittel bekämpfen können. Von solchen Mitteln habe ich besonders Adrenalin und Suprarenin versucht. Über diese Versuche ist in meiner Kasuistik nicht ausführlich berichtet, weil dies zu weit führen würde. Die Adrenalininjektionen habe ich sowohl in älteren wie in frischeren Fällen und auch prophylaktisch gegeben. Die Resultate sind nicht ermutigend, trotzdem die Haut nach den Injektionen oft in hohem Grade abgeblaßt war. Dieses negative Resultat kann - wie mir scheint-vielleicht darauf beruhen, daß Adrenalin ein peripher angreifendes Sympathicusmittel ist, während das Quecksilber die Gefäßerweiterung durch zentrale Sympathicuswirkung verursachen könnte, was wir doch nicht wissen. Oder man kann sich denken, daß die Gefäßverengerungen der Adrenalinwirkung von einer Reaktion mit vermindertem Tonus gefolgt wird, wodurch die Quecksilberwirkung später sogar unterstützt werden würde.

Einigemale schienen doch die Adrenalininjektionen eine gute therapeutische Wirkung gehabt zu haben, nämlich in 2 Fällen, welche die erste Adrenalininjektion schon wenige Stunden nach dem Auftreten der erythematösen Flecken bekamen. Die Haut blaßte hier ganz ab, und nach Wiedererscheinen der natürlichen Hautfarbe waren auch die Flecken nicht so rot wie früher und gingen bald zurück. Da solche Erytheme aber auch sonst sehr schnell (binnen 24 Stunden) zurückgehen können, kann man nicht sicher sein, daß der kurze Verlauf in diesen Fällen eine Adrenalinwirkung war. Ich kann deshalb die Adrenalinbehandlung vielleicht im allerersten Anfangsstadium des Quecksilbererythems empfehlen, ansonsten habe ich keine Gründe gefunden, dieselbe bei Quecksilberdermatose zu verwenden.

Ebenso habe ich das Atropin in vielen Fällen versucht, mit demselben negativen Resultat wie beim Adrenalin.

Dagegen scheinen mir Digitalis, Coffein und Campher dieses Leiden günstig zu beeinflussen. Doch ist es mir nicht möglich zu entscheiden, ob der Erfolg bei diesen Mitteln durch herzstimulierende oder gefäßverengende Wirkung bedingt ist.

3. Sehr wichtig - ich möchte sogar sagen das Wichtigste bei dieser Behandlung - ist es, die Bakterienentwicklung in der Haut zu verhin- 
dern. Denn diese Entwicklung ruft alle Gefahren der mercuriellen Dermatose hervor; ohne sie ist das Leiden gefahrlos und verschwindet, sobald das Quecksilber teilweise oder ganz aus dem Körper ausgeschieden ist, oder wenigstens eine gewisse Zeit danach. Man soll deshalb möglichst frühzeitig versuchen, die Haut so gut wie möglich zu desinfizieren. Dabei muß man aber jede Reizung der Haut vermeiden, denn durch eine Entzündung oder Reizung wird die Entwicklung der Bakterien befördert. Man muß deshalb solche hautdesinfizierende Mittel anwenden, welche keine Hautreizung erzeugen. Von diesen scheinen mir wieder diejenigen am geeignetsten, welche antiseptische Gase entwickeln, da diese Gase in die Hornschicht eindringen können. Es sind besonders zwei Mitte, welche mir sehr gute Dienste geleistet haben, nämlich Ichthyol und Pyroleum litanthracis, welche ich gleich bei Beginn der Hautveränderungen auf die erythematös veränderte Haut einpinsle. Manche Fälle scheinen am besten durch das Ichthyol, andere durch das Pyroleum litanthracis beeinflußt zu werden. Früher habe ich, wie aus den Krankengeschichten hervorgeht, statt der eben erwähnten Mittel das Liniment von Caesar Boeck angewandt, dessen Gehalt an Bleiwasser gleichfalls eine Hautdesinfektion zustandebringen kann, bin aber später mehr zu den beiden anderen Mitteln übergegangen und verwende das Liniment von Boeck nur, wenn die Haut sehr empfindlich ist und Ichthyol oder Pyroleum nicht verträgt. In Fällen, wo die Hautveränderungen schon in ein ekzematöses oder anderes entzündliches Stadium übergegangen sind, muß man natürliche mildere Mittel anwenden, wie Umsehläge von halbprozentiger Resoreinlösung oder essigsaurer Tonerde, Höllensteinpinselungen usw., in anderen Stadien Salben oder Öle mit Salicylsäure und anderen hautantiseptischen Mitteln, jeweils entsprechend den verschiedenen Veränderungen, welche die Haut erlitten hat.

\section{Chronologisches Register derjenigen Autoren, die über merkurielle Dermatosen geschrieben haben.}

\begin{tabular}{|c|c|c|c|c|c|}
\hline 1686 & Bonet (Bonetus). & 1812 & Nicholson, J. & 1825 & Plumbe, S. \\
\hline 719 & Jussien. & 1814 & Bateman, I. & 1825 & Schmalz, G. \\
\hline 793 & Bell, Benjamin. & 1814 & Horn, Ernst & 1826 & Esser, Carl Judwi \\
\hline & & 1815 & Frank, Joseph. & 1827 & Johnstone, J. \\
\hline 804 & Alley, George. & 1815 & Hreezyma. & 1828 & Bacot, John. \\
\hline 804 & Moriatry, A. & 1817 & Becker, Hermannus. & 1828 & Lagneau, L. V. \\
\hline $\begin{array}{l}1805 \\
1805\end{array}$ & $\begin{array}{l}\text { Mc Mullin, Joannes. } \\
\text { Spens, Thom. }\end{array}$ & 1817 & Kopp, Fr. & 1829 & Bacot, John. \\
\hline 80 & Pearson, John. & $\begin{array}{l}1820 \\
1820\end{array}$ & $\begin{array}{l}\text { Crawford, Andrew. } \\
\text { Grattan, R. }\end{array}$ & $\begin{array}{l}1833 \\
1835\end{array}$ & $\begin{array}{l}\text { Cullerier et Ratier. } \\
\text { Rayer. }\end{array}$ \\
\hline 310 & Alley, George. & 1822 & Hecker, A. Fr. & 1835 & Alexandre. \\
\hline 811 & Ramsay, A. & 1823 & Kahleis, Benjamin. & 1837 & Ascherson. \\
\hline & Chisholm, C. & 1823 & Rambach, J. J. & 1837 & Dieterich,G.Ludvig. \\
\hline 12 & Frank, Joseph. & 1823 & Wendt, J. C. & 1838 & Briquet. \\
\hline
\end{tabular}




\begin{tabular}{|c|c|c|c|c|c|}
\hline 1838 & Loewenhardt. & $\begin{array}{l}1888 \\
1888\end{array}$ & $\begin{array}{l}\text { Lesser, Edm. } \\
\text { Lesser, Edm. }\end{array}$ & $\begin{array}{l}1895 \\
1896\end{array}$ & $\begin{array}{l}\text { Zysman. } \\
\text { Beck, M. }\end{array}$ \\
\hline 1847 & Azum. & 1888 & Pignot, A. & 1896 & Du Castel. \\
\hline 317 & Simon. & 1889 & Dubreuilh. & 1896 & Endlitz. \\
\hline 348 & Canstatt, Carl. & 1889 & Guelpa. & 1896 & Fournier, Alfred. \\
\hline & & 1889 & Klamman. & 1896 & Fournier, Alfred. \\
\hline 850 & Baron, C. & 1889 & Le Gendre, P. & 1896 & Herxheimer, Karl. \\
\hline 850 & Rapp, J. A. & 1889 & Spannochi, T. & 1896 & Issersohn. \\
\hline 851 & Brunslow. & 1889 & Touton, K. & 1896 & Montgomery, \\
\hline 851 & Durkee, S. & 1889 & Wickham, L. & & Dougl. W. \\
\hline 856 & Grabscheid, E. & & & 1896 & Oro, Mario. \\
\hline 359 & Marx, E. & 1890 & Besnier, E. & 1896 & Szadek. \\
\hline & & 1890 & Flitner. & 1897 & Bossard, Gustav. \\
\hline 360 & Auer. & 1890 & Fox, Colcott. & 1897 & Carieveaud, A. \\
\hline 861 & Kussmaul, Adolf. & 1890 & Jarnsoff. & 1897 & Courtade, J. \\
\hline 861 & Overbeck, Robert. & 1890 & Robinson. & 1897 & Faierman. \\
\hline 862 & Bazin. & 1890 & Saint-Germain. & 1897 & Lieven, A. \\
\hline 865 & Underwood, L. L. & 1890 & Shepherd, F. T. & 1897 & Rosenblatt. \\
\hline 866 & Marx. E. & 1890 & Streffer, Paul. & 1897 & Rosenthal, 0. \\
\hline 368 & Ferrand. & 1891 & Buertzeff. & 1897 & Taylor, G. G. \\
\hline 368 & Blanchon. & 1891 & Caspary. & 1897 & Billard, G. \\
\hline & & 1891 & Morel-Lavallée. & 1897 & Fisichella. \\
\hline 870 & Eich. & 1891 & Morel-Lavallée. & 1898 & Fournier, Alfred. \\
\hline 871 & Kalbé, Louis. & 1891 & Mouflier. & 1898 & Milian, G. \\
\hline 1871 & Meeres, Edv. E. & 1891 & v. Petersen. & 1898 & Slepjan, Rebecka. \\
\hline 1873 & Farquarhson, Rob. & 1891 & Petrini. & 1899 & cher. \\
\hline 1874 & Bérenguier. & 1891 & Ramally. & 1899 & Kaposi, M. \\
\hline 1875 & Waegelin, Friedrich & 1892 & Fournier, Alfred. & & \\
\hline & & 1892 & fff, P. I. & 1900 & Schulze, Bernh. \\
\hline 1877 & Gwalter. & 1892 & Ledermann. & 1900 & Stark. \\
\hline 1878 & Hallopeau. & 1892 & Lewin, G. & 1901 & Allgeyer, $\nabla$. \\
\hline 1878 & Watson. & 1892 & Lewin, G. & 1901 & Arkin. \\
\hline 1879 & Behrend, G. & 1892 & Morel-Lavallée & 1901 & Audry, Ch. et \\
\hline 1879 & Engelmann, Friedr. & 1893 & Brouardel et Ogier. & & Laurent. \\
\hline & & 1893 & Ehrmann, S. & 1901 & Berliner, Alfred. \\
\hline 1882 & Lowe. & 1893 & Fournier, Alfred. & 1901 & Callomon, Fritz. \\
\hline 1882 & Snell, Simeon. & 1893 & Gastou. & 1901 & Hirschfeld, Hans. \\
\hline 1882 & Stern, Emil. & 1893 & Herz. & 1901 & Leven, Leonard. \\
\hline 1883 & Wolff, A. & 1893 & Schockeel. & 1901 & Patoir. \\
\hline 1884 & Alexander. & 1893 & Staveley. & 1902 & Baer, $\mathrm{K}$. \\
\hline 1884 & Dupré. & 1894 & Claessen. & 1902 & Ehrmann, S. \\
\hline 884 & Green, W. E. & 1894 & Roth. & 1902 & Grön, Fredr. \\
\hline 884 & Reichel, Paul. & 1894 & Sackur. & 1902 & Hoffmann, E. \\
\hline 1885 & Descroizilles. & 1894 & Siredey. & 1902 & Holmes, Lav- \\
\hline 886 & Brun, F. & 1895 & Allgeyer und Spre- & & rence $\mathrm{E}$. \\
\hline 1886 & Gaucherand. & & che & 1902 & Neubeck. \\
\hline 886 & Schumacher. & 1895 & Fordyce, John A. & 1902 & Thimm, P. \\
\hline 1886 & Sommerbrodt, Jul. & 1895 & Friedheim. & 1902 & Fanelli, da Laiano. \\
\hline 1887 & Blanc. & 1895 & Galewsky, V. & 1904 & Joseph, Max. \\
\hline 1887 & Kreidmann. & 1895 & Jadassohn, J. & 1905 & Jadassohn, J. \\
\hline 1888 & Du Mesnil. & 1895 & Lewin, G. & 1905 & Sugyen, E. J. \\
\hline 1888 & Lesser, Edm. & 1895 & Neisser, A. & 1905 & Fränckel. \\
\hline
\end{tabular}




\begin{tabular}{|c|c|c|c|}
\hline $\begin{array}{l}1906 \\
1906\end{array}$ & $\begin{array}{l}\text { Gaucher. } \\
\text { Riehl. }\end{array}$ & 1909 & $\begin{array}{l}\text { Füsész-Napzràrad, } \\
\text { Jenõ. }\end{array}$ \\
\hline 1906 & Selenew. & 1909 & Loygue, G. \\
\hline 1907 & Bonnet. & & \\
\hline 1907 & Bruhns. & 1910 & Feuerhake, Ernst. \\
\hline 1907 & Crippa, J. F. und & $\begin{array}{l}1910 \\
1910\end{array}$ & Kreibich, C. \\
\hline & Lindenhaim, Hans. & & pechot. \\
\hline & Suchy, Siegfried. & 1911 & Burnaud. \\
\hline & Emery et Lacapere. & 19 & Juliusberg, Fritz. \\
\hline & Stein, & 10 & Shebunew. \\
\hline
\end{tabular}

\author{
1913 Jordan. \\ 1914 Petrow. \\ 1915 Sanz de Grado. \\ 1916 Brandweiner. \\ 1916 Neisser, A. \\ 1916 Wechselmann. \\ 1919 Sobinsky. \\ 1920 Hermann. \\ 1921 Almkvist.
}

\section{Literatur.}

1) Alexander, Ein Fall von akutem universellem Mercurialekzem. Arch. f. Dermatol. u. Syphilis 16, 105. 1884. $\left.-{ }^{2}\right)$ Alexandre, Observation d'hydrargyrie. Journ. hebdom. de méd. Paris 1836, Nr. 4, Janv. 24.; Gaz. des hôpitaux, Paris 9, 46. 1835. - ${ }^{3}$ ) Alley, George, An essay on a peculiar eruptive disease arising from the exhibition of mercury. Dublin $1804,8^{\circ}$, VI, S. $\left.80 .-{ }^{4}\right)$ Alley, George, Observations on the Hydrargyria, or that vesicular disease arising from the exhibition of mercury. London $1810,8^{\circ} .-{ }^{5}$ ) Allgeyer, $V$. , Esantema roseoliforme da iniezioni di salicilito e protocloruro di mercurio. Rif. med. 1901, Nr. 20. Ref.: Eruption roséoliforme consécutive à des injections de salicylate et de protochlorure de mereure. Ann. de dermatol. et de syphiligr. 1901, S. 897. - 6) Allgeyer und Sprecher, Ein Fall von Quecksilberintoxication mit Scharlacherythem nach hochdosierter Sublimatinjektion. Dtsch. med. Wochenschr. 1895, Nr. 38, S. 636. $\left.{ }^{7}\right)$ Almkvist, Johan, Beiträge zur Kenntnis der Plasmazellen, insbesondere beim Lupus. Arch. f. Dermatol. u. Syphilis 58. 1901. - $\left.{ }^{8}\right)$ Almkvist, Johan, Experimentelle Studien über die Lokalisation des Quecksilbers bei Quecksilbervergiftung. Nord. med. Arch. 1903, Abt. II, H. 2. - 9) Almkvist, Johan, Über die Pathogenese der mercuriellen Colitis and Stomatitis. Dermatol. Zeitschr. 13, 827. 1906. 10) Almkvist, Jokan, Weitere Untersuchungen über die Pathogenese der merkuriellen Colitis und Stomatitis. Dermatol. Zeitschr. 19, 949. 1912. - ${ }^{11}$ ) Almkvist, Johan, Über die Behandlung der merkuriellen Stomatitis mit Salvarsan. Nord. med. Arch. 1914, Abt. II, Nr. 27. - ${ }^{12}$ ) Almkvist, Johan, Über die primären Ursprungsstellen und die sekundäre Ausbreitung der mercuriellen ulcerösen Stomatitis. Dermatol. Zeitschr. 23. 1916. — ${ }^{13}$ ) Almkvist, Johan, Die experimentelle Quecksilberstomatitis des Kaninchens. Dermatol. Zeitschr. 24, 1. 1917. — $\left.{ }^{14}\right)$ Almkvist, Johan, Beiträge zur Kenntnis der Ausscheidung des Quecksilbers besonders durch den Magendarmkanal. Arch. f. exp. Pathol. u. Pharmakol. 82, 221. 1917. 15) Almkvist, Johan, UUber die Pathogenese des mercuriellen Speichelflusses und Durchfalls. Dermatol. Zeitschr. 1918. - 16) Almkvist, Johan, Welche Rolle spielen Quecksilber und Bakterien in der Pathogenese der mercuriellen ulcerösen Stomatitis und Colitis. Arch. f. Dermatol. u. Syphilis 12\%. 1920. Übersetzt in Englisch: Acta derm.-ven. 1, 312. 1920. - 17) Almkvist, Johan, Beobachtungen über die Ursachen der verschiedenen Lokalisation der syphilitischen Exantheme. Arch. f. Dermatol. u. Syphilis 183, 207. 1916. - ${ }^{18}$ ) Arkin, Wratsch 1901, Nr. 28, Ref.: Ein Fall von diffuser Dermatitis nach $\mathrm{Hg}$-Einreibungen. Monatsschr. f. prakt. Dermatol. 34, 42. 1902. - $\left.{ }^{19}\right)$ Ascherson, Idiosynkrasie gegen Quecksilber. Wochenschr. f. d. ges. Heilkunde, Berlin 1837, Nr. 51. Schmidts Jahrbüicher 19, 41. $\left.{ }^{20}\right)$ Andry, Ch. und Laurent, Zona survenu au cours d'une hydrargyride. Ann. de 
dermatol. et de syphiligr. 1901, S. 178. - ${ }^{21}$ ) Auer, Bayer. ärztl. Intelligenzbl. 1860, Nr. 43; Ref. Kussmaul, S. 308, Bossard, S. 75. - 22) Azum, Comparer les effets du mereure sur l'homme sain avec ceux que produit la syphilis. Thèse de Paris 1844, Nr. 170. - ${ }^{23}$ ) Bacot, John, Essays on syphilis. London med. Gaz. 1828, Vol. III, S. 33, 97, 161, 353, 481, 545, 673, 737, 769, 801; June/Dec. - ${ }^{24}$ ) Bacot, John, A treatise on syphilis. London 1829. — ${ }^{25}$ ) Baer, $K$., Über Behandlung der Syphilis mit Asterol. Wien. med. Wochenschr. 1902, Nr. 32. S. 1534. _- ${ }^{26}$ ) Baron, C., Observations d'hydrargyrie chez les enfants. Gaz. méd. de Paris 1850, Nr. 2. u. 4; Über die Hydrargyrie oder das Mercurialexanthem bei Kindern. Journ. f. Kinderkrankh. Erlangen 1850, XV, S. 1-8. Prager Vierteljahrsschr. 2\%. 1850, Nr. 3. 27) Bateman, T., On the erythema mercuriale. The med. chirurg. transactions. London 1814, Vol. V. Med.-chirurg. Zeitg. 2, 13. 1816. — $\left.{ }^{28}\right)$ Bazin, Leçons théoriques et cliniques sur les affections cutanées artificielles. Paris 1862, S. $110 \mathrm{u}$. 197. - ${ }^{29}$ ) Beck, M., Drei Fälle von schwerem Exanthem nach Quecksilbereinreibungen. Berl. klin. Wochenschr. 1896, Nr. 7, S. 153; Arch. f. Dermatol: u. Syphilis 4\%, 442. 1899. Über Quecksilberexantheme. Charité-Ann. 1895, Jahrg. XX, S. 587-594. — ${ }^{30}$ ) Becker, Hermannus, De erysipelate mercuriali. Inaug.-Diss.. Duisburg 1817. - $\left.{ }^{31}\right)$ Behrend, G., Zur allgemeinen Diagnose der Arzneiausschläge. Berl. klin. Wochenschr. 1879, S. 214. - ${ }^{32}$ ) Bell, Benjamin, A treatise on gonorrhoea virulenta and lues venerea. Edinburgh 1793, Vol. II, S. 288. - ${ }^{33}$ ) Bérenguier, Des éruptions provoqués par l'ingestion des médicaments. Paris 1874, S. 58. 34) Berliner, Alfred, Über schwere Formen von Mercurialexanthemen. Dermatol. Zeitschr. 8, 13. 1901. - ${ }^{35}$ ) Besnier, E., Pathogénie des érythemes. Ann. de dermatol. et de syphiligr. 1890, S. I (voir pages 18-20). - ${ }^{36}$ ) Billard, G., Hydrargyrie cutanée d'origine interne. Arch. méd. de Toulouse 1898, S. 339-344. Ref.: Quecksilberexanthem nach internem Gebrauch von Quecksilbersalzen. Monatsschr. f. prakt. Dermatol. 29, 579. 1899. - ${ }^{37}$ ) Blanc, Observation d'érytheme mercuriel scarlatiniforme. Province méd. Lyon 1887, II, S. 393-396. - ${ }^{38}$ ) Blanchon, C., De l'intoxication mercurielle. Thèse de Paris1868, Nr. 299. - ${ }^{39}$ ) Bonet (Bonetas), Medicinae septentrionalis collatitia. Genev. 1686, 2, 384-386. - ${ }^{40}$ ) Bonnet, Lyon méd. 1906, Nr. 37. Ref.: Quecksilberexanthem in Form eines Erythema circinatum et iris. Monatsschr. f. prakt. Dermatol. 44, 645. 1907. — $\left.{ }^{41}\right)$ Bossard, Gustav, Über seltene Formen der Quecksilbervergiftung. Dermatol. Zeitschr. 4, 50. 1897. — ${ }^{42}$ ) Brandweiner, Quecksilber- oder Salvarsandermatitis. Wien. klin. Wochenschr. 1916, Nr. 10. - ${ }^{13}$ ) Briquet, Mémoire sur l'emploi des topiques mercuriels dans le traitement des éruptions varioleuses. Arch. gén. de méd., Octobre 1838. - ${ }^{44}$ ) Brouardel und Ogier, Empoissement par le sulfocyanure de mercure. Ann. d'hyg. publ. $3^{e}$ Série, T. XXIX, 1893, S. 352. - ${ }^{45}$ ) Bruck, Annales de la Policlinique de Bordeaux, 1, Nr. 1, S. 48. - $\left.{ }^{46}\right)$ Bruhns, Tödlich verlaufende Quecksilberintoxikation. Berl. dermatol. Ges. 14. V. 1907. Monatsschr. f. prakt. Dermatol. 44, 625. 1907. $\left.{ }^{47}\right)$ Brun, $F$., Des accidents imputables à l'emploi chirurgical des antiseptiques. Thèse agrég. Paris 1886. - ${ }^{48}$ ) Brunslow, Preuß. Vereins-Ztg. 1851, Nr. 21. Ref.: Schmidts Jahrb. r1, 307. 1851. — 49) Buertzeff, Meditzinskea Pribaolen usw. Maj 1891. Ref.: The Brit. journ. of dermatol. 1891, dec. S. 396 und Dermatol. Zeitschr. 4, 56. 1897 und Berl. klin. Wochenschr. 1895, S. 501. - 50) Burnaud, Rev. Suisse m. 1911, Nr. 5. Ref. : Ein Fall von merkurieller Idiosynkrasie, Monatsh. f. prakt. Dermatol. 54, 358. 1912. - ${ }^{51}$ ) Callomon, Fritz, Beobachtungen an QuecksilberExanthemen. Dermatol. Zeitschr. 8, 407. 1901. - 52) Canstatt, Carl, Über Hydrargyrosis. Klin. Rückblicke u. Abhandlungen. Erlangen u. Frankfurt a. M. 1848, H. 1, S. 91--102. - ${ }^{53}$ ) Carieveaud, A., Note sur un cas d'érytheme hydrargyrique. Journ. de méd. de Bourdeaux 2\%, 14-16. 1897. - ${ }^{54}$ ) Caspary, Zur Diagnose des Scharlachs. Verh. d. Dtsch. Dermatol. Ges., 3. Kongreß 1891, S. 371. — ${ }^{55}$ ) Chis- 
holm, C., Are those diseases attributed to mercurial action on the system of the human body peculiarly exclusively generated by it? Edinburgh. med. and surg. yourn. 8, 291-309. 1812. - ${ }^{56}$ ) Claessen, Über die Behandlung der Syphilis mit 50 proz. Ol. cinereum. Therap. Monath. 1894, Oktober, S. 496. - ${ }^{57}$ ) Courtade, J., Contribution à l'étude des hydrargyries. Thèse de Toulouse, juillet 1897. Ref.: Ann. de dermatol. et de syphiligr. 1897, S. 1173. - 58) Crawford, Andrew, Case of Eczema Rubrum with Remarks. Edinburgh med. and surg. journ. 16, 37. 1820. 59) Crippa, J. F. und Feichtinger, F., Ein Fall von tödlich verlaufender Quecksilberintoxikation. Münch. med. Wochenschr, 1907, Nr. 26, S. 1282. - 60) Cullerier und Ratier, Dict. de médecine et de chirurgie pratiques, art. Mercure, 11, 461. 1833. -61) Descroizilles, Eczéma hydrargyrique coincidant avec une stomatite de même nature et observé chez un jeune garçon à la suite des frictions faites avec l'ongent napolitain. France méd. Paris 1, 447-451. 1885. - 62) Dieterich, G. Ludwig, Die Mercurialkrankheit in allen ihren Formen. Leipzig 1837, S. 219-243 (Exanthemata, Hautausschläge). - ${ }^{63}$ ) Dubreuith, Erythème hydrargyrique consécutif à l'usage interne du mercure. Ann. de la Policlin. de Bourdeaux 1, 48-50. 1889. 64) Du Castel, Eruption généralisée chez un ouvrier employé aux désinfections. Ann. de dermatol. et de syphiligr. 1896, S. 1081. - ${ }^{65}$ ) Du Mesnit, Zur Kasuistik der Quecksilberexantheme. Münch. med. Wochenschr. 1888, Nr. 28, S. 465. - ${ }^{66}$ ) Durré, De l'hydrargyrie. Thèse de Paris 1884, Nr. 82. - ${ }^{67}$ ) Durkee, S., Eczema mercuriale. Americ Journ. of the med. sciences. Philadelphia 1851, N. S. 12, 106-112. ${ }^{68}$ ) Ehrmann, S., Zur Kasuistik der irritativen Neuritis syphilitica periphericae. Wien. med. Wochenschr. 1893, Nr. 33 u. 34. - ${ }^{69}$ ) Ehrmann, S., Toxische und infektiöse Erytheme chemischen und mikrobiotischen Ursprungs. Wračeks Handb. d. Hautkrankh., 4. Abt., Wien 1902, S. 648. — ${ }^{70}$ ) Evch, Die Behandlung der Syphilis mittelst intramuskulärer Injektionen von Quecksilbersalicylat. Therap. Monatsh. 1891, Aug. S. 425. - $\left.{ }^{71}\right)$ Emery und Lacapere, Ann. des malad. vénér. 1908, 3, Fasc. 12. Ref.: Differentialdiagnose zwischen Erscheinungen der Syphilis und solchen merkurieller Intoxikation. Monatsh. f. prakt. Dermatol. 48, 326. 1909. 72) Engelmann, Friedrich, Fall von Erythema universale nach Gebrauch von Kalomel. Berl. klin. Wochenschr. 1879, Nr. 43, S. 647. — ${ }^{73}$ ) Esser, Carl Ludwig, Einige durch den Mißbrauch des Quecksilbers hervorgebrachte Krankheitsfälle. Graefes und Walthers Journ. Berlin 1826., 9, 624-638. - 74) Eudlitz, Dermatite exfoliatrice d'origine mercurielle à la suite de pansements au sublimé. Ann. de dermatol. et de syphiligr. 1896, S. 883. - ${ }^{75}$ ) Faierman, L'hydrargyrie cutanée. Thèse de Paris (16 juillet 1897). Ann. de dermatol. et de syphiligr. 1879, S. 901. - ${ }^{76}$ ) Fanelli da Loiano, Rif. med. 1902, Nr. 67. Ref.: Idiosynkrasie gegen Quecksilberpräparate. Monatsh. f. prakt. Dermatol. 36, 271. 1903. - 77) Farquharson, Rob., The action of mercury. Brit. med. journ. 1873, febr. 8, S. 136. Ref.: Jahresber. ü. d. Leistung u. Fortschr. i. d. ges. Med. (Virchow-Hirsch), 1, 366. 1873. - ${ }^{78}$ ) Faworsky, A. W., Vereinig. d. Nervenklin. d. Kais. Univers. Kasan, Sitzg. 20. Okt. 1898; Neurolog. Centralbl. 15. April 1900, S. 375. - ${ }^{79}$ ) Ferrand, Union med. 1868, Nr. 32, S. 401. 80) Feuerhake, Ernst, Über Quecksilberexantheme. Inaug.-Diss. Göttingen 1910. s1) Fisichella, Dermatite mercuriale maligna ad esita letale. Rif. med. 1897, S. 461. Ref.: Hydrargyrie maligne terminée par la mort. Ann. de dermatol. et de sypiligr. 1898, S. 395. - ${ }^{82}$ ) Fleischmann, $K$., Tödliche Sublimatvergiftung nach einer zweimaligen Scheidenausspülung. Zentralbl. f. Gynäkol. 1886, Nr. 47, S. 766. 83) Flitner, Über das Auftreten von Erythema mercuriale bei subcutanen Injektionen von Hydrargyrum salicylicum. 4. Kongr. d. russ. Ges. f. Dermatol. n. Syph. Aug. 1890. Ref.: Virch.-Hirsch. Jahresbericht 1890, 2, 635. - ${ }^{84}$ ) Fardyce, John A., Erythema scarlatiniforme following the Application of mercurial ointment to the Pubis Region. Journ. of cut. and genito-uranary diseases 1895, 13, 198. 
${ }^{85}$ Foumier, Alfred, Traitement de la syphilis. Paris, Rueff et Cie. 1893, S. 137-146 (Accidents cutanés - Hydrargyrie). - ${ }^{86}$ ) Fournier, Alfred, Un cas d'intolérance extraordinaire. Ann. de dermatol. et de syphiligr. 1892, S. 854。_ ${ }^{87}$ ) Fournier, Alfred, Hydrargyrie de cause externe. Eruption scarlatiniforme sur le corps; éruption revetant à la face l'aspect de l'impetigo larvalis. Ann. de dermatol. et de syphiligr. 1893, S. 272. - ${ }^{88}$ ) Fournier, Alfred, Sur un cas de dermatite exfoliante d'origine mercurielle. Ann. de dermatol. et de syphiligr. 1896, S. 194. - $\left.{ }^{89}\right)$ Fournier, Alfred, Trois cas d'hydrargyrie. Ann. de dermatol. et de syphiligr. 1896, S. 725-728. ${ }^{90}$ ) Fournier, Alfred, Hydrargyrie purpurique. Ann. de dermatol. et de syphiligr. 1898, S. 564-566. — 91) Fox, Colcott, Exanthemata medicinalia externa. Monatsh. f. prakt. Dermatol. 11, 245. 1890. - ${ }^{92}$ ) Fränckel, Levy, Journ. de pratic. 1906, Nr. 21. Ref.: Pemphigoides Erythem merkuriellen Ursprungs. Monatsh. f. prakt. Dermatol. 43, 720. 1906. - ${ }^{93}$ ) Frank, Joseph, Erythema mercuriale. Acta instit. clin. Caesar. Universit. Vilniensis, Lipsiae 1812, S. 22-29; Med. chirurg. Zeitung 1, 369. 1814. - ${ }^{94}$ Frank, Joseph, Praxeos medic. univ. praecepta. Lipsiae 1815, Pars I, Vol. II, S. 177. - ${ }^{95}$ ) Friedheim, Einige Bemerkungen über Veränderungen der Haut nach Quecksilbergebrauch und ein Fall von Digitalisexanthem. Dtsch. med. Wochenschr. 1895, Nr. 11, S. 182. - ${ }^{96}$ ) Froloff (Proloff ?), P. I., Urticaria nach subcutanen Quecksilberinjektionen bei Syphilis. Med. Obozrainie, Moskwa 3\%, 504-511. 1892. - ${ }^{97}$ ) Füsesz-Napzràrad, Jeno, Bud. Orv. Ujz. 1908. Ref.: Ein Fall von schwerer Quecksilbervergiftung. Monatsh. f. prakt. Dermatol. 48, 280. 1909. - ${ }^{98}$ ) Galewsky, $\nabla$., Diskussionsäußerung über sog. „mercurielle Exantheme". Verh. d. Deutsch. Ges. V. Kongr. 1895, S. 144-145 - ${ }^{99}$ ) Gastou, Hydrargyrie d'origine externe. Dermatite eczémateuse exfoliatrice mercurielle. Ann. de dermatol. et de syphiligr. 1893, S. 736-739. - ${ }^{100}$ ) Gaucher, Journ. de Praticieus 1899, Nr. 48. Ref.: Quecksilberintoxikation mit tödlichem Ausgang. Monatsh. f. prakt. Dermatol. 30, 401. 1900. - 101) Gaucher, Hydrargyrie. La Syphilis, 1905, Vol. III, Fase. 11 u. 1906, Vol. IV, Fasc. 5. Ref.: Monatsh. f. prakt. Dermatol. 42, 100, 43, 84. 1906. - 102) Gaucherand, Des éryptions cutanées causées par l'administration interne de mercure. Thèse de Paris 1886. - 103) Grabscheid, $E$., De l'action physiologique et thérapeutique du mercure. Thèse de Montpellier 1857, No. 81. - ${ }^{104}$ ) Grattan, R., Case of gangrene occasioned by the use of mercury. Transactions of the Association of fellows and licentiates of the King's and Queen's College of Physicians in Ireland. Dublin 1820, 3, 236-244. - 105) Green, W. E., Brit. med. Journ. 3, V, S. 858. 1884. Ref.: Virch.-Hirsch. Jahresber. 1, 363. 1884. - $\left.{ }^{106}\right)$ Grön, Fredr., Om merkurielle exanthemer. Norskt Magazin för Laegevideskap 1902, Nr. 5, S. 555-581. Ref.: Dtsch. med. Wochenschr. 1902, Nr. 24, S. 144. ${ }^{107)}$ Guelpa, Manifestation d'hydrargyrie simulant une éruption de variole. Journ. des mal. cut. et syph. Paris 1889-1890, 1, 39-42. - 108) Gwalter, Inaug.-Diss. Zürich 1877. Ref.: Bossard S. 80. - 109) Häggqvist, Gösta, Bidrag till kännedomen om blodlymfkörtlarnas ställning. Svenska Läkaresällsk. handl. II, 43, 688-700. 1917. - i10) Hallopeau, Du mercure, action physiologique et thérapeutique. Thèse d'agrégation. Paris 1878, S. 108-112 (Action sur la peau. Un cas de hydrargyrie scarlatiniforme, S. 110). - 111) Hecker, A. Fr., Erythema mercuriale. Lexicon medicum theoretico-practicum reale. 3. 1822. - 112) Hermann, Die maligne Entartung von Salvarsan-Hg-Exanthemen (exfoliierende generalisierte Erythrodermie). Dermatol. Wochenschr. ro, 401. 1920. - ${ }^{113}$ ) Herxheimer, Karl, Zur Technik der endermatischen Syphilisbehandlung. Therapeut. Monatsh. 1896, Febr., S. 77. 114) Herz, Über die Behandlung der Syphilis mit subeutanen Injektionen von Succimidquecksilber. Tnaug.-Diss. Straßburg i. E. 1893. Ref.: Vollert, Therapeut. Monatsschr. 1894, November, S. 543. - ${ }^{115}$ ) Herzog, Zur Frage der Granulocytenbildung bei der Entzündung. Zentralbl. f. allg. Pathol. 31, Nr. 18, S. 481-485. - 
116) Hirschfeld, Hans, Ein Fall von Nagelerkrankungen nach gewerblicher Quecksilbervergiftung. Berl. klin. Wochenschr. 1901, Nr. 18. _ 117) Hoffmann, E., Über Quecksilberdermatitis und die ihr zugrunde liegenden histologischen Veränderungen nebst Bemerkungen über die dabei beobachtete lokale und Bluteosinophilie. Berl, klin. Wochenschr. 1902. S. 908 u. 939. -- $\left.{ }^{118}\right)$ Holmes, Lavrence E., Phil, med. Journ. 15 nov. 1902. Ref.: Ein Fall von schwerer Dermatitis nach Mercurialsalbe. (Fall 2 Sublimatumschläge 1:2000.) Monatsh. f. prakt. Dermatol. 3g, 70. 1903. - $\left.{ }^{119}\right)$ Horn, Ernst, Die Mercurialrose. Horns Arch. 1915, H. 4 (Juli/Aug.), S. 662; New-England Journ. Boston 1814, Vol. III. April. - 120) Hreczyma, De exanthemate mercuriali. Inaug.-Diss. Vilnae 1815. - 121) Issersohn, Ein Fall von schwerer Quecksilberexanthem. Botkin Hospitalztg. 1896, Nr. 19. Ref.: Monatsh. f. prakt. Dermatol. 23, II, 642. 1896. - 122) Jadassohn, J., Zur Kenntnis des medikamentösen Dermatosen. Verh. d. Dtsch. dermatol. Ges. V. Kongr. in Graz. 1895 S. 103-129. Diskussion S. 140-151. - 123) Jadassohn, J., Die Toxidermien. Dtsch. Klin. 10, 2 Abt., S. 117-153. 1905. ${ }^{124}$ ) Jarusoff, Urticaria nach Quecksilbergebrauch. Med. Obozrenii 1890. 125) Johnstone, $J$., On the Lepra mercurialis. Transactions of the med. and physical society of Calcutta 3, 281-294. 1827. - Neue Sammlung auserlesener Abhandlungen zum Gebrauche prakt. Ärzte, Leipzig 1829, 3\%, 183-198. _ 126) Jordan, Dermatologia, 1, März 1913, Nr. 4. Ref.: Über einen Fall von Dermatitis mercurialis kompliziert durch Vitiligo. Dermatol. Wochenschr. 5\%, 813. 1913. 127) Joseph, Max, Über ungewöhnliche Entstehung eines Quecksilberexanthems. Dermatol. Zentralbl. Okt. 1904. - ${ }^{128)}$ Juliusberg, Fritz, Ein Fall von schwerer Quecksilbervergiftung. Arch. f. Dermatol. u. Syphilis 110, 409. 1911. - ${ }^{129}$ ) Jussieu, Mémoires de l'Académie des sciences de Paris 1719. — ${ }^{130}$ ) Kablé, Observations d'hydrargyrie à la suite do frictions mercurielles. Thèse de Paris 1871. - ${ }^{131}$ ) Kahleis, Benjamin, Über die Mercurialrose (Erythema mercuriale). Hufelands Journal, Berlin 1823. 56, H. 6, S. 49-68. Ref. bei Bossard. - 132) Kaposi, M., Fall von Erythema-toxicum-universale. - Tod. Arch. f. Dermatol. u. Syphilis 4\%, 442. 1899. - 133) Rlamman, Sublimatexanthem nach Einspritzungen in den Zahn. Allg. med. Zentral-Zeit. 1889, S. 69. Ref.: Arch. f. Dermatol. u. Syphilis 22, 234 u. 240. 1890. - - $\left.{ }^{134}\right)$ Kobert, Rudolf, Lehrbuch der Intoxikationen. Band II. Stuttgart 1906, S. 329. - ${ }^{135}$ ) Kopp, Fr., De exanthematibus externum mercurialium usum sequentibus. Inaug.-Diss. Landishut 1817. - ${ }^{136}$ ) Kreibich, $C$., Übex lokale Unterempfindlichkeit der Haut. Arch. f. Dermatol. u. Syphilis 103, 133. 1910. _- 137) Kreidmann, Hydrargyrum-Erysipel. Allg. med. Zentral-Zeit. Berlin 1887, L. VI, S. 957. ${ }_{138}$ ) Kussmaul, Adolph, Untersuchungen über den konstituionellen Mercurialismus. Würzburg 1861, S. 303-325 VIII. (Von den mercuriellen Hautleiden.) - ${ }^{139}$ ) $\mathrm{La}$ gneau, L. V., Traité des maladies syphilitiques. Paris $1828,6^{\circ}$ édit. t. II, S. 299 (Note). - 140) Lawrence, Lond. med. Gaz. 5, 742. - 141) Ledermann, Lewin, Bruck, Verhandl. der Berl. dermatol. Vereinig. 3. V. 1892. Areh. f. Dermatol. u. Syphilis 1892, S. 904-905. - 142) Le Gendre, P., Hydrargyrie local et exanthème scarlatiniforme par application excessive d'ongent napolitain belladoné sur les seins d'une nourrice. Revue prat. d'obstét. et d'hyiène de l'enfance. Paris 1889, II, S. 317-320. $\left.{ }_{1.43}\right)$ Lesser, $E d m$., Über Nebenwirkungen bei Injektionen unlöslicher Quecksilberverbindungen. Arch. f. Dermatol. u. Syphilis 20, 909. 1888. - 144) Lesser, Edm., Fin Fall von universellem Quecksilbererythem nach einer subcutanen Kalomelinjektion und über das Verhältnis zwischen den durch äußere Applikation und den durch interne Hg-Aufnahme entstandenen Ausschlägen. Arch. f. Dermatol. u. Syphilis 20, 100. 1888. - 145) Lesser, Edm., Beiträge zur Lehre von den Arzneiexanthemen. Dtsch. med. Wochenschr. 1888, Nr. 14, S. 264. _- ${ }^{146}$ ) Leven, Leonhard, Eine neue Form des Mercurialexanthems (squamöses, annulöses Mercurial- 
exanthem). Monatsh. f. prakt. Dermatol. 32, 558. 1901. - 147) Lewin, G., Demonstration eines Falles von Erythema mercuriale in der Berl. dermatol. Vereinigung. Arch. f. Dermatol. u. Syphilis 24, 904. 1892. — 148) Lewin, G., Quecksilberexanthem. Monatsh. f. prakt. Dermatol. 15, 23. 1892. - ${ }^{149}$ ) Lewin, G., Über den relativen Wert meiner subcutanen Sublimatinjektionskuren zu arderen Quecksilberkuren. Berl. klin. Wochenschr. 1895, Nr. 12, 13 u. 14, S. 245, 281 u. 299. - ${ }^{150}$ ) Lewin, L., Die Nebenwirkungen der Arzneimittel. Pharmakologisch-klinisches Handbuch. Berlin, August Hirschwald, 1899, S. 266-328 (Quecksilberverbindungen). 151) Lieven, A., Kasuistischer Beitrag zur Lehre von den Mercurialkrankheiten. Monatsh. f. prakt. Dermatol. I, 24, 302. 1897. - ${ }^{152}$ ) Lindenheim, Hans, Über eine Fieberreaktion im Anschluß an die erste Quecksilberapplikation im Frühstadium der Syphilis. Berl. klin. Wochenschr. 1907, Nr. 11. - ${ }^{153}$ ) Loewenhardt, Diagnostisch-praktissche Abhandlungen aus dem Gebiete der Mediz. u. Chirurgie. T. 2, Prenzlau 1838. Ref.: Schmidts Jahrb. 1842, 3. Supplementbd., S. 447. — 154) Lowe, Brit. med. journ. 1882, H. 11. - $\left.{ }^{155}\right)$ Loygue, G., Press. méd. 1909, Nr. 30. Ref.: Syphilitische Injektion oder mercurielle Intoxikation? Monatsh. f. prakt. Dermatol. 49, 193. 1909. - 156) Marx, E., Observation d'hydrargyrie. Journ. de méd. de Bordeaux 1859, $2^{\mathrm{e}}$ Sér., IV. S. 169-174. Ref. Schmidts Jahrb. 103, 317. 1859. -. 157) Marx, E., Hydrargyrie consécutive à l'emploi de frictions mercurielles. Mémoires de la soc. méd.-chir. des hôpitaux de Bourdeaux, 1, 278-285. 1866. ${ }^{158}$ ) Meeres, $E d w \cdot E$., Poisoning by the application of bichloride of mercury. Lancet 1871, Sept. 16, S. 413. Ref.: Jahresb. d. Leist. u. Fortschr. d. Ges. Med. (VirchowHirsch) 1871, VI. Jahrg. I, S. 315. — ${ }^{159}$ ) von Mering, Über die Wirkung des Quecksilbers auf den tierischen Organismus. Arch. f. exp. Pathol. u. Pharmakol. 13. 86. 1880. - $\left.{ }^{160}\right)$ Milian, G., Dermatite exfoliatrice généralisée par intoxication: mercurielle d'origine digestive. Ann. de dermatol. et de syphiligr. 1898, S. 167. 161) Mountgomery, Dougl. W., Eruptions from mercury. Transact. of the med. soc. of California 26, 265 268. 1896; Americ. Med. News 1896, 21. XI. S. 574. 162) Morel-Lavallée, Eruptions pathogénétiques. Rev. de méd. 11, 448. 1891. 163) Morel-Lavallée, Hydrargyrie ab ingestis. Ann. de dermatol. et de syphiligr. 1892, S. 851. - $\left.{ }^{164}\right)$ Morel-Lavallée, Des hydrargyries pathogénétiques, érythèmes polymorphes scarlatiniformes dus à l'usage interne de mercure. Rev. d. med. juin 1891, S. 499. Ref.: Ann. de dermatol. et de syphiligr. 1892, S. 227. - ${ }^{165}$ ) Moriatry, A., Description of the mercurial Lepra. Duplin 1804. - ${ }^{166}$ ) Mouflier, Hydrargyrie à forme bulleuse. Union méd. et scienctif. du Nord-Lst, 1891, déc. S. 377-379. - ${ }^{167}$ ) Mc Mullin, Joannes, De erythemate mercuriali. Inaug.-Diss. Edinburgh 1805. - In etwas anderer Ordnung übersetzt als: Essay on Erythema Mercuriale or that Eruption, which sometimes occurs from the use of Mercury. Edinburgh med. and surg. journ. 2, 25-27. 1806 oder Med.-chir. Ztg., Ergänzungsband 18, S. 132. — $\left.{ }^{168}\right)$ Neisser, A., Über sogenannte „mercurielle Exantheme“. V. Kongr. d. Dtsch. dermatol. Ges. 1895, S. 129 -139. Diskussion S. 140-151. - ${ }^{169}$ ) Neisser, A., Des eczémas dits mercuriels. Ann. de dermatol. et de syphiligr. 1896, S. 73. _ ${ }^{170}$ ) Neisser, A., Über die Verwechselung von Quecksilber- und Salvarsanexanthem. Münch. med. Wochenschr. 1916, Nr. 4. - ${ }^{171}$ ) Neubeck, Quecksilbervergiftung mit tödlichem Ausgang nach Einspritzung von Hydrargyrum salicylicum. Dermatol. Zeitschr. 9, H. 4. 1902. - ${ }^{172}$ ) Nicholson, J., Case of erythema mercuriale, accompanied by an affection of the cornea. Edinburgh med. and surg. journ. 8, 39-41. 1812. 173) Oro, Mario, Un caso di dermatite mercuriale maligna ad esito letale. Giornale ital. d. mallat. vener. e d. pelle 31, 207-298. 1896. — ${ }^{174}$ ) Overbeck, Robert, Mercur und Syphilis, Berlin 1861. - ${ }^{175}$ ) Patoir, Intoxication mercurielle aiguë. Paralysie hystéro-mercurielle. Gaz. hebdom. de méd. et de chirurg. 4. X. 1900, S. 937. Ref.: Ann. de dermatol. et de syphiligr. 1901, S. 823. - ${ }^{176}$ ) Pearson, John, Observations 
on the effects of various articles of the materia medica in the cure of Lues venerea. 1. Edit. London 1800; 2. Edit. 1907. - 177) Petersen, Über Temperatursteigerung nach Injektionen von Hydrargyrum salizylicum bei Syphilis. Verhandl. d. Dtsch. Dermatol. Gesellsch. 3. Kongr. zu Leipzig 1891, S. 382-401. Wien u. Leipzig, Wilh. Braumüller 1892. - ${ }^{178}$ ) Petrini, Hydrargyrie bulleuse. Soc. de dermatol. et de syph. 12 mars 1891. Ann. de dermatol. et de syphiligr. 1891, S. 223. 179) Petrow, Dermatologia 1914, 3, Nr. 5, Ref.: Fin Fall von schwerer Dermatitis mercurialis. Dermatol. Wochenschr. 59, 971. 1914. - ${ }^{180}$ ) Pignot, A., Hydrargyrie. Dictionn. encyclop. des sciences méd. Paris 1888, 4me Sér., 14, 537-542. 181) Plumbe, S., A practical treatise on the skin. London 1825. $2^{\text {nd }}$ edit. ib. 1827; Deutsche Übersetzung: Prakt. Abhandl. über d. Hautkrankheiten. Weimar 1825, S. 285-286. - 182) Ramally, Erythème mercuriel scarlatiniforme. Union méd. 1891, Nr. 119. Ref.: Ann. de dermatol. et de syphiligr. 1892, S. 227. - 183) Rambach, J. J., De hydrargyrosi, Inaug.-Diss. Dorpati 1823. - ${ }^{184}$ ) Ramsay, A., Case of erythema mercuriale. Edinburgh med. and surg. journ. 8, 269-274. 1811. 185) Rapp, J. A., Ein Fall von Eczema merouriale. Dtsch. Klinik, Berlin 2, 500. 1850. - $\left.{ }^{186}\right)$ Rayer, Traité complet théorique et pratique des maladies de la peau. Vol. I, Paris 1826, S. 292, Vol. II, 1835. - 187) Reichel, Paul, Fall von einem durch Sublimatgazeverband erzeugten Erythema universale. Berl. klin. Wochenschr. 1884, Nr. 2, S. 18. - ${ }^{188}$ ) Riehl, Residuen einer Hg-Dermatitis. Wien. dermatol. Ges. 21. XI. 1906. Monatsh. f. prakt. Dermatol. 44, 292. 1907. _ 189) Robinson, Eruption hydrargyrique consécutive à l'usage interne du mercure. Bull. et mém. de la soc. de thérap. Paris 1890, 2me Sér., XVII, S. 36-39. - - ${ }^{190}$ ) Rosenblatt, Ref. Virchow-Hirschs Jahresbericht 1892, I, S. 369 u. Dermatol. Zeitschr. 4, 57. 1897. - ${ }^{191}$ ) Rosenthal, O., Über mercurielle Exantheme. Berl. klin. Wochenschr. 1895, Nr. 23 u. 24, S. 500 u. 524; Dtsch. med. Wochenschr. 1894, Nr. 26, S. 594. Wien. med. Wochensehr. 1897, Nr. 42 u. 43. - ${ }^{192}$ ) Roth, Üher Granuloma mereuriale. Schweiz. Korrespondenzbl., 1893, S. 626 u. 1894, S. 313. - $\left.{ }^{193}\right)$ Rutter, Lond. med. and physic. journ., Vol. XXI und Edingburgh. med. and surg. journ. Vol. V. - $\left.{ }^{194}\right)$ Sackur, Zentralbl. f. d. med. Wiss. 1894. - ${ }^{195}$ ) Saint-Germain, Deux observations d'Hydrargyrie searlatiniforme de cause interne. Ann. de dermatol. et de syphiligr. 1890, S. 657. - ${ }^{196}$ ) Sanz de Grado, J., Act. dermo-sifiligr. 1914, IV, 4. Ref.: Scarlatiniformes Erythem merkuriellen Ursprungs. Dermatol. Wochenschr. 61, 749. 1915. - 197) Schmalz, G., Versuch einer medizinischen-chirurgisch. Diagnostik. Dresden u. Leipzig 1825, S. 239. - 198) Schnell, Idiosynkrasie gegen Quecksilber. Reichs-Med. Anz. 1893, Nr. 3. Ref. Monatsh. f. prakt. Dermatol. 16, 441. 1893. - $\left.{ }^{199}\right)$ Schockeel, Eczéma mercuriel généralisé. Arch. méd.belges. Bruxelles 1893, $4^{\mathrm{e}}$ Sér., I, S. 5-9. - ${ }^{200}$ ) Schulze, Bernh., Idiosynkrasie gegen Anwendung von Hydrargyrumpräparaten. Monatsh. f. prakt. Dermatol. 30, 206. 1900. $\left.{ }^{201}\right)$ Schuhmacher, Verhandl d. Deutsch. Kongr. f. inn. Med. 1886, S. 404. -- 202) Selenew, Russ. Zeitschr. f. Haut- und ven. Krankh. 11, 1906. Ref.: Merkurielle Herpes zoster. Monatsh. f. prakt. Dermatol. 44, 438. 1907. - ${ }^{203}$ ) Shebunew, Russ. Zeitschr. f. Haut- und ven. Krankheiten. 21. 1911. Ref.: Zur Frage der Hg-Exantheme. Monatsh. f. prakt. Dermatol. 53, 408. 1911. — ${ }^{204}$ ) Shepherd, Francis, $J$., Two cases of eczema mercuriale from the application of Scott's dressing. Journ. of cutan. and genito-urin. diseases. New York 1890, 8, 61-63. - ${ }^{205}$ ) Simon, Comparer les effets du mercure sur l'homme sain avec ceux que produit la syphilis. Thèse de Paris, 1847, Nr. 170. - ${ }^{206}$ ) Slepjan, Rebecka, Zur Kenntnis der Arzneidermatosen. Inaug.-Diss. Bern. 1898. Ref.: Tomasczewski, S. 455. - ${ }^{207}$ ) Siredey, Note sur un cas d'érythème scarlatiniforme désquamatif. Soc. méd. des Hôp. de Paris, scéance 19. X. 1894. Ref.: Ann. de dermatol et de syphiligr. 1895, S. 894. ${ }^{208)}$ Snell, Simeon, Practitioner 1882, July S. 18. Ref.: Virchow-Hirschs Jahresber. 
1, 398. 1882. - ${ }^{209}$ ) Sobinsky, Wratschebnaja gaseta 1916, Nr. 39. Ref.: Zur Frage der merkuriellen Dermatitiden. Dermatol. Wochenschr. 68, 366. 1919. 210) Sommerbrodt, Julius, Über im Pharynx lokalisierte Hydrargyrose. Berl. klin. Wochenschr. 1886, Nr. 47, S. 811. - ${ }^{211}$ ) Spannochi, T., Eruzione cutanea da avvelenamento mercuriale. Raccoglitore med. Forli 1889., 5. Ser. VIII., S. 144-148. Ref. Bossard, S. 66. - 212) Spens, Thom., History of three cases of erythema mercuriale. Edinburgh med, and surg. journ. 1805, Vol. I, S, 7-20. Med.-chirurg. Zeitung. Ergänzungsb. 18, S. 67. - 213) Sprecher, F. und V. Allgeyer, Estrato della Riforma medica Nr. 209, Settemb. 1895. - ${ }^{214}$ ) Stark, Ein Fall von hochgradiger Idiosynkrasie gegen Injektionen mit Hydrargyrum salicyl. Monatsh. f. prakt. Dermatol. 30, 201. 1900. - ${ }^{215}$ ) Staveley, W. H. C. und Denison Pedley, R., Brit. journ. of dermatol. 29. IV. 1893, S. 889. - ${ }^{216}$ ) Stein, Ein Fall von schwerer HgIntoxikation. Dtsch. med. Wochenschr. 1908, Nr. 49. - 217) Streffer, Paul, Über die Häufigkeit unangenehmer Nebenwirkungen verschiedener Merkurialien. Inaug.Diss. Würzburg 1890. Ref.: Jahresber. ü. d. Leist. u. Fortschr. d. Ges. Med. (Virchow-Hirsch) 1890, XXV. Jahrg. 1, 389. - ${ }^{218}$ ) Stern, Emil, Über das Quecksilber-Chlornatrium und seine subcutane Anwendung. Berl. klin. Wochensehr. 1882, Nr. 5, S. 63. - ${ }^{219}$ ) Suchy, Siegfried, Ein Fall von hochgradiger Idiosynkrasie gegenüber der Einreibungsku.. Wien. med. Wochenschr. 1907, Nr. 2. - ${ }^{220}$ ) Sugyen, E. $J$., Brit. med. journ. 8. April 1905. Ref. : Ein Fall von akuter letaler Quecksilbervergiftung. Monatsh. f. prakt. Dermatol. 41, 276. 1905. - ${ }^{221}$ ) $S z a d e k$, Nowiny lek. 1896, Nr. 11, S. 476. -- 222) Taylor, G. G., Eruptions after mereurical inunction. Brit. journ. of dermatol. London 1897, IX, S. 246-351. - ${ }^{223}$ ) Thimm, $P$., Ein schweres spät eingetretenes bullöses Quecksilberexanthem nach 12 Einreibungen mit grauer Salbe. Dermatol. Zeitschr. 9, 782. 1902. - ${ }^{224}$ ) Tissier und Corpechot, Bull. méd. 1910, Nr. 26. Ref.: Außerordentliche Überempfindlichkeit der Haut gegen Quecksilber. Monatsh. f. prakt. Dermatol. 53, 40. 1911. 225) Tomasczewski, Egon, Über Quecksilberexantheme und Quecksilberidiosynkrasie. Zeitschr. f. klin. Med. 51, 439-474. 1904. - ${ }^{226}$ ) Touton, K., Zoster femoralis im Anschluß an eine intramuskuläre Salicylquecksilberinjektion. Arch. f. Dermatol. u. Syphilis 21, 775. 1889. - ${ }^{227}$ ) Underwood, A. L., Mercurial gangrene. Cincinnati Lancet and Observer 1865, N. S. 8, 585-588. - ${ }^{228}$ ) Waegelein, Friedrich Withelm, Über Eczema mercuriale. Inaug.-Diss. Berłin 1875, S. 31. - ${ }^{229}$ ) Watson, Unusual action of Mercury and Chloral. Boston med. and surg. journ. 18. VII. 1878. Ref. bei Bossard. - ${ }^{230}$ ) Wechselmann, Über die Verwechselung von Quecksilber und Salvarsanexanthem. Münch. med. Wochenschr. 1916, Nr. 13. - ${ }^{231}$ ) Wendt, J. C., De abusu hydrargyri. Prolusio academ. Havn. 1823, S. 26-31. - ${ }^{232}$ ) Wickham, L., Dermite hydrargyrique consécutive à des frictions et à des bains de sublimé ordonnés comme traitement d'un pityriasis rosé de Gibert. - ${ }^{233}$ ) Wolff, A., Über die subcutane Anwendung des Glycocoll-Aspargin- und Alaninquecksilbers. Inaug.Diss. Straßburg 1883, S. 52. Vierteljahrsschr. f. Dermatol. u. Syphilis 1884, S. 105. - ${ }^{284}$ ) Zigler, M., Anaphylaxie gegen Quecksilber. Med. Record, New York, 4. nov. 1916. Ref.: Dermatol. Wochenschr. 66, 418. 1918. - ${ }^{235}$ ) Zysman, Erythème desquamatif récidivent et hydrargyrie. Thèse de Paris, 12 déc. 1895. Ann. de dermatol. et de syphiligr. 1895, S. 947 


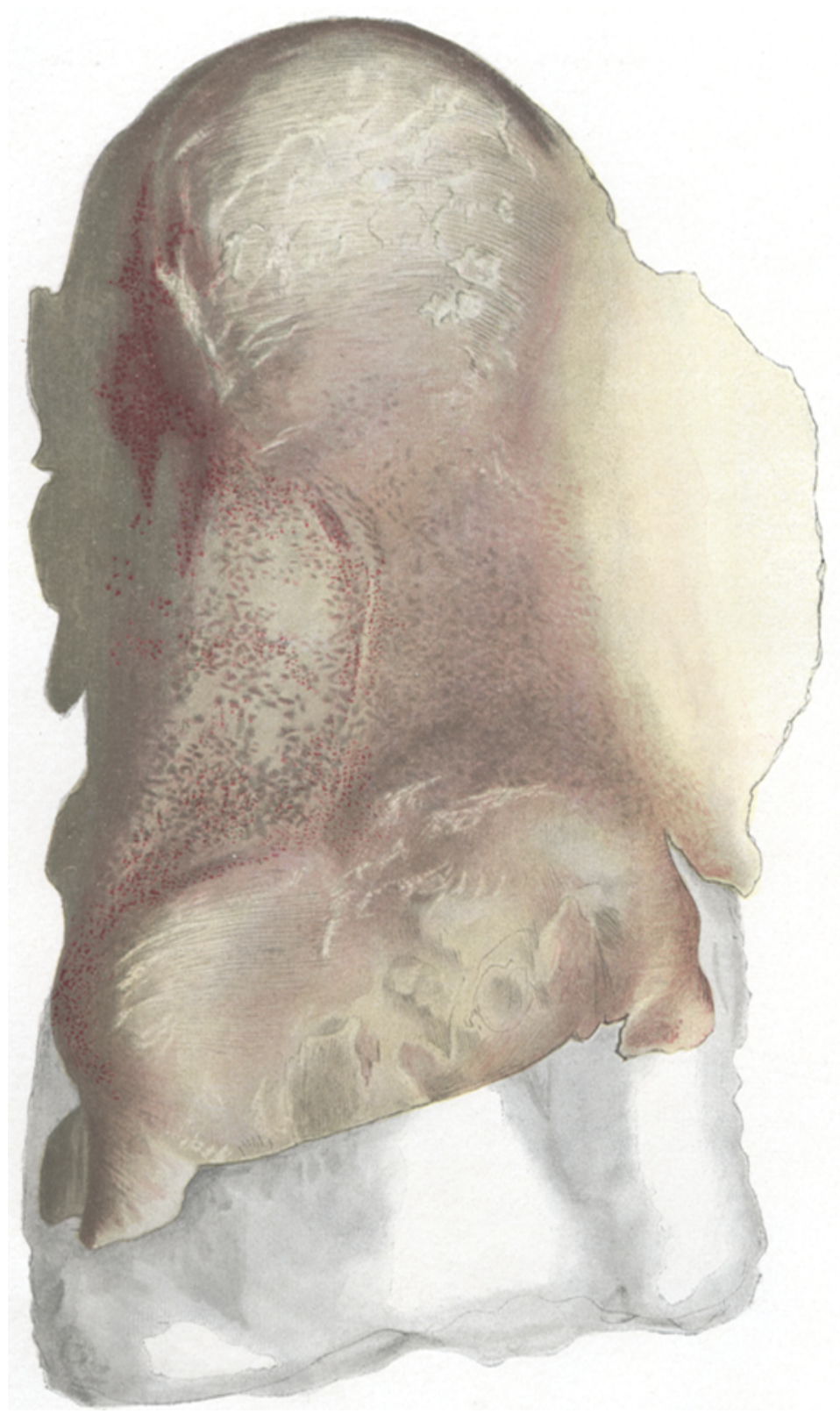

Abb. 1. F'all 30. Grollamellöse Abschuppung. Die ganze Hornschicht der Planta pedis ist zusammenhängend, sandalformig abgestoßen. Imı Hohlfuß sind zahlreiche stecknadelkopfgroße Blutungen zu sehen. 


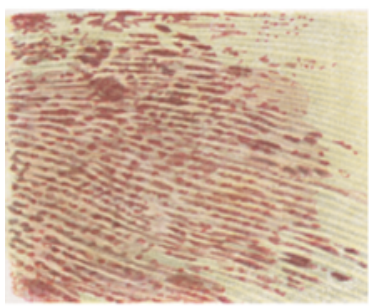

Abb. 2 stellt die Innenseite eines Teiles dor in Abb. I abgcbildeten Hornlamelle dar. Man sieht, wie die Blutungen, reihenförmig angeordnet, an der inneren Seite der Hornschichl haften. Lupenvergrößerungen.

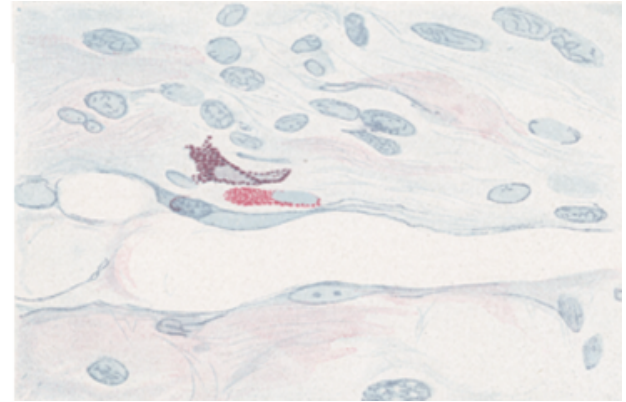

$\ldots$

Abb. 3. Fall a3. An der Seite eines Lymphgefäßes sieht man dicht nebeneinander eine langgestreckte Mastzelle, eine langgestreckte eosinophilc Zelle und eine Endothelzelle. Giemsa-Fürbung. Zeiss' Obj. $2 \mathrm{~mm}, 0 \mathrm{k}, 6 \mathrm{~mm}$.

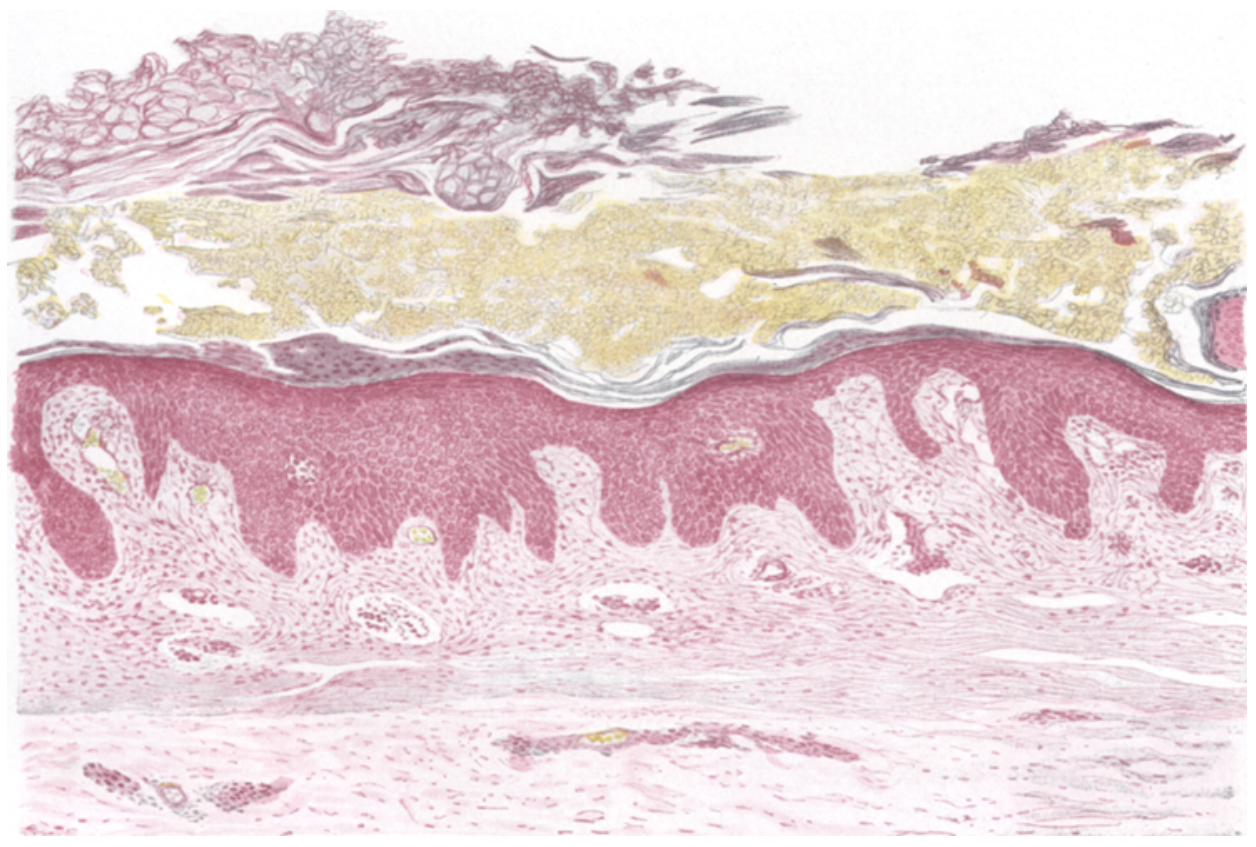

Abb. 4. Fall 15. Man sieht in den Cutispapillen und dem Corpus papillare dilatierte Blutgefäße, besonders in den Papillenspitzen, erwciterte Lymphrüume, teilweise um die dilatierten GefäBe herum, Zellenvermehrung, teils perivaseulär, teils mehr diffus im Bindegewebe; fcrner ödem im Bindegewebe und Epidermis, kernhaltige Hornzellon in den untersten Teilen der Fornschicht, die von einer gelben Flüssigkeit zerteilt ist. Oberflächlich einige Fibrinablagerungen. Färbung nach Pappenheim. Zeiss' Obj. $16 \mathrm{~mm}, \mathrm{Ok}, 6 \mathrm{~mm}$. 


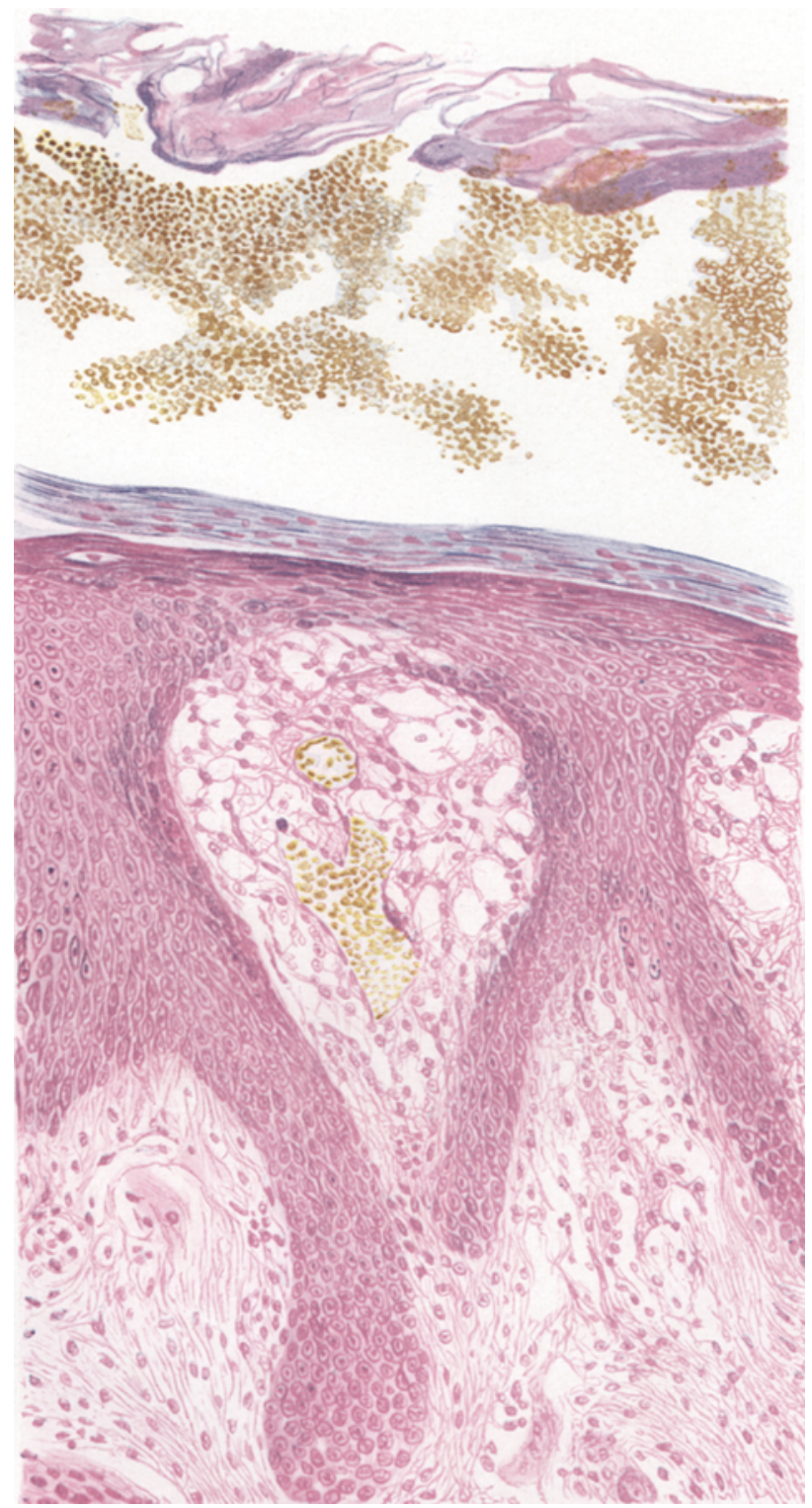

Abb. 5. Fall 15. Eine Hautstelle neben Abb. 4 unter stärkerer Vergrößerung. Dic Papillenspitze ist keulenförmig angeschwollen infolge des durch starke ödemansammlung ausgespunnten Bindegewebes, wodurch die Retezapfen versehmälert worden sind. Das dilatierte 13lutgefäß mit vermehrten, reihenförmig angeordneten Endothelkernen. Sonst dasselbe wie in Abb. 1. Dieselbe Färbung wie in Abb. 4. Zeiss' Obj. $4 \mathrm{~mm}$, Ok. $4 \mathrm{~mm}$. 


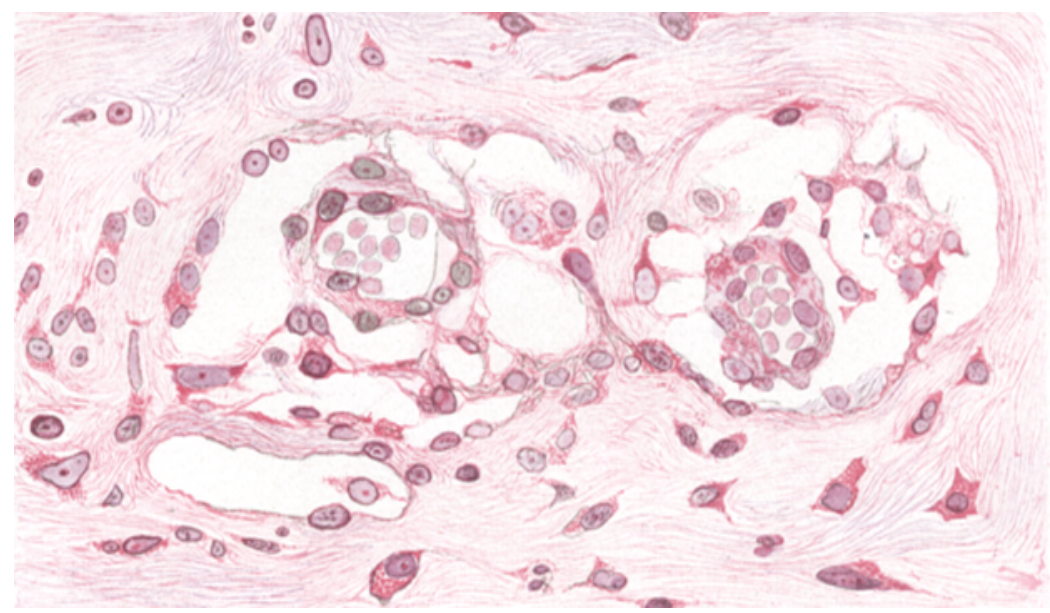

Abb. 6. Fall 39. Zwei dilatierte Blutgefaße mit Vermehrung der londothelkerne, ausgedehnten perivasculären Lymphräumen und proliferierenden Perithelzellen. Im Bindegewebe zerstreut nengebildete Zellen, einige eckige mit Ausläufern, andere mehr rund; jedoch beidc mit stark gefärbten Trotoplasma, und die lctzteren deshalb ahulich einer Plasmazelle. Färbung nach Papponheim. Zelss' Ob.j. $2 \mathrm{~mm}$, Ok. $4 \mathrm{~mm}$.

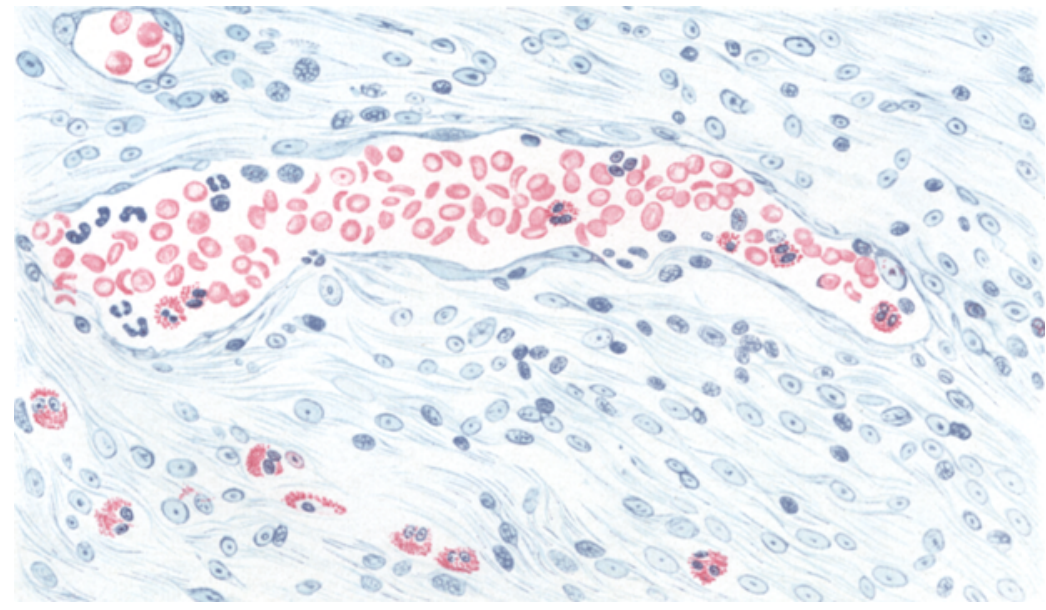

Abb. 7. Fall 15. Ein dilatiertes Gefaß mit vermehrten Endothelkernen in der Wand und gefüllt von roten und weiken Blutkörperchen. Unter den letateren sieht man 6 eosinophile Leakocyten. Außerhalb des Gefaßes diffuse Zellenproliferation und 7 eosinophile Jellen, von welchen 6 denselbon Charakter wie die eosimophilen innerhalb des (jeftaes haben, eine dagegen eine langgestreckte, tnehx bindegewebszellenăhnliche Form darbicteti Giemsa-Fiarbung. Zeiss' (3bj. 2 mm Ok. $4 \mathrm{~mm}$. 
Archiv f. Dermatologie u. Syphilis. Bd. 141.

'Tafel V.

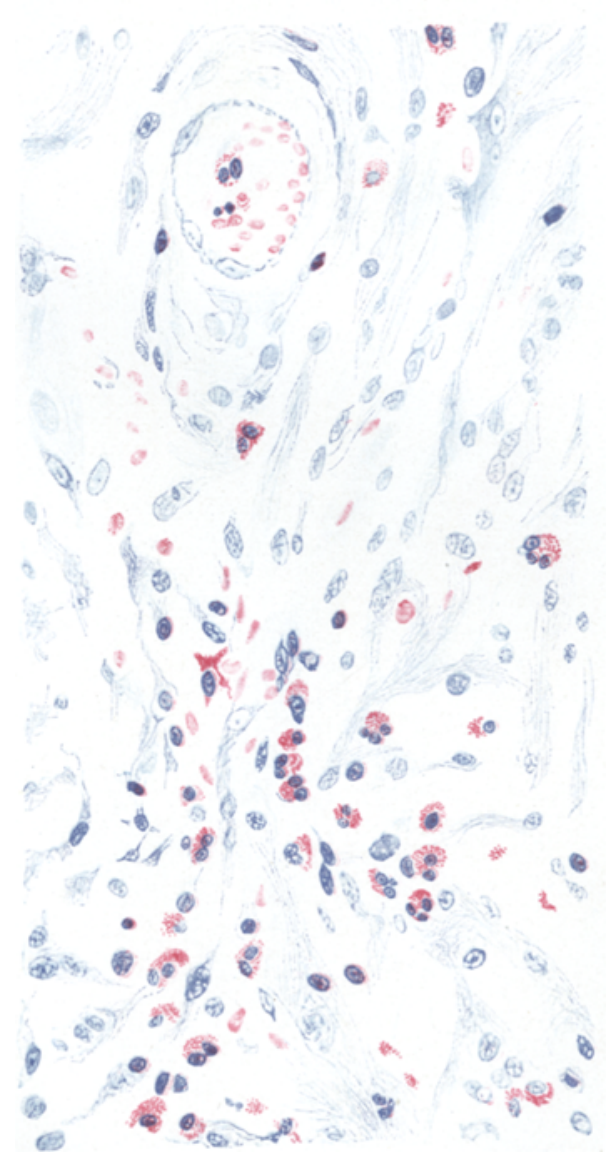

Abb. 8. Fall 32. Diffuse Zellenproliferation im Bindegewebe, in welchem man reichlich zerstreute eosinophile Zellen, eosinophile Körnchen und rote Blutkörperchen sieht. Die ersterwähnten sind von sehr verschiedener Form, einige unregelmäßig mit Auslänfern, die letzterwähnten teilweise blaß und zerfallen. Auberdem ein dilatiertes Blutgefäß mit zwiebelförmig um sich angeordneten, proliferierenden Perithelzellen. May-GiemsanFärbung. Zeiss' Obj. 2 mm, Ok. $4 \mathrm{~mm}$. 


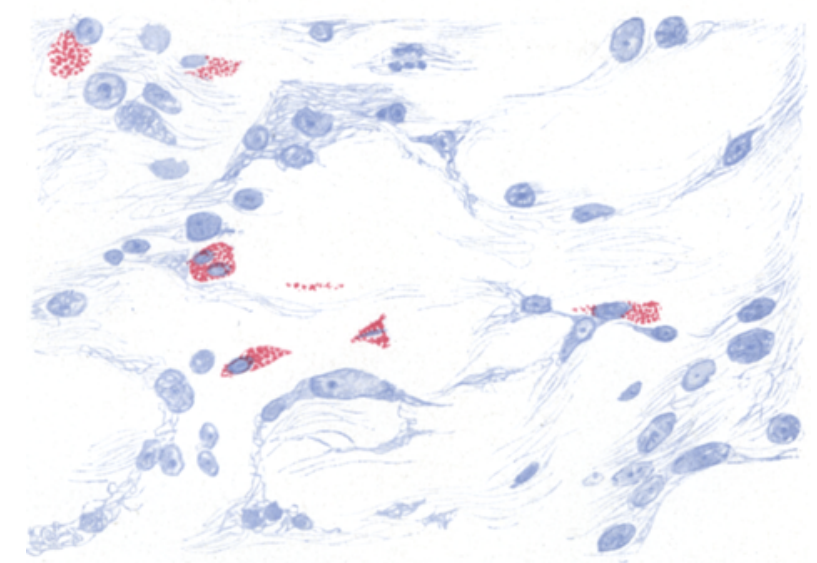

Abb. 9. Fall 15. In dem ödematösen Bindegewebe mehrere eosinophile Zellen von verschiedener Form, einige langgestreckt, eine dreieckig. Außerdem eosinophile Körnchen ohne Kern. GiemsaFärbung. Zeiss' Obj. $2 \mathrm{~mm}$, Ok. $4 \mathrm{~mm}$.

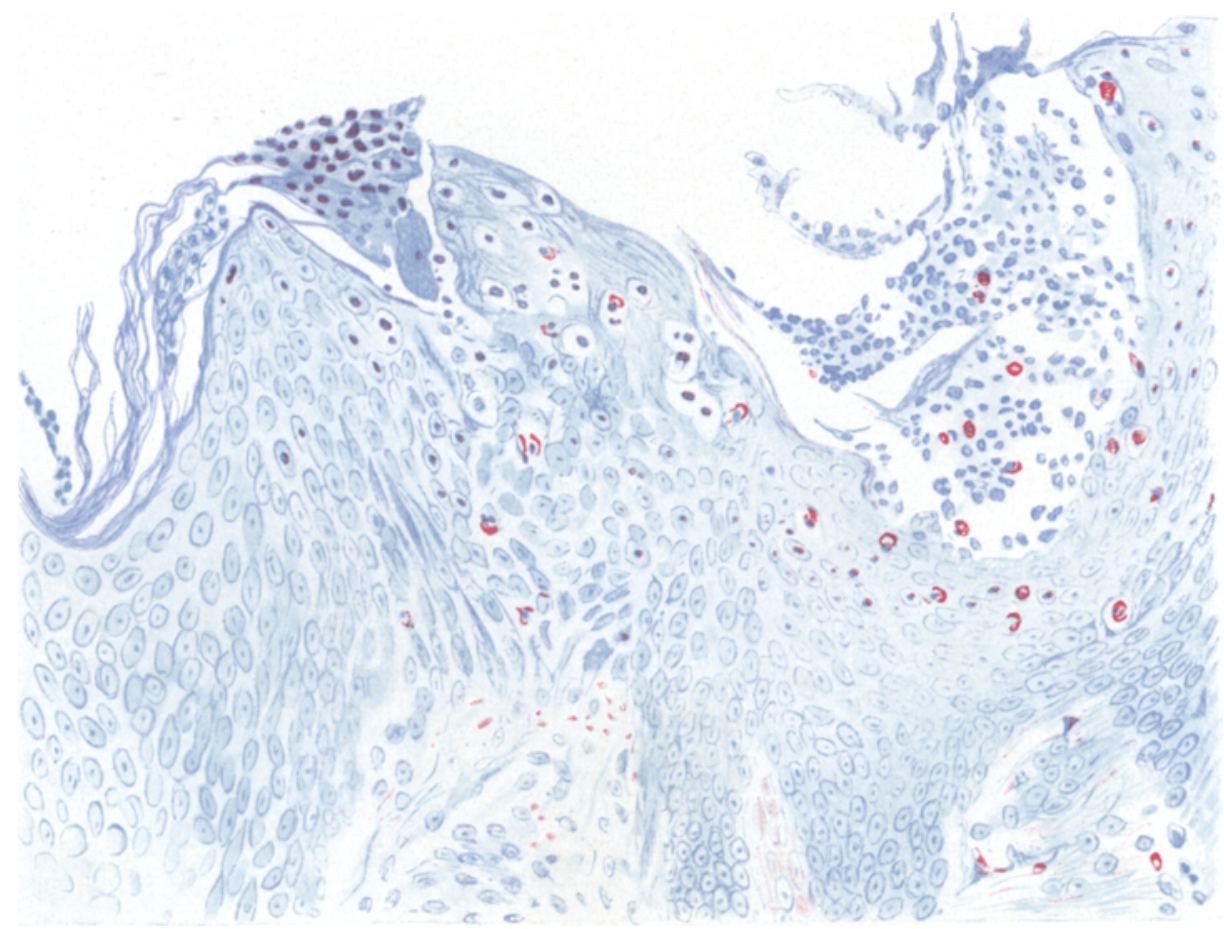

Abb. 10. Fall 36. Beginnende Eiterbildung an der Oberfläche des Rete Malpighii. Die Hornschicht ist abgestoßen. Man sieht die oberfläehliche Eitersammlung, aus welcher vereinzelte Leukocyten in das Rete hinabdringen. Ziemlich zahlreiche eosinophile Zellen. Giemsa-Färbung. Zeiss' Obj. $4 \mathrm{~mm}$, Ok. $4 \mathrm{~mm}$. 


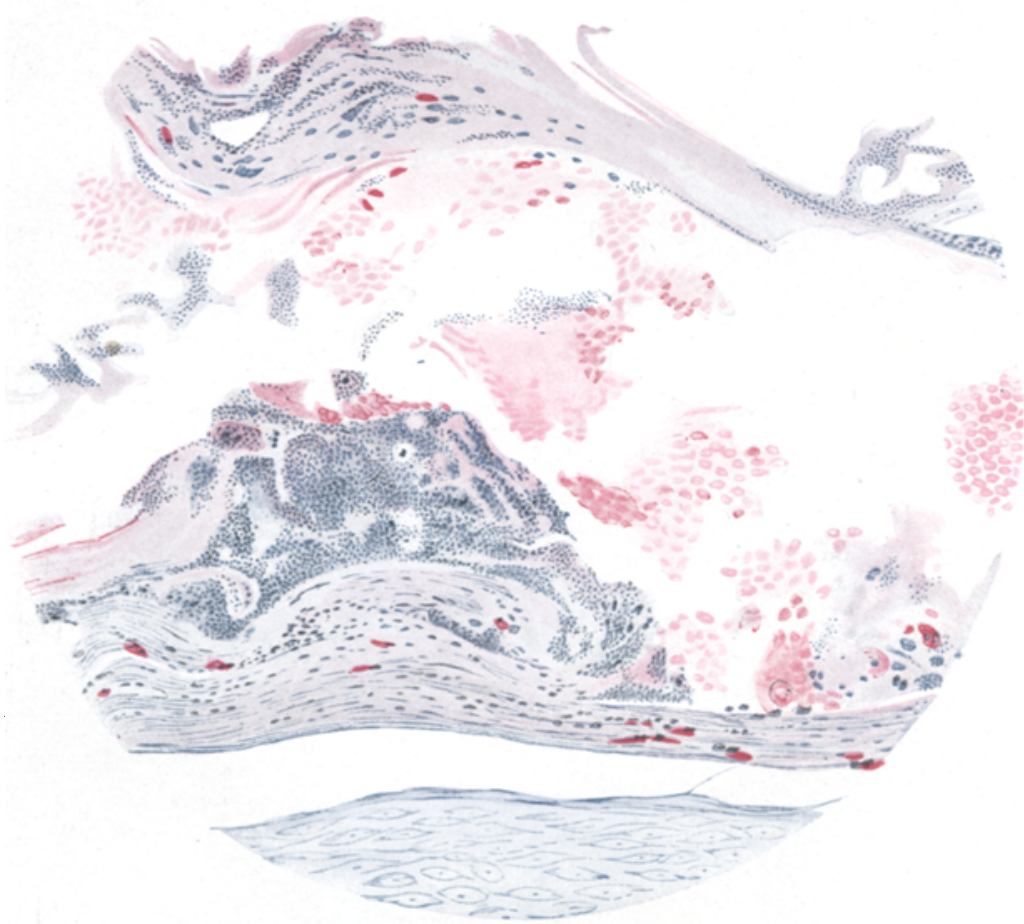

Abb. 11. Fall 21. Beginnende Bakterienentwicklung in der Hornschicht. Eosinophile Zellen von besonderem, langgestrecktem Typus im unteren Teil der Hornschicht. Giemsa-Färbung. Zeiss' Obj. ${ }^{1 / 2}$, Ok. $4 \mathrm{~mm}$. 


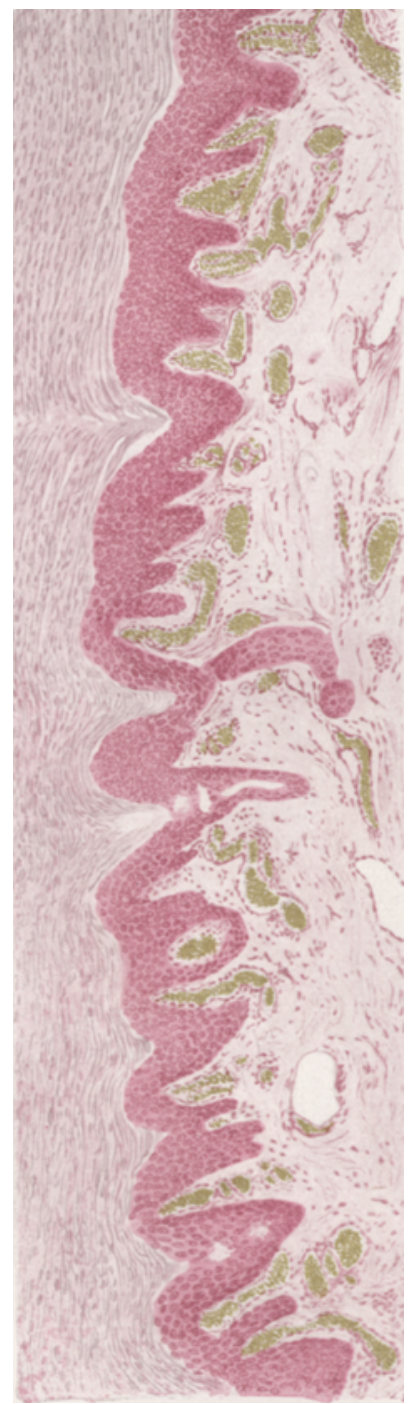

Abb. 12. Katze 10. Hant der Vorderpfote. Man sieht die Blutgefäße der Papillen und des subpapillären Gefäßnetzes hochgradig dilatiert und mit Blut prall gefüllt. AuBerdem die Endothelkerne der Gefäßwände vermehrt, sonst aber keine Gewebsveränderungen. Nur der unterste Teil der mächtigen Hornschicht ist gezeichnet. Färbung nach Pappenheim. Zeiss' Obj. $16 \mathrm{~mm}$, Ok, $4 \mathrm{~mm}$.

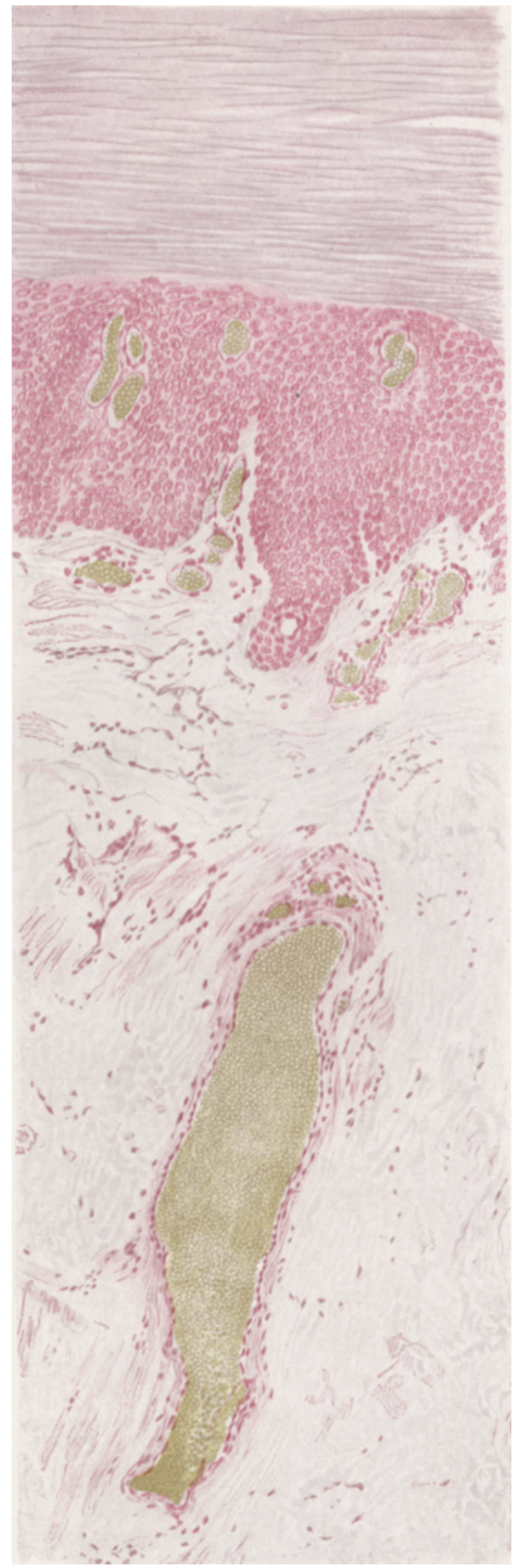

Abb. 13. Katze 11. Haut der Vorderpiote, Man sieht dasselbe wie in der Abb. 12 und außerdem ein tieferes Gefäß besonders dilatiert. Färbung nach Pappenheim. Zeiss' Obj. $8 \mathrm{~mm}$, Ok. $4 \mathrm{~mm}$. 